FEASIBILITY STUDY OF AN ADVANCED COAL FIRED HEAT EXCHANGER/GAS TURBINE TOPPING CYCLE. FOR A HIGH EFFICIENCY POWER PLANT

FInal Report

By

Peter R. Solomon

Yuxin Zhao

David Pines

Richard C. Buggein

Stephen J. Shamroth

November 1993

Work Performed Under Contract No. AC22-92PC92196

For

U.S. Department of Energy

Pittsburgh Energy Technology Center

Pittsburgh, Pennsylvania

By

Advanced Fuel Research

Fast Hartford, Connecticut 


\section{DISCLAIMER}

This report was prepared as an account of work sponsored by an agency of the United States Government. Neither the United States Government nor any agency thereof, nor any of their employees, makes any warranty, express or implied, or assumes any legal liability or responsibility for the accuracy, completeness, or usefulness of any information, apparatus, product, or process disclosed, or represents that its use would not infringe privately owned rights. Reference herein to any specific commercial produch, process, or service by trade name, trademark, manufacturer, or otherwise does not necessarily constitute or imply its endorsement, rocommendation, or favoring by the United States Government or any agency thereof. The views and opinions of authors expressed herein do not necessarily state or reflect those of the United States Government or any agency thereof.

This report has been reproduced directly from the best available copy.

Available to DOE and DOE contractors from the Office of Scientific and Technical Information, P.O. Box 62, Oak Ridge, TN 37831; prices available from (615) 576-8401.

Available to the public from the National Technical Information Service, U.S. Department of Commerce, 5285 Port Royal Rd., Springfield, VA 22161, (703) $487-4650$. 


\section{Feasibility Study for An Advanced Coal Fired Heat Exchanger/Gas Turbine Topping Cycle for A high Efficiency Power Plant}

\section{Final Report}

Prepared for

U.S. Department of Energy Pittsburgh Energy Technology Center

Contract No. DE-AC22-92PC92196

Prepared by

\section{Peter R. Solomon}

Yuxin Zhao

David Pines

and

Richard C. Buggeln

Stephen J. Shamroth

ADVANCED FUEL RESEARCH, INC.

87 Church Street

East Hartford, CT 06108

November 1993

"U.S. Patent Clearance is not required prior to the publication of this document" 


\title{
Feasibility Study for An Advanced Coal Fired Heat Exchanger/Gas Turbine Topping Cycle for A high Efficiency Power Plant
}

\author{
Final Report \\ U.S. DOE/PETC Contract No. DE-AC22-92PC92196 \\ TABLE OF CONTENTS
}

Abstract

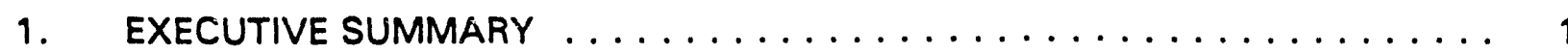

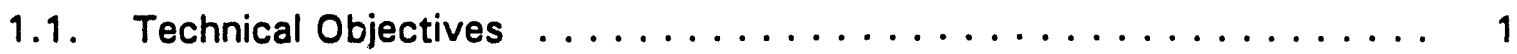

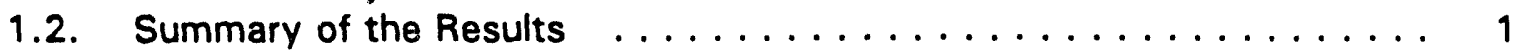

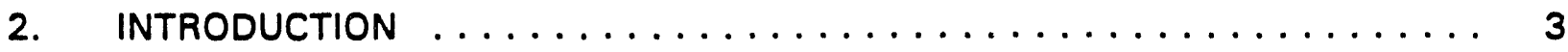

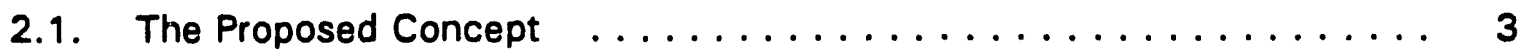

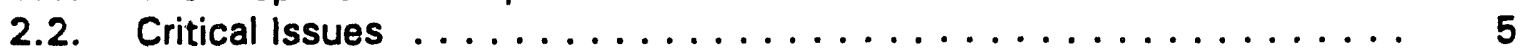

2.3. Overall Project Objective .................... 5

2.4. The Research and Development Team $\ldots \ldots \ldots \ldots \ldots \ldots$

3. THE TECHNICAL ISSUES AND OBJECTIVES $\ldots \ldots \ldots \ldots \ldots$

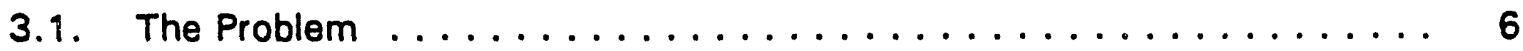

3.2. The Proposed Solution . . . . . . . . . . . . . . . . . . 6

3.3. The Major Technical Issues and Questions $\ldots \ldots \ldots \ldots \ldots \ldots \ldots$

4. PRELIMINARY ANALYSIS OF THE CONCEPT $\ldots \ldots \ldots \ldots \ldots \ldots$

4.1. General Cycle Description and Rationale $\ldots \ldots \ldots \ldots \ldots \ldots \ldots$

4.2. Plant Conditions and Assumptions .............. 17

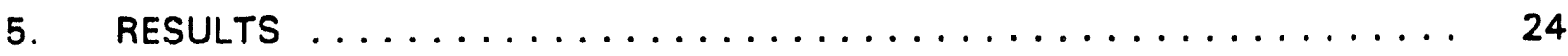

5.1. Management Plan (Task 1) ................... 24

5.2. Computational REACH/Exchanger Design (Task 2) . . . . . . . . . 24

5.3. The Coal Combustion Efficiencies of HITAF/REACH-Exchanger

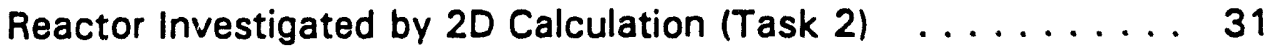

5.4. Particle Turbulent Dispersion Model (Task 2) .............. 40

5.5. 3D CFD Modeling (Task 3) ... . . . . . . . . . . . . . 44

5.6. Emissivity Measurment of Ceramic Heat Exchanger
Materials (Task 2) $\ldots \ldots \ldots \ldots \ldots \ldots \ldots \ldots \ldots$

6. CONCULSIONS AND RECOMMENDATIONS $\ldots \ldots \ldots \ldots \ldots$

REFERENCES $\ldots \ldots \ldots \ldots \ldots \ldots \ldots \ldots \ldots \ldots \ldots \ldots \ldots \ldots \ldots \ldots$

APPENDIX A "A Coal Fired Heat Exchanger for an Externally Fired Gas Turbine" Prepiont kernored 


\section{ABSTRACT}

Significant improvements in efficiency for the conversion of coal into electricity can be achieved by cycles which employ a high temperature gas turbine topping cycle. The objective of this project is the development of an externally fired gas turbine system. The project computationally tested a new concept for a High Temperature Advanced Furnace (HITAF) and high temperature heat exchanger with a proprietary design to reduce the problems associated with the harsh coal environment. The program addressed two key technology issues: 1) the HITAF/heat exchanger heat transfer through a 2-D computer analysis of the HITAF configuration; 2) 3-D Computational Fluid Dynamics (CFD) model application to simulate the exclusion of particles and corrosive gases from the heat exchanger surface. The basic concept of this new combustor design was verified through the 2D and 3D modeling. It demonstrated that the corrosion and erosion of the exchanger material caused by coal and ash particles can be largely reduced by employing a specially designed firing scheme. It also suggested that a proper combustion geometry design is necessary to maximize the cleaning effect. 


\section{Executive summary}

\subsection{Technical Objectives}

The overall objective of this project is to prove the feasibility of the designs and concepts for a high efficiency coal fired generating plant using the HITAF/REACH. Exchanger concept to power an externally fired gas turbine.

The project was carried out in three tasks with the following specific goals:

Task 1 - Project Work Plan Preparation - To develop a research plan based on the program objectives to address the critical issues and answer the key questions.

Task 2 - Two-Dimensional Computations - To demonstrate the heat exchange in the proposed design using a 2-dimensional CFD comprehensive (PCGC-2) and high temperature emissivity measurements.

Task 3 - Three-Dimensional Computations - To demonstrate the aerodynamic cleaning of the heat exchanger.

\subsection{Summary of the Results}

- A computational cylindrical HITAF/REACH-Exchanger reactor was designed. This is one of the ten HITAF/REACH-Exchanger units in the proposed plant, which is designed to deliver $100 \mathrm{MW}$ of electricity at $47.4 \%$ efficiency by burning $719 \times 10^{6} \mathrm{BTU} / \mathrm{hr}(211 \mathrm{MW})$ of fuel. The plant is assumed to have 10 burner HITAF/REACH-Exchanger units, each burning $3,954 \mathrm{lbs} / \mathrm{hr}$ of coal and $503 \mathrm{lbs} / \mathrm{hr}$ of natural gas. The HITAF/REACH-Exchanger raises the working fluid temperature from $1280^{\circ} \mathrm{F}$ to $2111^{\circ} \mathrm{F}$. An additional 5030 $\mathrm{lbs} / \mathrm{hr}$ of natural gas are fired in an in-duct burner to raise the working fluid temperature to $2530^{\circ} \mathrm{F}$ so that a turbine inlet temperature of $2300^{\circ} \mathrm{F}$ is achieved after mixing with the first stage cooling air.

- For the cylindrical HITAF/REACH reactor, the 2D fluid mechanics calculations with PCGC2 show that the combustion efficiency is not significantly affected by the alternations in the oxidant air injection schemes. It is quite flexible to change the air injection position. Hence, it is permissible to redesign the firing scheme to optimize the aerodynamics cleaning effect in HITAF/REACH reactor without adversely affecting the combustion.

- The application of the swirl air in the system was shown to increase the difficulty of controlling the coal particle dispersion and should be avoided in the HITAF/REACH-Exchanger reactor design.

- Due to the flexibility of placing the air injection, an air buffer can be created between the coal flame and the heat exchange tubes to provide the protection by using a specially designed firing scheme. Calculations show that this air buffer is very effective in controlling the flame and redirecting the large particles and that the particle fouling on the heat exchange tubes 
was significantly reduced. Noticeably, this is achieved with only $15 \%$ excess air.

Both 2D and 3D two phase fluid mechanics calculation with CELMINT demonstrated that the firing scheme can be favorably redesigned to control the gas flow pattern and the particle stream in the reactor.

- Three particle transport mechanisms were identified, i.e., i). the transport by the background flow, ii). the initial particle injection angle on inflow, and iii). the gas turbulence dispersion. Calculation showed that mechanisms $\mathrm{i}$. and ii. can be effectively controlled by the firing scheme, so the key process is the particle dispersion by the turbulence. Our results suggested that the control of turbulence dispersion can be achieved by optimizing the reactor geometry.

- The spectral emittance of three $\mathrm{SiC} / \mathrm{Al}_{2} \mathrm{O}_{3}$ composite heat exchanger materials were determined at elevated temperatures up to $1500^{\circ} \mathrm{C}\left(2732^{\circ} \mathrm{F}\right)$. These composites are commercially available and were supplied by DuPont Lanxide Composites, Inc. Measurements were performed in the mid-IR region, from $6500 \mathrm{~cm}^{-1}$ to $500 \mathrm{~cm}^{-1}(1.54 \mu \mathrm{m}$ to $20 \mu \mathrm{m})$ with a unique FT-IR based emissometer developed by AFR. Acceptably high average emissivities $(-0.8)$ were observed for each candidate materials.

- A particle turbulent dispersion model was developed as a post processor of PCGC-2 to model the particle turbulent dispersion.

- Two papers were written based on the results of this project. One was presented in 1993 ACS Fall Meeting. The other was submitted for publication (see Appendix A). 


\section{Introduction}

\subsection{The Proposed Concept}

Significant improvements in efficiency for the conversion of coal into electricity can be achieved by cycles which employ a high temperature recuperative gas turbine topping cycle. The objective of this project is the development of a new and proprietary concept for an externally fired gas turbine system. The chief advantage of this route is that the potential problems caused by the coal's inorganic constituents are diverted from the high temperature rotating parts of the gas turbine to the high temperature stationary parts of a heat exchanger. The key technology issue is, then, the development of methods to fire a high temperature heat exchanger with coal in such a way that the potential damage from the inorganic constituents is minimized.

The solution offered in this project is the design of a High Temperature Advanced Furnace (HITAF) with a Radiatively Enhanced, Aerodynamically Cleaned Heat-Exchanger (REACH-Exchanger). The REACH-Exchanger is fired by radiative and convective heat transfer from a moderately clean fuel stream and radiative heat transfer from the flame of a much larger uncleaned fuel stream. The approach is to utilize the best ceramic technology available for high temperature parts of the REACH-Exchanger and to shield the high temperature surfaces from interaction with coal minerals by employing clean combustion gases that sweep the tube surface exposed to the coal flame.

The proposed base case REACH-Exchanger configuration and HITAF is shown schematically in Fig. 2.1. The HITAF contains several burner/REACH-Exchanger units. The REACH-Exchanger receives air preheated to $1280^{\circ} \mathrm{F}$ elsewhere in the furnace using a metal heat exchanger. The temperature is raised to $2111^{\circ} \mathrm{F}$ in the REACH-Exchanger and further heated in an in-duct burner to $2530^{\circ} \mathrm{F}$ before introduction to the gas turbine.

In the proposed system, $80 \%$ of the energy to the REACH-Exchanger is supplied by radiation. The clean stream can be natural gas (base cycle) or volatile products of pyrolysis, low BTU gas from coal carbonization, or products of coal gasification (evolutionary cycle). The uncleaned stream can be coal or char.

Preliminary calculations and assessments indicate that:

- the proposed REACH-Exchanger can be incorporated into a proven furnace design for low reactivity fuels.

- the HITAF/REACH-Exchanger can be employed in a cycle similar to that presented in PRDA No. DE-RA22-90PC90159 with at least $47.3 \%$ efficiency generation of electricity

- the plant can meet stringent emission goals using available technologies

- the proposed plant would have a cost of electricity at least $11 \%$ lower than that of a conventional pulverized coal-fired plant with scrubber

- development and commercialization of the proposed plant appears accomplishable in ten years 


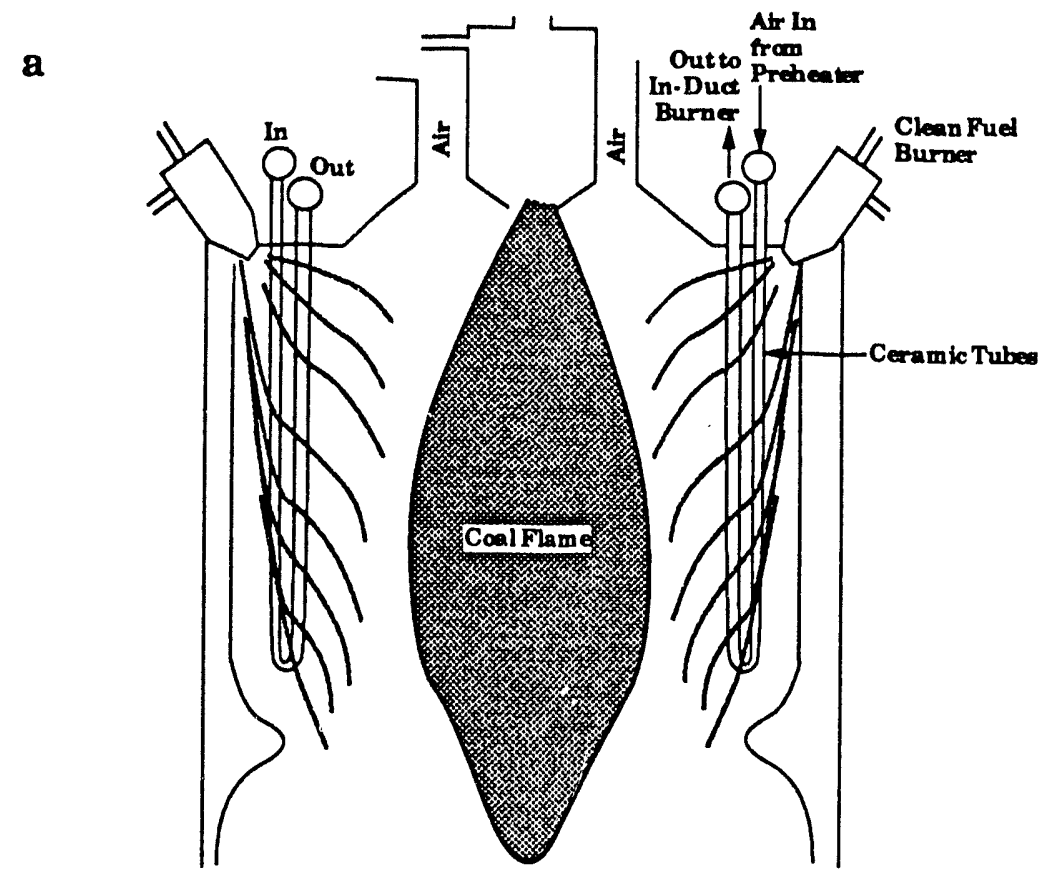

$8 / 23523110$

b
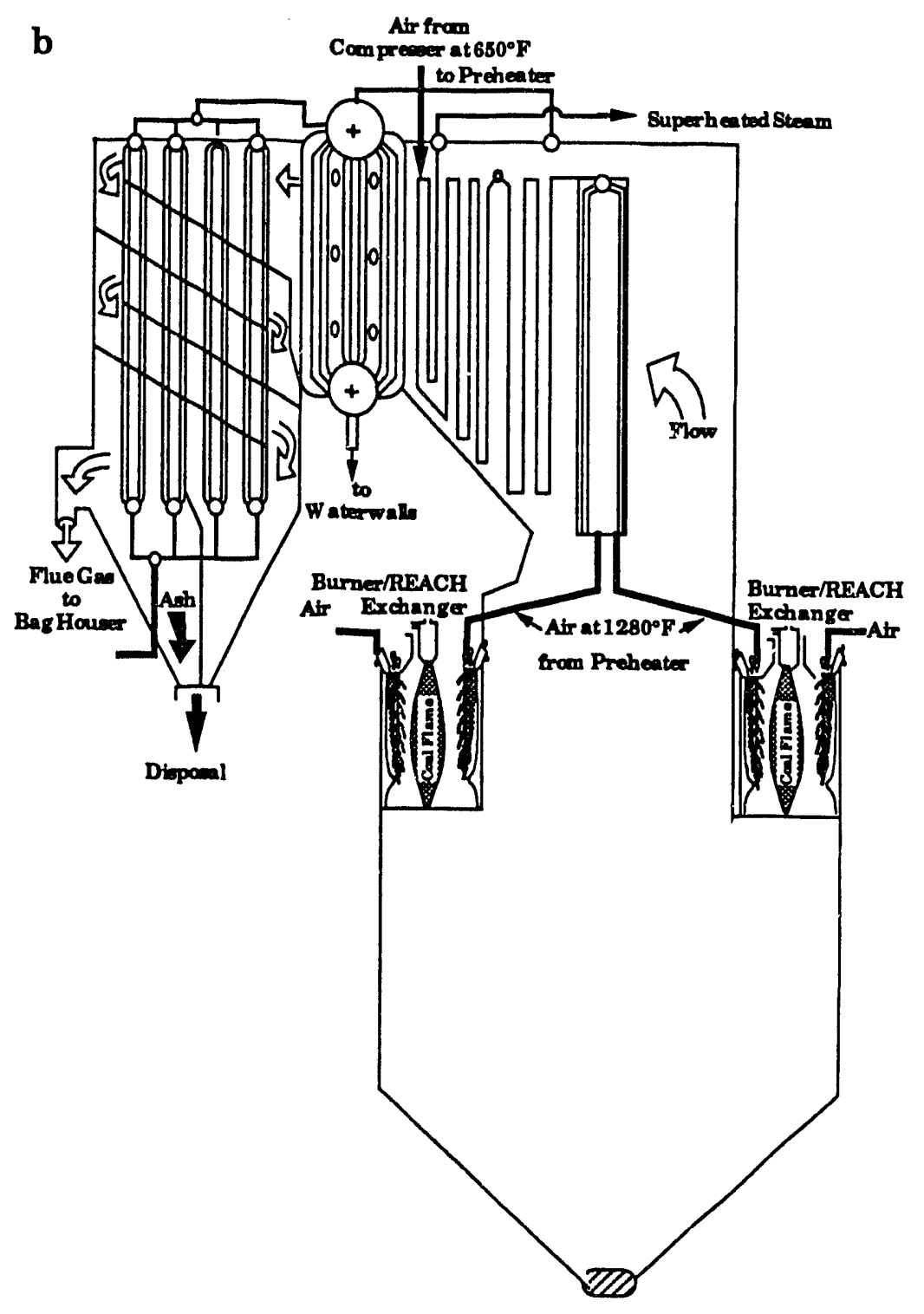

Figure 2-1. HITAF/REACH-Exchanger. a) Burner REACH-Exchanger Unit; b) HITAF Showing Two REACH-Exchanger Burner Units. 


\subsection{Critical Issues}

There are two critical technology areas addressed in this project.

\section{1). HITAF/REACH-Exchanger Combustion and Radiative Heat Transfer}

A design will be developed which allows sufficient radiation to the heat exchanger from the uncleaned stream and allows the heat exchanging surfaces to be kept clean using the flow of combustion products from the clean stream. Initial calculations show that the configuration of Fig. 2.1 has the required low turbulence flows to keep the surface clean and allows sufficient radiative heat transfer from the coal flames in the REACH-Exchanger while meeting the overall requirement for energy balance and burnout in the HITAF. This was tested using a comprehensive computer model for coal combustion and heat transfer, PCGC-2 $(1,2)$. High temperature emissivity measurements on advanced ceramics were performed and showed ensure that the up-to-date ceramic technology will provide us with materials with high temperature mechanical and optical properties that meet the needs of the heat exchanger components in HITAF/REACH system.

\section{2). 3-D CFD Modeling}

To test the ability to keep the heat exchanger surface clean by aerodynamics, we applied an advanced 3-D Computational Fluid Dynamics (CFD) model, CELMINT $(3,4)$, which included particles but not coal combustion.

\subsection{Overall Project Objective}

The overall objective of this project is to prove the feasibility of AFR's concepts for a high efficiency coal-fired generating plant using the REACH-Exchanger concept to power an externally fired gas turbine.

\subsection{The Research and Development Team}

The prime contracting concern is Advanced Fuel Research, Inc. (AFR). Scientific Research Associates, Inc. (SRA) is a subcontractor. Both companies are small businesses incorporated in Connecticut. 


\section{The Technical Issues and Objectives}

\subsection{The Problem}

The combined pressures to establish energy security, improve pollution control, and reduce global warming are encouraging the development of cleaner, more efficient technologies to convert coal into electricity. Significant improvements in efficiency can be achieved by cycles which employ a high temperature, highly recuperative gas turbine topping cycle. The principal difficulty of employing a gas turbine in a coal fired power generation system is the possible erosion and corrosion of the high temperature rotating gas turbine components caused by the coal's inorganic and organically bound constituents (ash, sulfur, and alkali metals). One route to overcome this problem is the development of an externally fired gas turbine system employing a coal fired heat-exchanger. The chief advantage of this route is that the problems caused by the coal's inorganic constituents are switched from the high temperature rotating parts of the gas turbine to the high temperature stationary parts of a heat-exchanger. The technology barrier is that ceramics are required because of the high temperature, but state-of-the-art materials are either mechanically and thermally deficient $\left(\mathrm{Al}_{2} \mathrm{O}_{3}\right)$, or mechanically durable $(\mathrm{SiC})$, but susceptible to oxidation or to corrosion from the coal's ash, sulfur, or alkali. The key issue is, then, the development of methods to fire a high-temperature heat-exchanger with coal in such a way that the potential damage from the inorganic constituents is minimized.

The objective of this project is the development and the validation of the basic concept of an externally fired gas turbine system. One system which employs a ceramic heat exchanger is currently under development by Hague International $(5,6)$. Hague is designing a device to remove slag prior to the heat-exchanger. Two additional projects were recently awarded under DoE's Combustion 2000 program to Foster Wheeler Development Corp. (7) and United Technologies Research Center (8). The approach being pursued by United Technologies is the development of a ceramic heat-exchanger protected from slag by an outer refractory layer, while Foster Wheeler is focusing on a coal carbonizer to produce enough clean fuel to fire a separate high temperature heatexchanger. This contract addresses a combined experimental/computational study of an innovative technique for firing high temperature heat exchangers in which heat exchangers placed near the furnace outer diameter are fired by radiant energy from a central coal flame and convective energy from a clean burning stream introduced at the burner outer diameter. This clean burning stream also provides flow management to shield the ceramic heat exchangers from the coal's inorganic and organically bound constituents.

\subsection{The Proposed Solution}

The solution offered in this proposal is the design of an advanced technology furnace/heat exchanger combination in which a ceramic heat exchanger is aerodynamically protected from the corrosive particle laden coal combustion products. The heat exchanger is fired by radiative and convective heat transfer from a moderately clean fuel stream and by radiative heat transfer from the flame of a much larger uncleaned fuel stream. The fluid mechanics in the furnace/heat exchanger are controlled so that the flow of the combustion products, from the moderately clean fuel stream, sweeps past the heat exchanger to provent contact with the uncleaned stream. 
This coal fired, Radiatively Enhanised, Aerodynamically Cleaned Heat Exchanger (REACH-Exchanger) concept offers two advantages over alternative designs in which the coal combustion products are used afteı high temperature particle removal le.g., using slagging combustion):

1) the REACH-Exchanger surface in the proposed concept is subjected to substantially lower concentrations of alkali, sulfur, and ash, and so will allow a wider selection of ceramics (SiC which has the required thermal, mechanical, and radiative properties but, whose use is limited because of corrosion from the coal's inorganic constituents can now be einployed).

2) the exposure of the Heat Exchanger (HE) surface to the radiation from the: highly radiant coal flame allows for a significant increase in the heat exchange rate compared to that attainable from combustion gases down stream of the flame. In the proposed system, $80 \%$ of the energy to the HE is supplied by radiation.

For the REACH-Exchanger concept, slag removal prior to the exchanger is not required. However, if slag removal proves to be advantageous for emission control, a slagging section could be employed following the heat exchanger. The REACH-Exchanger concept is presently being drafted by Advanced Fuel Research, Inc. (AFR) for a patent application.

The clean stream can be supplied by combustion of natural gas, volatile products of pyrolysis or carbonization (i.e., fuel rich combustion of volatiles), or products of coal gasification. The uncleaned stream can be coal or char. The concept for the high temperature ceramic heat exchanger is shown schematically in Fig. 3.1. The figure presents one burner/HE unit in a large furnace. It is assumed that air is preheated in a moderate temperature metal $\mathrm{HE}$ to a temperature of $1280^{\circ} \mathrm{F}$, prior to entering the high temperature HE. The size of the burner is chosen so that the uncieaned fuel flame is optically thick and reaches its highest temperature in the region opposite the high temperature REACH-Exchanger outlet. Several of these burners will be integrated into the HITAF as shown in Fig. 3.2. The design pictured is Foster Wheeler's boiler arrangement for low reactivity fuels. This design provides a low turbulence burner which will minimize contamination of the clean streams. It is also an inherently low $\mathrm{NO}_{x}$ design.

Preliminary calculations based on measured flame properties suggest that the high temperature, uncleaned flame could radiate energy at an intensity of up to $0.9 \mathrm{MW} / \mathrm{m}^{2}$. The emissivity of candidate high temperature ceramics (e.g., silicon carbide) is between 0.8 and 0.9 , so a large fraction of the radiated power can be efficiently absorbed. A sample plant calculation shows that it will be possible to supply the remaining heat required by the heat exchanger, and to have sufficient flow to keep the heat exchanger surfaces clean by firing $17.5 \%$ of the fuel in the moderately clean stream. An additional $17.5 \%$ of clean fuel is used for an in-duct burner to boost the gas turbine inlet temperature.

Preliminary calculations and assessments indicate that:

- the REACH-Exchanger can be incorporated into a proven furnace design for low reactivity fuels. 


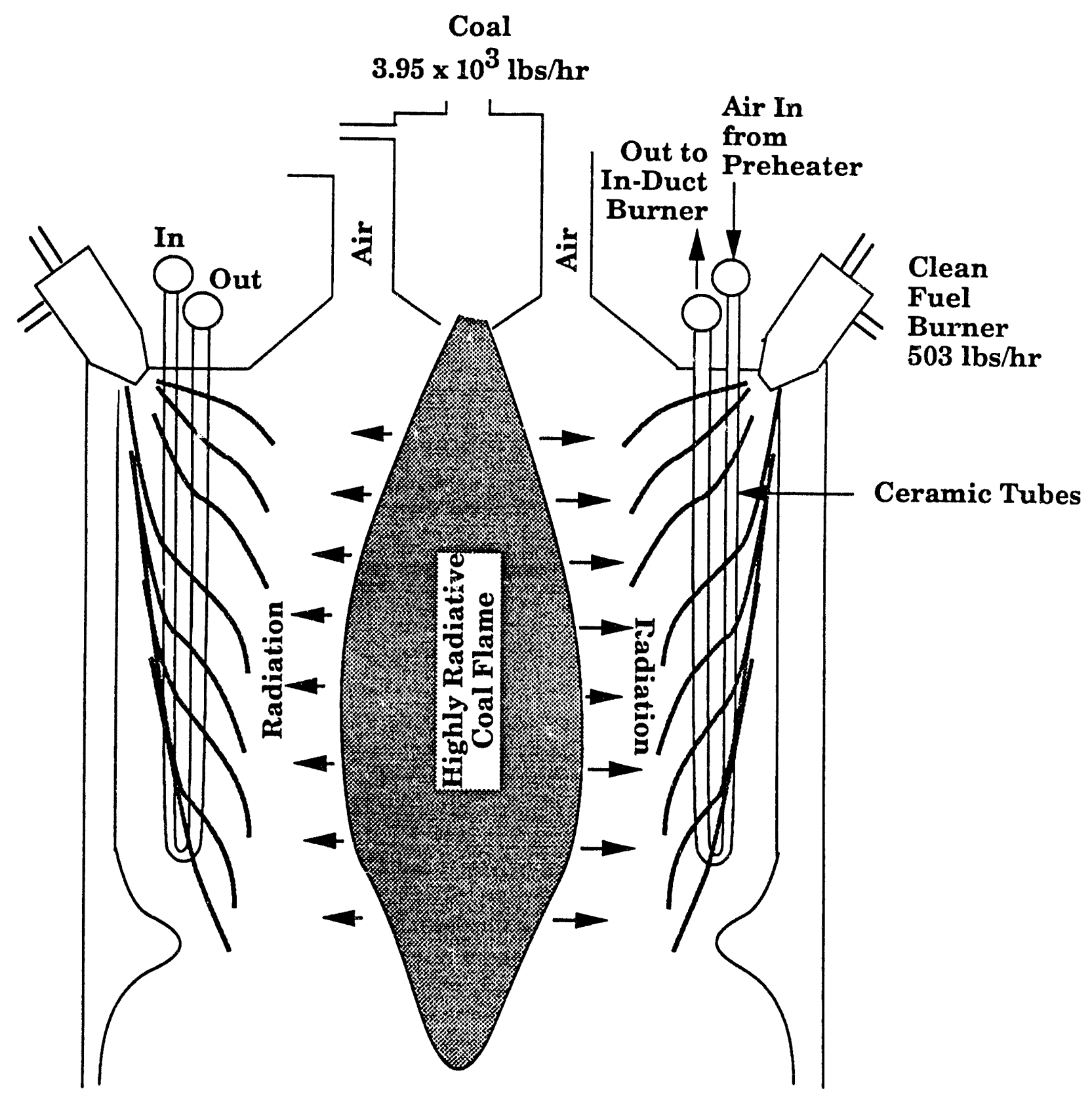

Figure 3.1. Schematic of Burner/REACH Exchanger. 

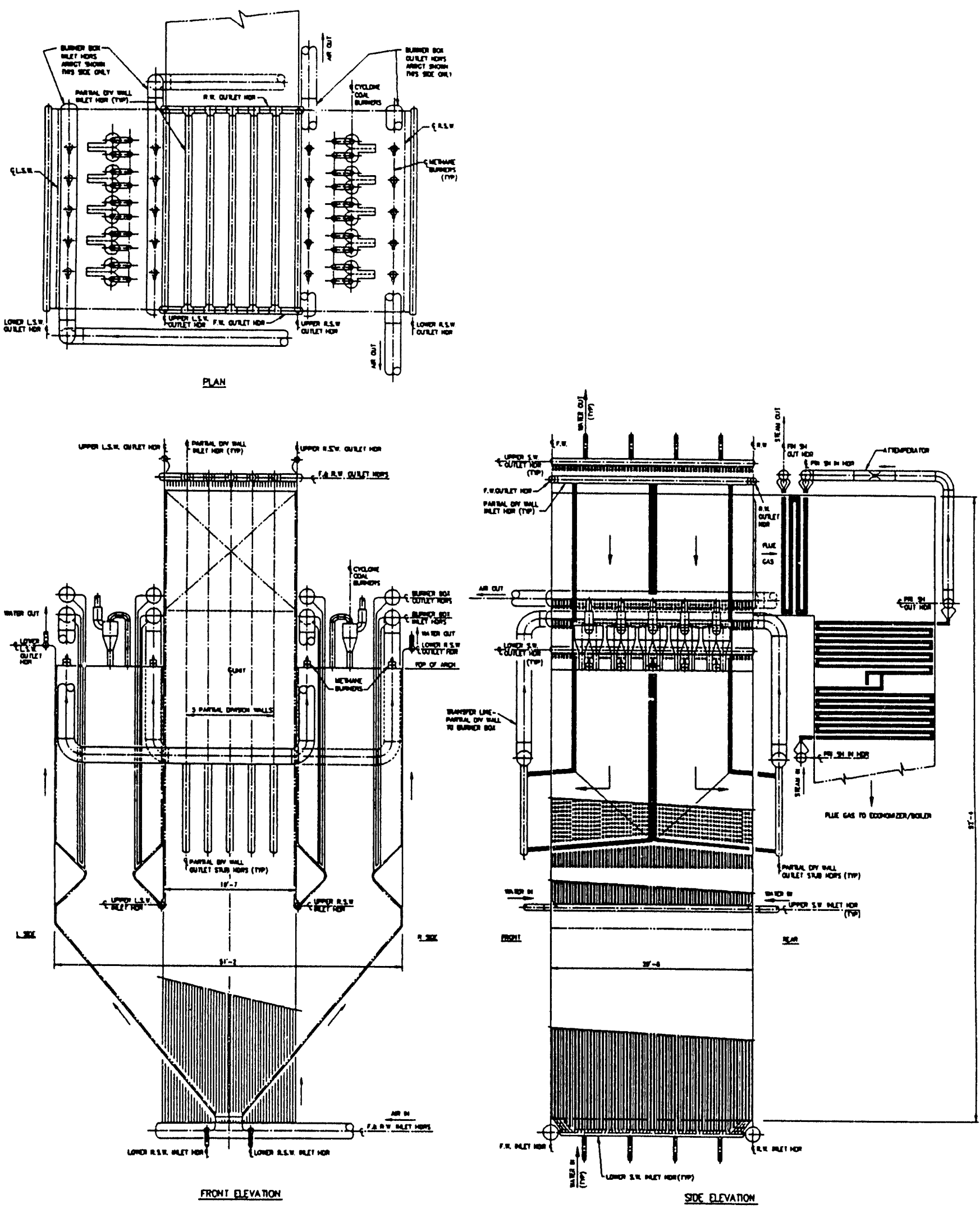

Figure 3.2 High Temperature Advanced Furnace and Convection Superheater Conceptual Design Developed by Foster Wheeler. 
- the HITAF/REACH-Exchanger can be employed in a cycle similar to that presented in PRDA No. DE-RA22-90PC90159 with at least $47.3 \%$ efficiency generation of electricity.

- the plant can meet the emissions goals using available technologies.

- the proposed plant would have a cost of electricity at least $11 \%$ lower than that of a conventional pulverized coal-fired plant with scrubber.

- a plant meeting these goals could be introduced in ten years.

Improvements in the system and reduction of the requirement for in-duct heating could be achieved by the following alternatives.

- Use of an aerodynamically shaped tube to improve the effectiveness of the sweep gas in keeping the REACH-Exchanger surfaces clean.

- Higher working fluid peak temperatures could be achieved by optimizing the ceramic material and REACH-Exchanger design. Higher temperature ceramics would allow a higher ceramic wall temperature. High strength ceramic material (e.g. fiber reinforced) with thinner walls, high thermal conductivity, and internal fins would improve the heat transfer to the working fluid.

- The use of the cleaned combustion exhaust stream as the working fluid would add radiative heat transfer to the working fluid due to the presence of $\mathrm{CO}_{2}$ and $\mathrm{H}_{2} \mathrm{O}$.

- The flow and energy delivered to the clean fuel stream can be independently adjusted by employing a fraction of the high temperature gas turbine exhaust stream to fire the clean stream.

- Increased protection for the REACH-Exchanger could be achieved by employing a slightly porous ceramic tube so that air diffusion out of the tube would keep the surface clean. This will be practicable only if the loss of high pressure air is very small.

- The use of a closed cycle employing a working fluid seeded with an IR absorber to aid radiative heat transfer.

- The use of helium as the working fluid in a closed cycle would improve the heat transfer between the REACH-Exchanger and working fluid through better gas thermal conductivity.

- The use of coal gasification products could be employed for the clean stream.

- Oxygen enriched air could be employed to provide higher temperatures in specific regions of the flame, if required. 
- The use of a slagging section following the REACH-Exchanger section would reduce the particulate loading prior to the convective section and down stream clean up devices.

\subsection{The Major Technical Issues And Questions}

The ultimate objective of this development program is to achieve the highest temperature possible in the REACH-Exchanger and, thus, minimize the requirement for direct firing of the gas turbine with premium fuels. Ash or slag deposition or chemical interaction (even from cleaned coal) with high temperature heat exchanger surfaces will, in time, create serious consequences of corrosion and loss in heat transfer capability. The approach is to utilize the best ceramic technology available for high temperature parts of the REACH-Exchanger and to shield the high temperature surfaces from interaction with coal minerals by employing clean combustion gases that sweep the tube surfaces exposed to the coal flame. These gases must exert sufficient pressure to prevent the intrusion of ash minerals into the heat exchanger region. The HITAF/REACH-Exchanger must be integrated into a gas turbine/steam turbine generating plant with high efficiency and low emissions. The key technology issues are in six areas:

1. HITAF/REACH-Exchanger Design - High heat input to the working fluid and protection of the tubes from interaction with ash minerals and sulfur are system requirements. The concept must combine combustion on opposite sides of the heat exchanger (the pulverized coal/char on one side, and the clean fuel stream on the other). The products arising from the combustion of the clean fuel sweeps the tube and joins the combustion products of the pulverized coal/char. The heat transfers should be taiiored to avoid gross temperature gradients in the tube. The concept may have to include staged burning of fuel to reduce $\mathrm{NO}_{\mathrm{x}}$. The design must control the uncleaned fuel flow to ensure a high temperature flame which radiates a maximum amount of its energy to the REACH-Exchanger.

An innovative design approach is needed to develop furnace and burner arrangements to accommodate a wide range of coal types and derived char.

If the clean fuel stream is derived from coal pyrolysis or carbonization, it may have to undergo particulate removal, possibly beyond that achievable in cyclone-type separators. High temperature filters may be needed; alkali getters may have to be introduced into the pyrolysis products for low rank coals.

Depending on coal type and pyrolysis conditions, the char produced from the pyrolysis process may have reactivities that require special furnace and burner arrangements to stabilize combustion. This need will also dictate furnace design and, consequently, heat transfer surface arrangement. The furnace combustion volume must be sized to cool the products of combustion to a temperature below ash softening or fusion.

The HITAF/REACH-Exchanger must be designed to survive the high levels of thermal and mechanical stress inherent in such a system. 
2. CFD Model Development - Because of the importance of careful control of the heat and mass transport in the furnace, an improved 3-D CFD model is required to aid in the design. The model must incorporate accurate descriptions of the particle dynamics and the radiative and convective heat transfers to the walls and heat exchanger tubes. Such models must be validated with reliable data and employed to design the furnace for the pilot facility and commercial prototype. We intend to demonstrate that state-ofthe-art computational fluid dynamics (CFD) can be effectively employed to provide design information prior to building and testing of a pilot plant.

3. Ceramic Technology - The selection of the ceramic material for the heat exchanger must be made from the most advanced technologies available. Development of reliable methods to join and seal the ceramic tubes to the main header are required. The resistance to thermal shock of ceramic tubular components is important, as is resistance to fatigue and corrosion. The ability to transport heat from the flame to the working fluid is of prime importance. The solution may be ceramic materials reinforced with fibers, new ceramic materials, and new fabrication techniques. The materials must satisfy economic requirements. The implementation would be facilitated by the development of a design for aerodynamic shapes for the HE tubes to sustain the sweeping of the surface as well as methods for fabricating these shapes.

In the furnace cavity, the ceramic materials are at temperatures above $1500^{\circ} \mathrm{C}$. They are subjected to flow-induced vibrations which will induce cyclic bending stresses. The ability of the materials to "live" in that environment depends on the unsupported length of the heat transfer surfaces which, in turn, dictates furnace design.

4. Emission Control - To achieve the stated $\mathrm{SO}_{2}, \mathrm{NO}_{x}$, and particulate emissions limits will require a combination of in-furnace $\mathrm{NO}_{x}$ control, stack gas treatment, and possibly up-front coal cleaning. A slag removal section following the burner/REACH-Exchanger section could be employed to reduce particulate loading on down stream components. The control of $\mathrm{NO}_{x}$ will be achieved by tailoring the flame temperatures, stoichiometries, and gas mixing (i.e., staged combustion).

The REACH-Exchanger furnace design presented here is based on proven concepts used by Foster Wheeler in Anthracite boiler design. It produces inherently low $\mathrm{NO}_{x}$ emissions. Further $\mathrm{NO}_{x}$ reduction if required can be achieved by $\mathrm{NH}_{3}$ injection.

5. System Analysis - To meet the efficiency requirements, it is essential to minimize heat rejection to the steam cycle. Maximum use must be made of the available heat for heating the gas turbine fluid and heat losses and auxiliary power consumption must be minimized. A condensing heat recovery section may have to be developed to achieve the desired results. Acceptable cycles in which to employ the HITAF/REACH-Exchanger must eventually be defined. 
6. Plant Description - The above concepts must be integrated into a system which meets the cost, efficiency, and pollution control standards required for commercialization. It is expected that the plant design including gas and steam turbines, $\mathrm{SO}_{\mathrm{x}}$ and particulate removal systems, and most of the ancillary equipment will be of current commercial design or modest improvements there of. 


\section{Preliminary Analysis of the Concept}

The base cycle evaluated in this program is an externally-fired gas turbine combined-cycle power plant that uses turbine exhaust gas to combust coal and natural gas in a HITAF/REACH-Exchanger. A near-term configuration, conceptually illustrated in Fig. 4.1 , is proposed using natural gas firing to provide $36 \%$ of the power plant energy. A $100 \mathrm{MWe}$ power plant size is specified as the plant basis.

\subsection{General Cycle Description and Rationale}

The near-term base cycle applies the following rationale:

- The near-term base cycle provides conditions that maximize the technical feasibility of the HITAF/REACH-Exchanger, consuming the maximum amount of natural gas to produce a clean ceramic heat exchanger sweep gas.

- A cycle similar to that in PRDA No. DE-RA22-90PC90159 cycle is used to demonstrate the relative merits, and the resulting changes, in the proposed cycle. Other cycles were considered, such as gas turbine reheat cycles, a low pressure ratio exhaust-fired turbine cycle, closed gas turbine cycles, and cycle variations that eliminate the steam cycle, but they are not further considered here to avoid to cloud the issues of the key process components of the HITAF/REACH-Exchanger. The HITAF/REACH-Exchanger is adaptable to a multitude of power cycles.

- Gas turbine conditions and blade cooling requirements reflecting only modest gains in technology, likely over the next ten years, were selected for the base cycle because this program is not a gas turbine development program. More advanced gas turbines could be selected that would improve the calculated plant efficiency, but their availability in the time frame of this program is not probable.

- Advanced steam turbine conditions can reasonably be incorporated into the base cycle because they have been achieved in past testing and are currently the subject of major development efforts.

- Some components in the plant are not currently commercially available, but are not major development issues. For example, the natural gas topping combustor is not a currently available component and will be an advanced refractory combustor for the base cycle. This topping combustor will also need to achieve low $\mathrm{NO}_{\mathrm{x}}$ generation. Westinghouse has advanced the state-of-the-art in the design of such topping combustors fired with high-temperature oxidant, and producing low $\mathrm{NO}_{x}$ emissions, in prior DOE development programs.

- The base cycle applies commercial, state-of-the-art components for pollution control:

- $\mathrm{SO}_{2}$ control by lime-slurry wet scrubbing with forced oxidation 


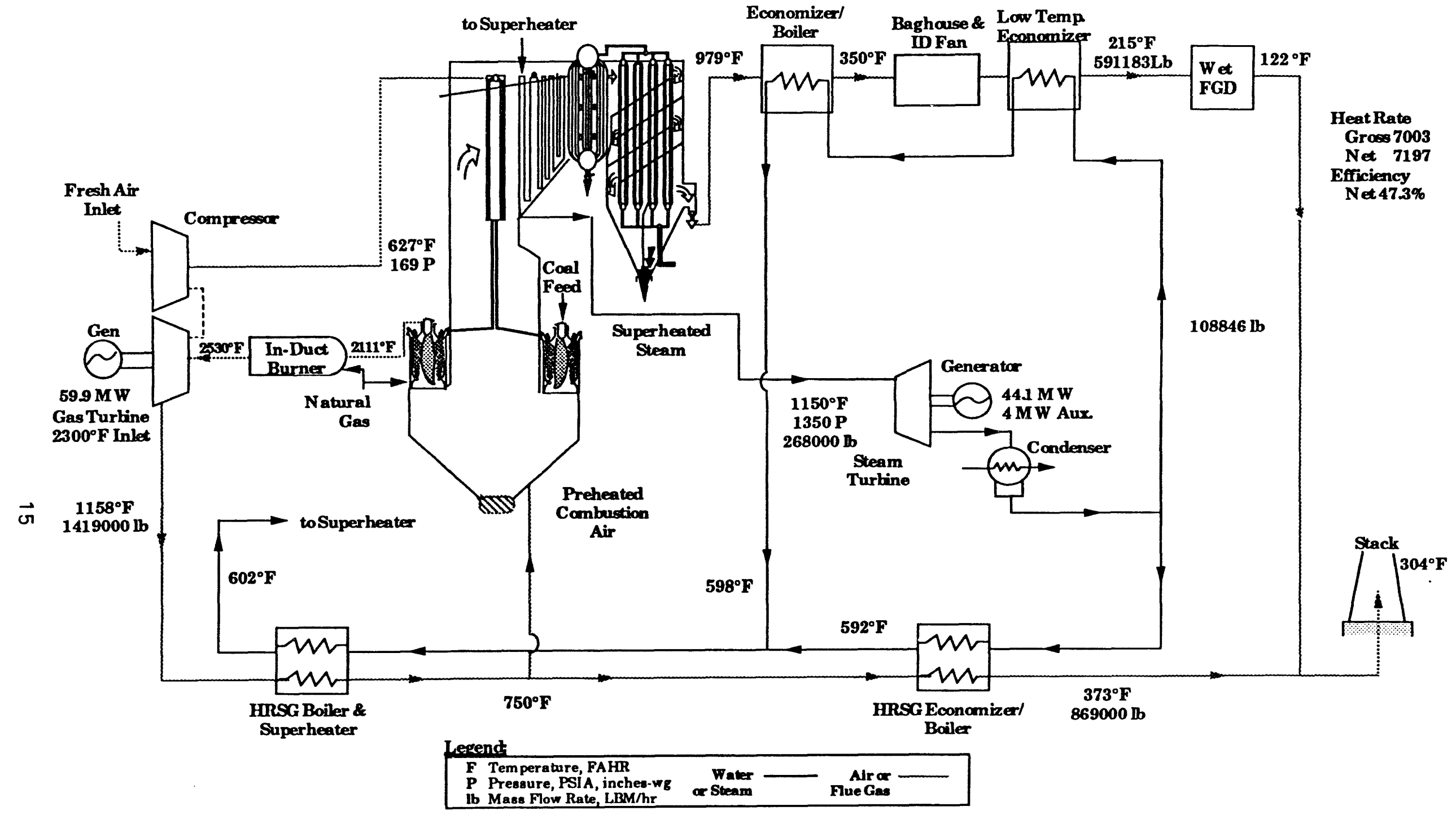

Figure 4.1. Schematic of a High-Performance, Externally-Fired Gas Turbine Combined Cycle. 
- NO $x$ control by burner staged combustion

- particulate control by fabric filter baghouse

- All other components in the base cycle are similar to conventional practice, are commercially available, or are currently within commercial design feasibility to supply.

The power plant efficiency is maximized by:

- maximizing the gas turbine inlet temperature

- minimizing the pressure drop through the compressed air heater circuit

- minimizing the pressure drop through the flue gas circuit

- minimizing process heat losses such as those associated with waste solids streams -- a non-slagging combustor is used, and flash is removed from the plant at a relatively low temperature

- eliminating stack gas reheat -- direct reheat of the FGD exhaust is accomplished by mixing with the turbine exhaust gas.

- using low temperature economizer technology

In the near-term base cycle about $38 \%$ of the natural gas consumed indirectly heats compressed air (simultaneously sweeping the ceramic heat transfer surface to protect it from slag deposition and corrosion) for use in a non-reheat gas turbine system. The other $62 \%$ portion of the natural gas is directly fired with the heated compressed-air in a gas turbine topping combustor to reach state-of-the-art turbine inlet temperatures. A portion of the gas turbine exhaust air (containing natural gas combustion products) is used for fuel combustion in the HITAF. This combustion air is split between three streams, one being primary coal combustion air (also providing coal drying in the pulverizer), another being secondary coal combustion air, and the last being natural gas combustion air. The remainder of the turbine exhaust air is used to raise steam in a high efficiency heat recovery steam generation system.

The HITAF burners are integrated with ceramic air heaters. The radiative coal flame provides a large portion of the compressed-air heating, in parallel with the natural gas combustion products, to achieve a compressed-air temperature of $2111^{\circ} \mathrm{F}$. In contrast with the PRDA No. DE-RA22-90PC90159 cycle, steam superheating is performed downstream of the ceramic heat exchanger section using lower-temperature combustion products. Metal heat transfer surfaces are used to preheat the compressed air from the compressor discharge temperature of $627^{\circ} \mathrm{F}$ up to $1280^{\circ} \mathrm{F}$. The cycle will be roughly equivalent with steam superheater placed directly after the REACH-Exchanger las shown in Fig. 4.2), to the cycle with the compressed-air preheater placed directly after the REACH-Exchanger, followed by the steam superheater (as shown in Fig. 4.1). Detailed design evaluation is needed to select the best arrangement. 


\subsection{Plant Conditions and Assumptions}

In this section we report a calculation of cycle efficiency and material and energy balances for a nominal near-term base cycle case. These calculations require a number of iterations to balance the plant, with parameter changes at each iteration. Because the initial calculations are time-consuming, very little of the parameter space available to meet the specifications has been explored, and the calculation should be considered a sample only. For the convergence reported here natural gas accounts for $36 \%$ of the energy input, compared with the $35 \%$ minimum in PRDA No. DE-RA22-90PC90159. This small difference could be eliminated, while maintaining the overall efficiency, by a number of parameter changes which lie within the permitted operating conditions of plant components.

The key operating conditions that define the sample cycle are:

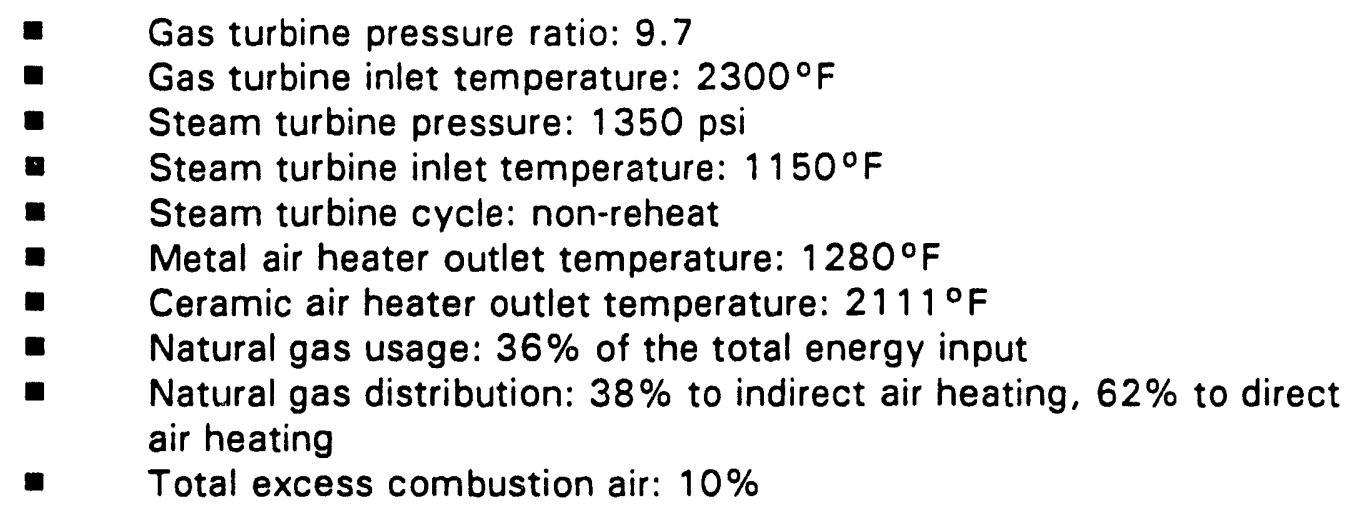

The gas turbine conditions and cooling air requirements described in PRDA No. DERA22-90PC90159 cycle are similar to those of state-of-the-art gas turbines, such as the Westinghouse 501-F. The 501-F operates with a higher pressure ratio (14:1) than the base cycle turbine assumed in the calculations, and at an air rate of about $914 \mathrm{lb} / \mathrm{sec}$ to produce considerably more power than the base cycle turbine. Blade cooling requirements are slightly greater in the $501-\mathrm{F}$ than in the base cycle turbine: $20 \%$ of the compressed air is used directly in the gas turbine for cooling in the $501-\mathrm{F}$ versus $18 \%$ in the base cycle turbine. The $501-\mathrm{F}$ combustor inlet temperature is about $2450^{\circ} \mathrm{F}$ compared to about $2530^{\circ} \mathrm{F}$ in the base cycle turbine. The cooling air reduction differences are considered to represent a reasonable improvement in turbine technology that may occur over the next ten years.

The coal assumed in the cycle calculations is an Illinois No. 6 coal with a HHV of $11,430 \mathrm{BTU} / \mathrm{lb}$, a moisture content of $5.0 \mathrm{wt} \%$, a sulfur content of $3.5 \mathrm{wt} \%$, and an ash content of $10.0 \mathrm{wt} \%$, similar to that used in PRDA No. DE-RA22-90PC90159. Its as-fed composition is:

$\begin{array}{ll}\text { carbon: } & 68.9 w t \% \\ \text { hydrogen: } & 4.4 \\ \text { oxygen: } & 7.0 \\ \text { sulfur: } & 3.5 \\ \text { nitrogen: } & 1.1 \\ \text { chlorine: } & 0.1\end{array}$


$\begin{array}{ll}\text { moisture: } & 5.0 \\ \text { ash: } & 10.0\end{array}$

Natural gas is assumed to have the following composition:

$\begin{array}{ll}\mathrm{CH}_{4}: & 90.0 \text { mole } \% \\ \mathrm{C}_{2} \mathrm{H}_{8}: & 5.0 \\ \mathrm{~N}_{2}: & 5.0\end{array}$

with a higher heating value of $22,590 \mathrm{BTU} / \mathrm{lb}$. Air is taken to have a composition of:

$\begin{array}{ll}\mathrm{O}_{2}: & 20.74 \text { mole } \% \\ \mathrm{~N}_{2}: & 77.28 \\ \mathrm{Ar}: & 0.96 \\ \mathrm{H}_{2} \mathrm{O}: & 1.02\end{array}$

A calcitic limestone is the feed for the lime wet scrubber system, having a composition of:

$\begin{array}{ll}\text { Ca: } & 38.0 \text { wt } \% \\ \mathrm{CO}_{3}: & 59.0 \\ \text { lnerts: } & 3.0\end{array}$

The assumed values of component efficiencies used in the cycle calculations are:

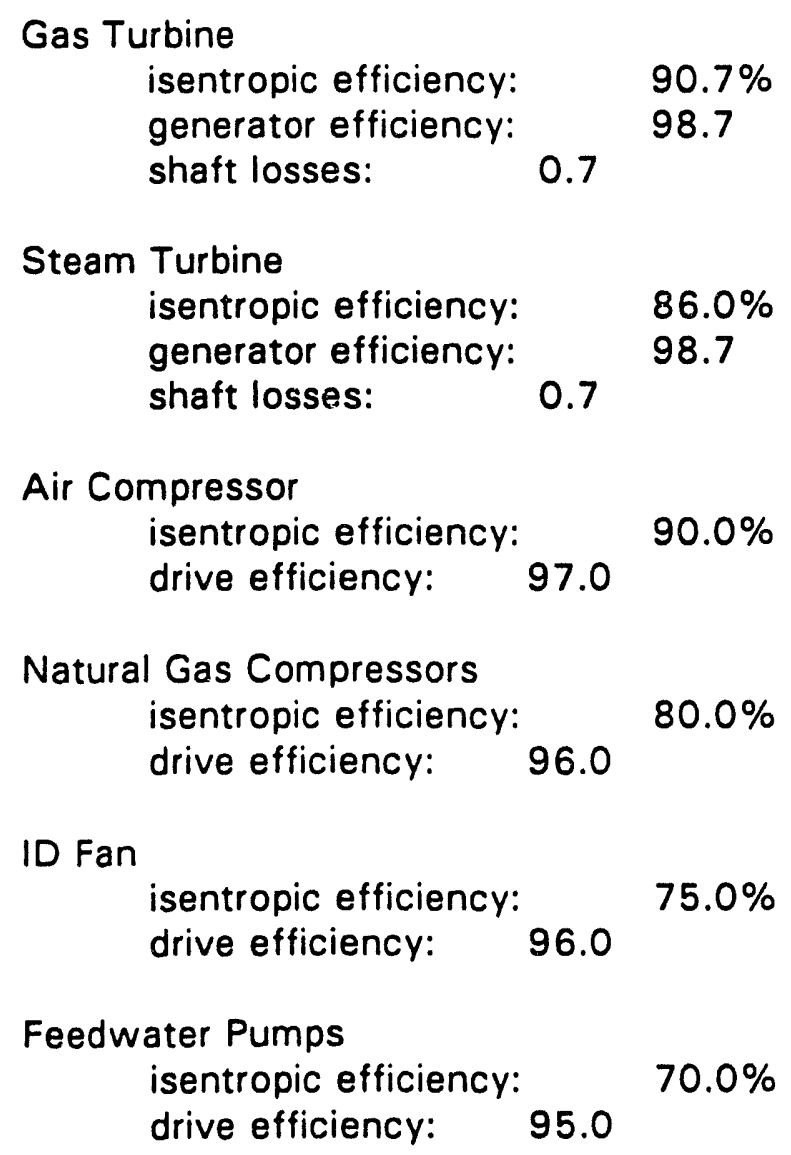


Heat losses through the heat recovery equipment are assumed to be $0.5 \%$ of the heat duty of each unit, mostly due to radiation losses. Pressure drops on the steam side are taken at standard utility pressure drop values. The HITAF is selected to be a balanced draft design. Pressure drops through the plant equipment are as follows:

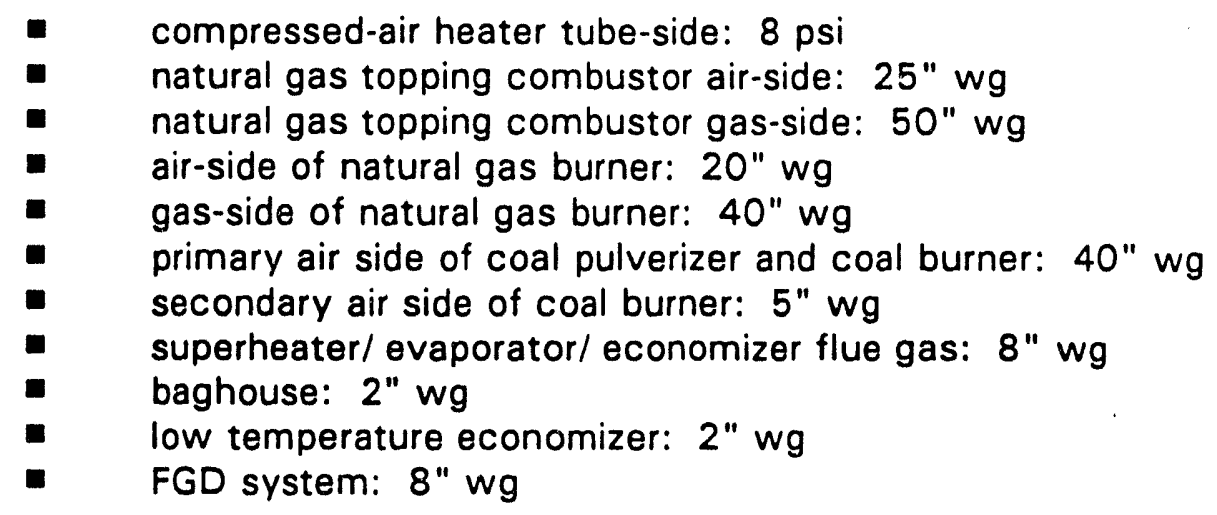

The ID fan pressure gain is $25 " \mathrm{wg}$. The flue gas side pressure drops through the steam heat recovery equipment are selected to be similar to a conventional power plant, as are the selected pressure drops on the steam side of the heat recovery equipment. Lime scrubbing FGD, with forced oxidation, design and operating information has been scaled from reports in the open literature $(9,10)$.

\section{Plant Performance}

The near-term base cycle material and energy balances and cycle efficiency have been calculated using a proprietary Westinghouse code, "SPA". This code has been widely applied by Westinghouse in prior DOE programs relating to advanced power generation systems such as MHD and fuel cells. Table 4.1 provides a listing of the numbered stream conditions designated in Fig. 4.2, giving the mass flow rate, temperature, and pressure of each stream. The compositions of some of the key streams in the plant are:

Gas turbine exhaust gas (stream 10):

$\begin{array}{ll}\mathrm{O}_{2} & 20.96 w t \% \\ \mathrm{~N}_{2} & 74.68 \\ \mathrm{CO}_{2} & 1.34 \\ \mathrm{H}_{2} \mathrm{O} & 1.70 \\ \mathrm{Ar} & 1.32 \\ \mathrm{SO}_{2} & 0\end{array}$

$\mathrm{HCl} \quad 0$

HITAF exhaust gas stream (stream 19):

$\begin{array}{ll}\mathrm{O}_{2} & 2.01 w t \% \\ \mathrm{~N}_{2} & 69.71 \\ \mathrm{CO}_{2} & 20.44 \\ \mathrm{H}_{2} \mathrm{O} & 6.12 \\ \mathrm{Ar} & 1.23 \\ \mathrm{SO}_{2} & 0.47 \\ \mathrm{Hcl} & 0.008\end{array}$


Table 4.1 - Near-Term Base Cycle Performance

Power Summary, MHe

Gas turbine power

Steam turbine power

59.9

Gross power

44.1

Auxiliaries

104.0

4.0

Net Power

100.0

Net Efficiency, \% (HHV)

47.3

Net Heat Rate, Btu/kWh

7213

Environmental emissions:

$\mathrm{SO}_{2}$ removal, \%

$\mathrm{SO}_{2}^{2}$ emission, $1 \mathrm{~b} / 10^{6} \mathrm{Btu}$

$\mathrm{NO}$ stack emission, ${ }^{\mathrm{ppmr}}$

$\mathrm{NO}$ emission, $1 \mathrm{~b} / 10^{6} \mathrm{Btu}$

particulate emission, $1 \mathrm{~b} / 10^{6} \mathrm{Btu}$

96.2

0.146

46

Consumables and Wastes

Coal feed, lb/hr (Btu/hr)

Natural gas feed, $\mathrm{lb} / \mathrm{hr}$ (Btu/hr)

Limestone feed, $\mathrm{lb} / \mathrm{hr}$

Coal ash waste, $\mathrm{lb} / \mathrm{hr}$

FGD waste, $\mathrm{lb} / \mathrm{hr}$

0.150

0.0073

Auxiliary Summary, kWe

Natural gas compressor 495

Natural gas blower 10

ID $f$ an

$40,388\left(4.6164 \times 10^{8}\right)$
$11,495\left(2.5967 \times 10^{8}\right)$

4,836

4,062

6,339

Condensate pump

821

556

Circ. \& service rater system 80

Steam turbine auxiliaries 12

Coal receiving, handling and . 250

pulverization

Limestone receiving, handling and 81 feeding

Solid waste handling

FGD system

Miscellaneous

Total Auxiliaries 


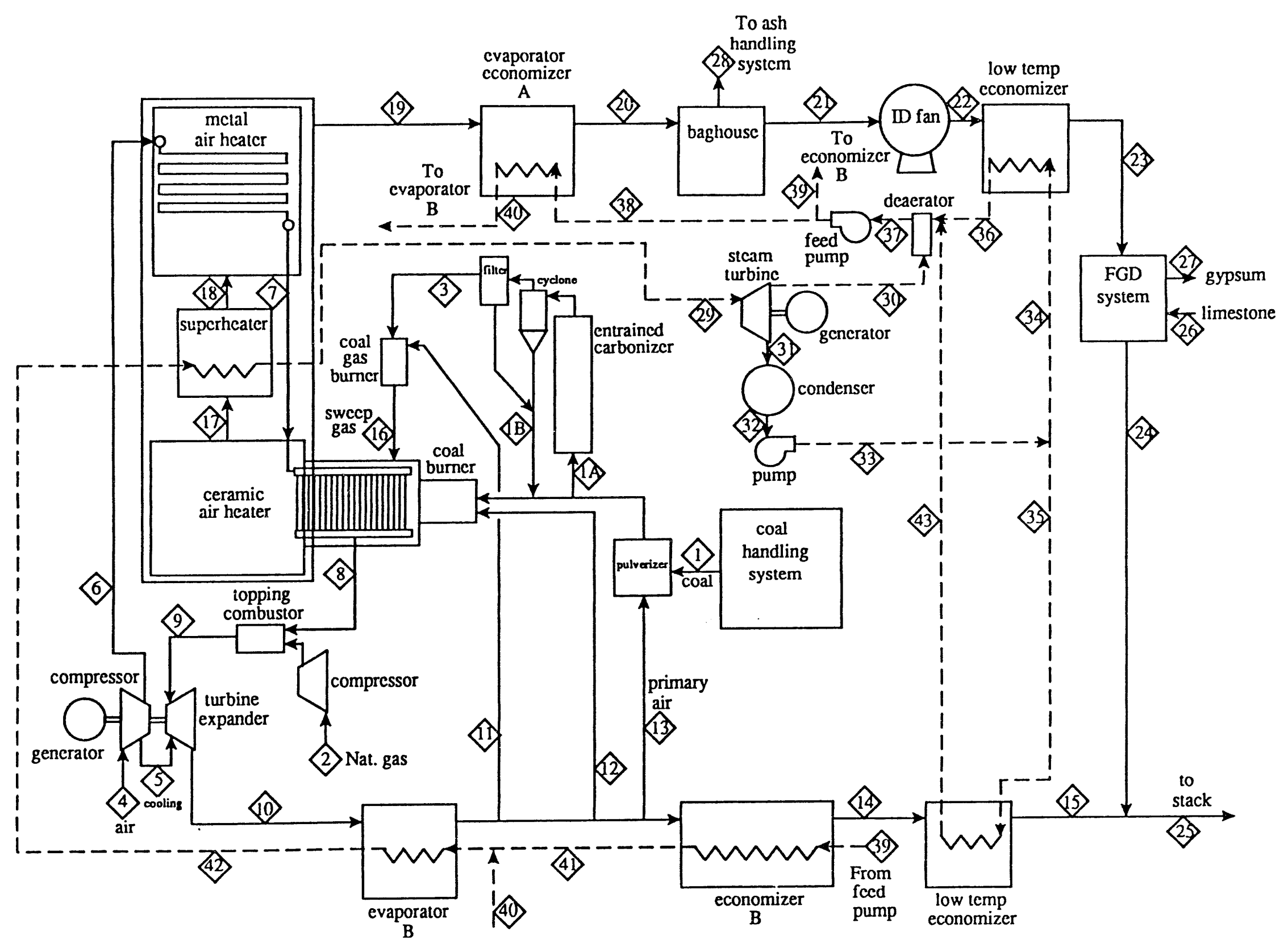

Figure 4.2. Evolutionary Base Line Cycle. 
FGD discharge gas (stream 24):

$\mathrm{O}_{2} \quad 1.97 \mathrm{wt} \%$

$\mathrm{N}_{2} \quad 68.21$

$\mathrm{CO}_{2} \quad 19.99$

$\mathrm{H}_{2} \mathrm{O} \quad 8.60$

Ar $\quad 1.20$

$\begin{array}{ll}\mathrm{SO}_{2} & 0.017\end{array}$

$\mathrm{HCl} \quad 0.00031$

Stack gas (stream 25):

$\mathrm{O}_{2} \quad 13.17 \mathrm{wt} \%$

$\mathrm{N}_{2} \quad 72.03$

$\mathrm{CO}_{2} 8.99$

$\mathrm{H}_{2} \mathrm{O} \quad 4.53$

$\mathrm{Ar} \quad 1.27$

$\begin{array}{ll}\mathrm{SO}_{2} & 0.0072\end{array}$

$\mathrm{Hcl} \quad 0.00013$

$\mathrm{NO}_{x} 45 \mathrm{ppmv}$

A summary of the advanced power generation system performance is presented in Table 4.2. The near-term base cycle power plant produces $100 \mathrm{MWe}$ of net power with an efficiency of $47.3 \%$ (heat rate $7213 \mathrm{BTU} / \mathrm{kWh}$ ) based on the higher heating value of the fuels. Overall, the near-term base cycle meets all of the cycle performance and environmental emissions constraints. It achieves $96.2 \%$ sulfur removal efficiency using conventional lime scrubbing FGD with $L / G$ ratio selected from available FGD design information. The near-term cycle has not been optimized and flexibility is available in the cycle to make improvements in natural gas consumption, cycle efficiency and solid waste consumption while retaining the essential features of the near-term base cycle. 
Table 4.2 - Near-Term Base Cycle State Points

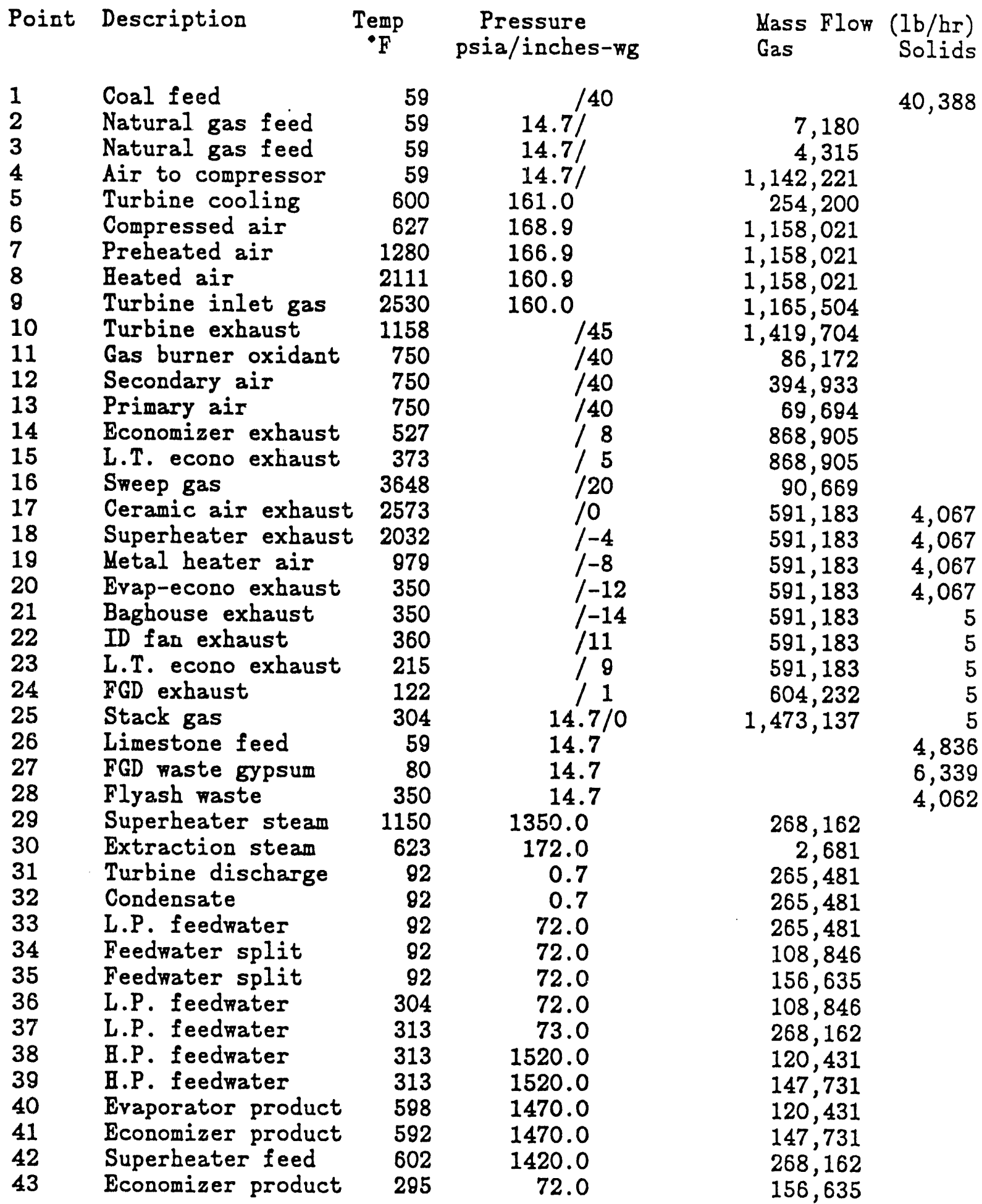




\section{Results}

Three tasks of this program have been performed as scheduled. The Main results are summarized as follows.

\subsection{Management Plan (Task 1)}

The objective of this Task is to develop a research plan based on the proposal to address the critical issues and answer the key questions. Several technical meetings between AFR and SRA personnel were held to discuss this coordinated research program. The management plan was written and submitted to the COTR during the first quarter of the program.

\subsection{Computational REACH/Exchanger Design (Task 2)}

As identified in Section 3, one of the critical issues of the HITAF/REACH concept is whether this design has sufficient radiation to the heat exchanger from the uncleaned stream and allows the heat exchanging surfaces to be kept clean using the flow of combustion products from the clean stream. The efficiency of coal combustion is also an important issue. The objective of this task is to verify the basic concept of this design by 2D combustion modeling. The calculations were performed for a number of computational reactors designed based on the REACH concept. These reactors are presented below.

\subsubsection{The Base Case (Case 1)}

\section{Basic Requirement}

As required in Section 6 of the proposal, the proposed plant is assumed to generate $100 \mathrm{MW}$ of electricity at $47.4 \%$ efficiency by burning $719 \times 10^{6} \mathrm{BTU} / \mathrm{hr}(211 \mathrm{MW})$ of fuel. The plant is assumed to have $10 \mathrm{HITAF/REACH}$-Exchanger units, each burning 3,954 $\mathrm{lbs} / \mathrm{hr}$ of coal and $503 \mathrm{lbs} / \mathrm{hr}$ of natural gas. The HITAF/REACH-Exchanger raises the working fluid temperature from $1280^{\circ} \mathrm{F}$ to $2111^{\circ} \mathrm{F}$. An additional $5030 \mathrm{lbs} / \mathrm{hr}$ of natural gas are fired in an in-duct burner to raise the working fluid temperature to $2530^{\circ} \mathrm{F}$ so that a turbine inlet temperature of $2300^{\circ} \mathrm{F}$ is achieved after mixing with the first stage cooling air.

Based on the plant with 10 HITAF/REACH-Exchanger reactor units, the energy and materials balances are:

1. A total of $10.06 \times 10^{3} \mathrm{lbs} / \mathrm{hr}$ of natural gas is fired, $5030 \mathrm{lbs} / \mathrm{hr}$ in the ten burner/heat exchanger units and $5030 \mathrm{lbs} / \mathrm{hr}$ in the in-duct burner.

2. The high temperature ceramic heat exchanger raises the temperature of $1.02 \times 10^{6} \mathrm{lbs} / \mathrm{hr}$ of air working fluid from $1280^{\circ} \mathrm{F}$ to $2111^{\circ} \mathrm{F}$. This requires $239 \times 10^{6} \mathrm{BTU} / \mathrm{hr}(70 \mathrm{MW})$ of power.

3. The natural gas in the heat exchangers $\left(5.3 \times 10^{3} \mathrm{lbs} / \mathrm{hr}\right.$ of natural gas plus $106 \times 10^{3} \mathrm{lbs} / \mathrm{hr}$ of air) transfers $48 \times 10^{6} \mathrm{BTU} / \mathrm{hr}(14.1 \mathrm{MW})$ of power to the heat exchanger as its temperature goes from $3428^{\circ} \mathrm{F}$ to $2000^{\circ} \mathrm{F}$. 
4. The coal combustion products $\left(502 \times 10^{3} \mathrm{lbs} / \mathrm{hr}\right)$ transfer $191 \times 10^{6} \mathrm{BTU} / \mathrm{hr}$ $(56 \mathrm{MW})$ to the heat exchanger by radiation. The initial energy in the combustion products are 1077 BTU/lbs of combustion products, of which $927 \mathrm{BTU} / \mathrm{lb}$ of combustion products comes from the coal and $150 \mathrm{BTU} / \mathrm{lb}$ of combustion products comes from the preheated air $\left(750^{\circ} \mathrm{F}\right)$. This enthalpy in the combustion products would produce a temperature of $3830^{\circ} \mathrm{F}$ if there were no losses. The temperature never gets that high because the flame is radiating energy away as the fuel burns. After a loss of $191 \times 10^{6} \mathrm{BTU} / \mathrm{hr}$, the combustion stream will be at $2647^{\circ} \mathrm{F}$.

5. $\quad 5.3 \times 10^{3} \mathrm{lbs} / \mathrm{hr}$ of natural gas is fired in the in-duct burner to raise the temperature from $2111^{\circ} \mathrm{F}$ to $2530^{\circ} \mathrm{F}$.

The geometry for the HITAF/REACH-Exchanger unit requires that the flame deliver $56 \mathrm{MW}$ of radiated energy to the heat exchanger. The net radiation intensity absorbed by the heat exchanger will be

$$
R=\sigma \epsilon\left(T^{4}{ }_{\text {tleme }}-T^{4}{ }_{\text {HE }}\right)
$$

where $T_{\text {fleme }}$ and $T_{H E}$ are the temperatures of the flame and heat exchanger, respectively, and $\epsilon$ is the emissivity of the heat exchanger tubes. The emissivity of the flame is assumed to be unity. The geometry of the flame and HE is shown schematically in Fig. 5.1 with the radiation emitted by both the flame and $H E$. At the hot end of the heat exchanger $T_{\text {fleme }}=3200^{\circ} \mathrm{F}$ and $T_{H E}=2580^{\circ} \mathrm{F}$, where we assume a $470^{\circ} \mathrm{F}$ difference between the outside ceramic temperature and the working fluid gas temperature. Only a fraction, $\epsilon$, of the radiation incident on the heat exchanger is absorbed by it, giving a net gain of

$$
R=40 \mathrm{~W} / \mathrm{cm}^{2}
$$

assuming an emissivity of 0.8 for the heat exchanger surface.

At the low temperature end of the heat exchanger

$$
R=24 \mathrm{~W} / \mathrm{cm}^{2} \text {, }
$$

assuming the average flame temperature seen by the surface is $2647^{\circ} \mathrm{F}$ and the ceramic surface temperature is $2000^{\circ} \mathrm{F}$. This assumes a $720^{\circ} \mathrm{F}$ difference between the outside ceramic temperature and the working fluid temperature. The radiative heat exchanging from the flame to the ceramic, is then,

$$
R_{\text {evg }}=32 \mathrm{~W} / \mathrm{cm}^{2} \text {. }
$$

An area of $1.75 \times 10^{6} \mathrm{~cm}^{2}\left(175 \mathrm{~m}^{2}\right)$ will thus be required to supply $56 \mathrm{MW}$ to the heat exchanger. The flame radiation can be distributed in ten burners each with $17.5 \mathrm{~m}^{2}$ of each burner unit. The Westinghouse base case would require $235 \mathrm{~m}^{2}$ to deliver $66 \mathrm{MW}$ of radiated power to the heat exchanger. 


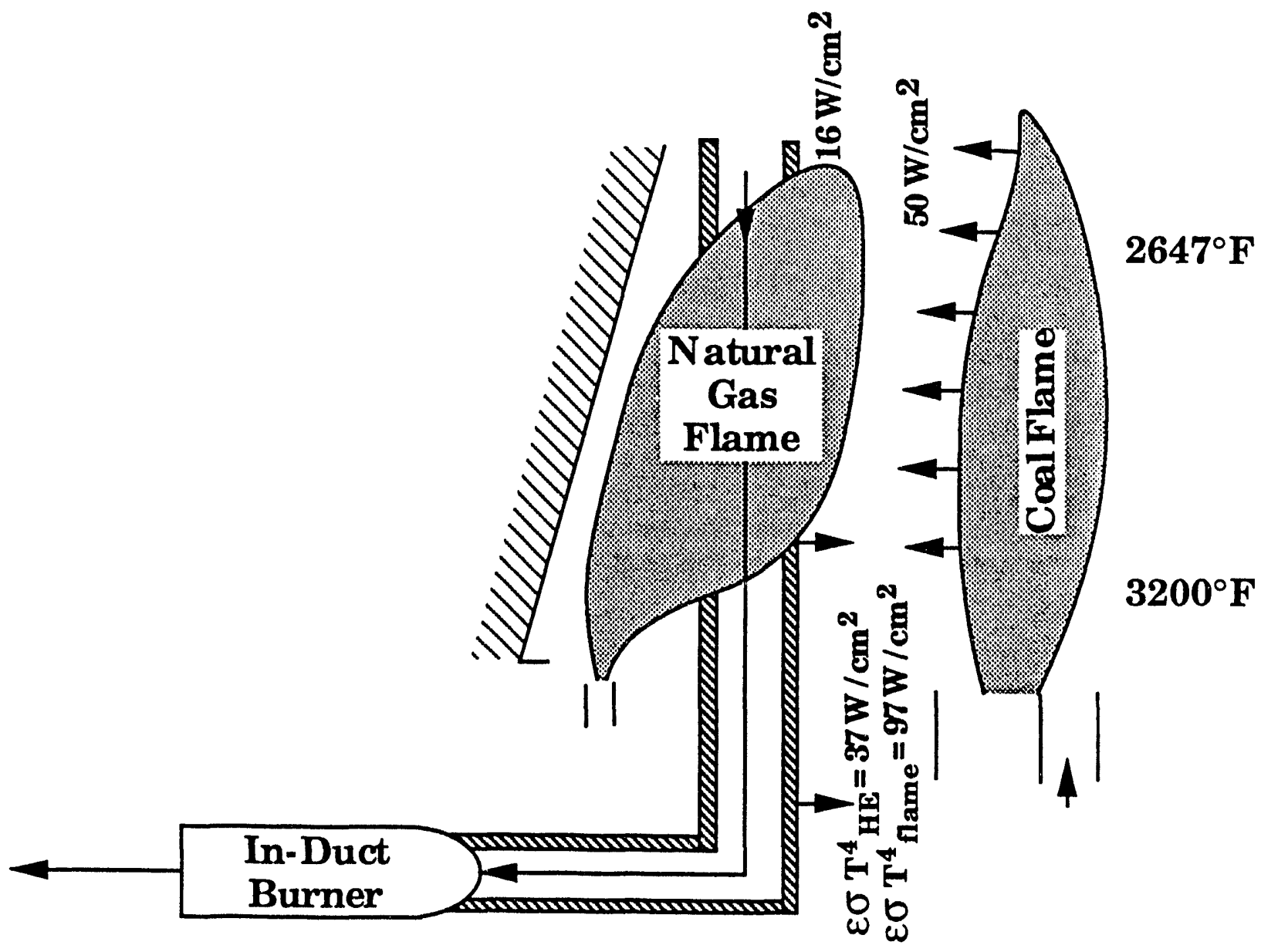

Figure 5.1. High Temperature Heat Exchanger and In-Duct Burner Radiative Heat Transfer. 


\section{Computational Reactor}

Based on the above calculation, the reactor is a $9 \mathrm{~m}$ tall cylinder with $2.75 \mathrm{~m} \mathrm{ID}$ as illustrated in Fig. 5.2. Coal is fired from the top of the reactor in a down fire configuration. Pulverized coal particles are fed from the primary tube in the center top position of the reactor (Fig. 5.1). The secondary inlet is an annular pipe around the primary to supply oxidant (air). The coal feed rate is $3954 \mathrm{lbs} / \mathrm{hr}$ per burner and the total air feed rate in the primary and the secondary is $46,300 \mathrm{lbs} / \mathrm{hr}$ per burner. The air temperature is $753^{\circ} \mathrm{F}$. Fifteen percent of the total air fed is in the primary and $85 \%$ is in the secondary. To prevent back fire, the primary gas velocity has to be higher than 50 $\mathrm{ft} / \mathrm{sec}$. This requires that the ID of the primary be smaller than $0.37 \mathrm{~m}$. The secondary tube ID is $0.85 \mathrm{~m}$ to give approximately the same gas velocity as in the primary.

56 ceramic exchange tubes were placed at a circumference of 1.125 meters from the center line of the reactor cylinder. The outside diameter of the tubes is $0.0635 \mathrm{~m}$. This gives a total of $100.5 \mathrm{~m}^{2}$ radiation absorption surface, half of which is facing the flame.

The relative positions of the primary and secondary inlets, the tubes, and the flame are given in Fig. 5.3. It is assumed that the coal is burned stoichiometrically with sufficient air so that a flame of the optimal thickness $(1.5 \mathrm{~m})$ can be achieved.

The tertiary inlet supplies the nature gas and air at rates of $503 \mathrm{lbs} / \mathrm{hr}$ and $10.6 \mathrm{x}$ $10^{3} \mathrm{lbs} / \mathrm{hr}$, respectively. The position and the feeding scheme are to be investigated to obtain the optimum dynamic cleaning effect.

The premixture of the primary air and the coal will lower the air temperature while increasing the coal temperature according to the following:

$$
6950(T-673) C_{p}(\text { air }) f(\text { air })+3954(T-300) C_{p}(\text { coal }) f(\text { coal })=0
$$

where $T$ is the air and coal temperature after the mixture, $C_{p}$ (air) and $C_{p}($ coal) are the specific heat of air and coal, respectively, and $f(a i r)$ and $f(c o a l)$ are the mass flow rates of air and coal. Before mixing the air temperature is $673 \mathrm{~K}\left(750^{\circ} \mathrm{F}\right)$ and coal temperature is $300 \mathrm{~K}$ (room temperature). Now $C_{p}$ (air) $=1.065$ and $C_{p}$ (coal) $=1.548$ so $T=504 \mathrm{~K}$.

\subsubsection{The Modified Cases}

To investigate the effect of flow conditions on the particle dispersion, a number of additional cases were studied with design modified from the base case (Case 1) given above. In all cases except Case 7, the coal was fed through the primary at the top center of the reactor, and air was injected in the annulus secondary. Starting from Case 2, a methane and air premixed inlet was added as an annulus located at the top of the furnace near the outer edge (tertiary inlet). It is the basic concept of HITAF/REACH-Exchange reactor that this clean combustion gas flow will provide an air buffer to protect the ceramic heat exchange tubes from coal particle fouling (see Fig. 5.1). The top view of the reactor of Case 2 is displayed in Fig. 5.4.

In Cases 3 to 5, the effect of swirl in the secondary was investigated. The purpose of adding swirl was to improve the mixing and to increase the burn-out of coal. Cases 3 


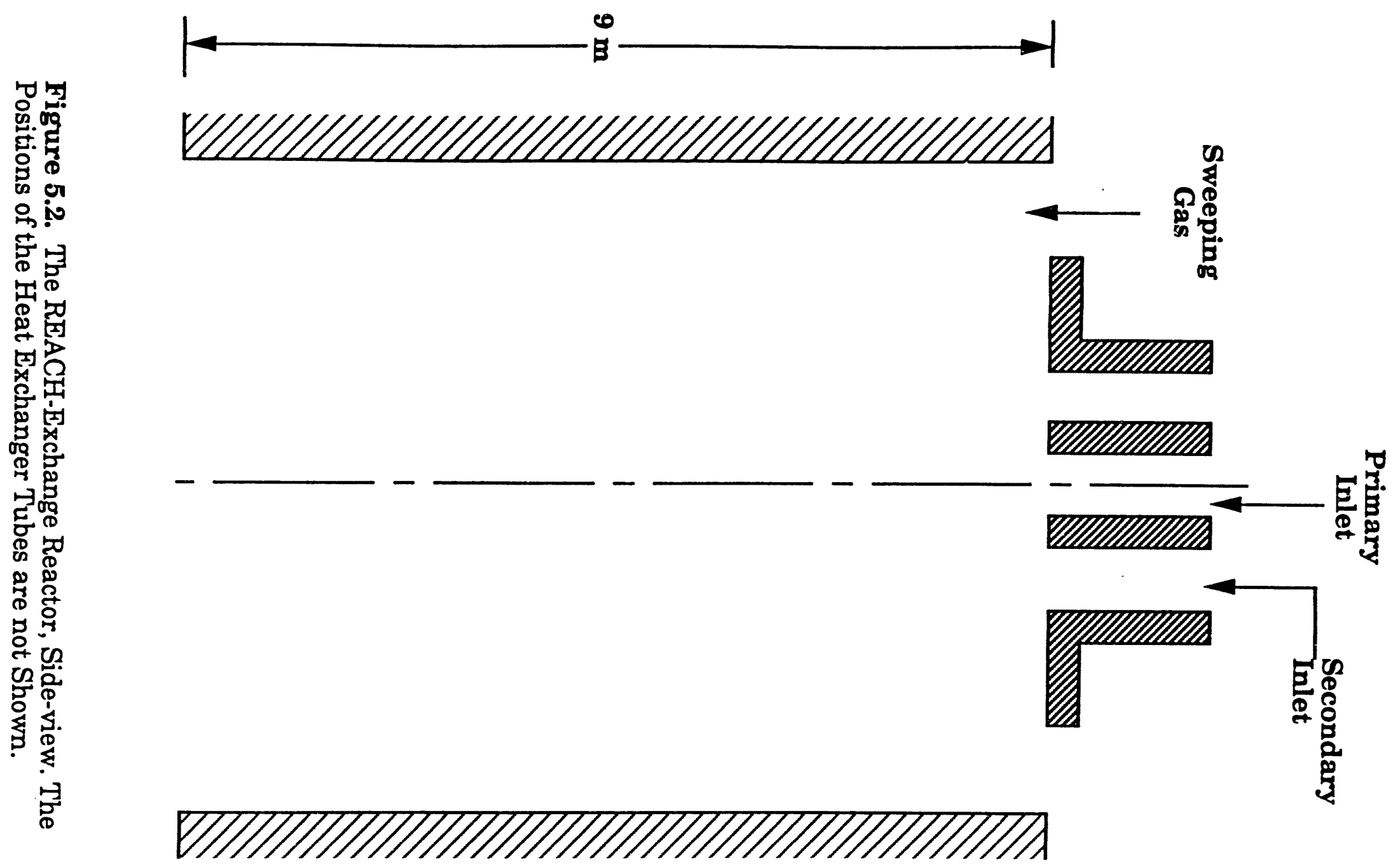




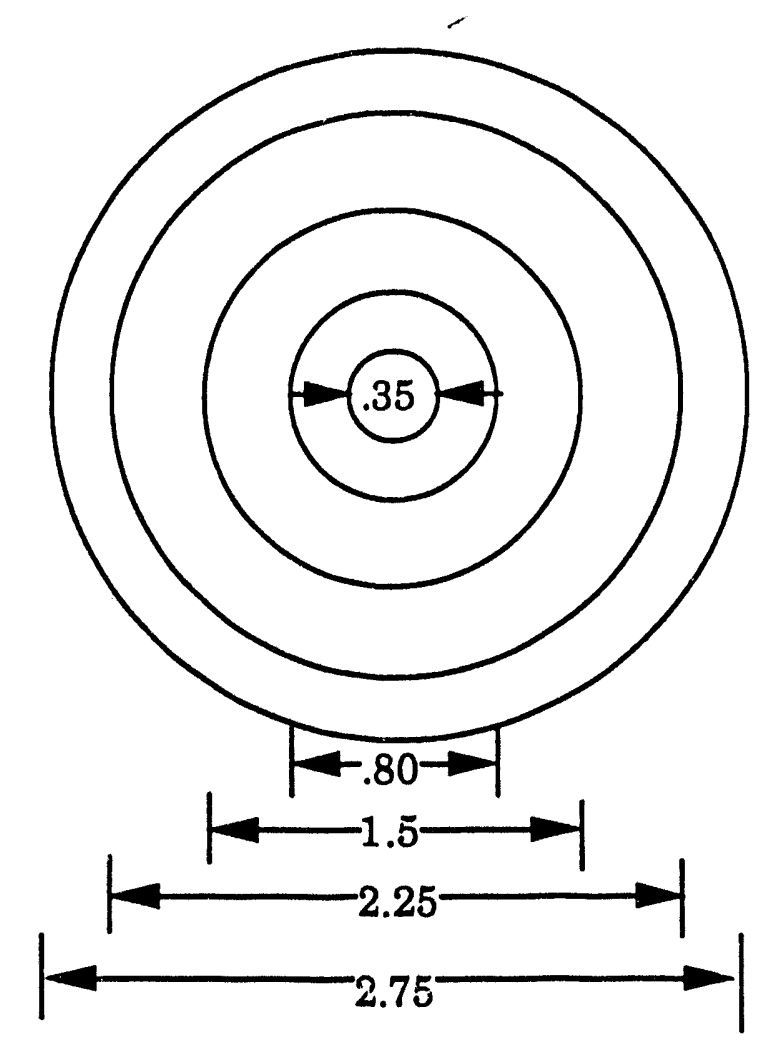

Summary

Primary Air and Coal $\quad=0.35 \mathrm{~m}$

Secondary Air $\quad=0.85 \mathrm{~m}$

Flame

$=1.5 \mathrm{~m}$

U-Tubes

$=2.25 \mathrm{~m}$

Reactor

$=2.75 \mathrm{~m}$

Figure 5.3. HITAF/REACH-Exchange Reactor, Top View. Case 1. 


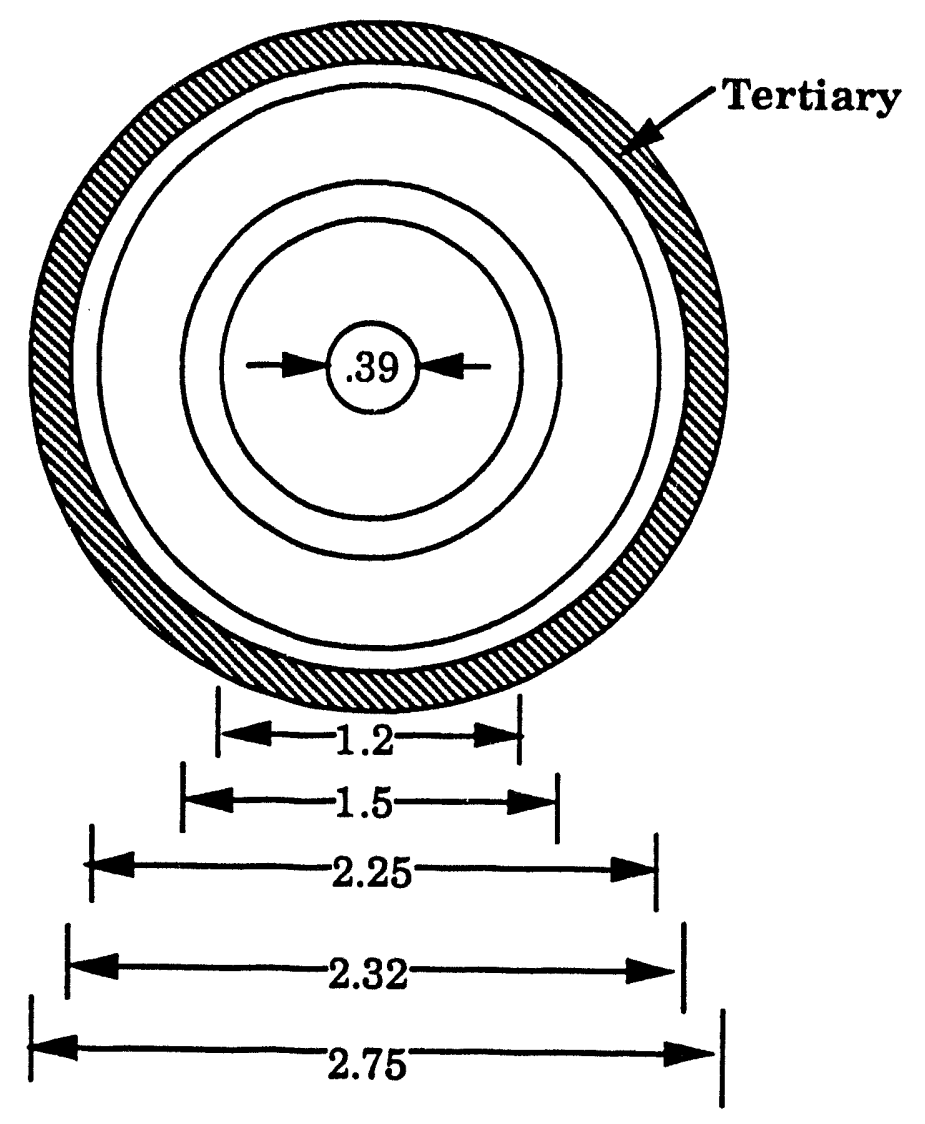

$\begin{array}{ll}\text { Summary } & \\ \text { Primary Air and Coal } & =0.39 \mathrm{~m} \\ \text { Secondary Air } & =1.20 \mathrm{~m} \\ \text { Flame } & =1.5 \mathrm{~m} \\ \text { U-Tubes } & =2.25 \mathrm{~m} \\ \text { Reactor } & =2.75 \mathrm{~m}\end{array}$

Figure 5.4. HITAF/REACH-Exchange Reactor, Top View. Cases 2 to 6. 
was featured with a quarl region around the secondary inlet (divergent), but computation convergence was not achieved for this case. The difficulty in converging the gas field might come from the special geometry and the swirl. Cases 4 and 5 had swirl numbers of 0.5 and 1.0, respectively, and had the same inlet configuration as Case 2 displayed in Fig. 5.4 .

The calculations of Cases 4 and 5 show that the strong turbulence dispersion resulted from the swirl in the secondary inlet, causing heavy particle fouling on the heat exchange tubes. To reduce the adverse effect of the swirl, Case 6 was designed that the secondary inlet had a convergent configuration, i.e., the secondary air entered with a radial velocity toward the center line of the reactor.

Another attempt to improve the mixing was made in Case 7 , in which the coal particles were fed through an annulus (secondary) around the primary inlet, in which part of the air was fed. The rest part of the air was injected from an additional annulus around the secondary inlet. This case was to simulate the multiple coal injector burner expected to be used in the practical combustors. The top view of this reactor is given in Fig. 5.5.

Additional variations in the inlet configuration were made in Cases 8 and 9 . The basic feature of these two cases is that two secondary injection ports were used. The top view of the reactor for these two cases is given in Fig. 5.6. The first secondary inlet, the secondary I, was around the primary inlet, and the secondary II inlet was placed between the secondary $I$ and the heat exchange tubes. In Case 8 , one half of the total secondary air was fed through the secondary II inlet. Since this inlet was placed about 0.25 meters in front of the heat exchange tubes, it was expected that the combined air flow from the tertiary and the secondary inlets would create an air buffer to prevent particle from hitting the wall. Another benefit expected from this design is a low $\mathrm{NO}_{\mathrm{x}}$ emission due to the staggered combustion.

\subsection{The Coal Combustion Efficiencies of HITAF/REACH-Exchanger Reactor investigated by 2D Calculation (Task 2)}

The modeling of the REACH! reactors designed above was performed under task 2 by using a comprehensive 2D coal combustion code, PCGC-2 $(1,2)$. This work used the latest 1993 version of PCGC-2 recently completed under a contract carried out jointly at AFR and Brigham Young University and sponsored by the Department of Energy with contract No. DE-AC21-86MC23075. Table 5.1 lists the flow and inlet conditions of nine cases studied in this task. In this section, we only discuss the results of combustion modeling and the effect of inlet flow conditions on the gas flow and particle dispersion will be discussed in Section 5.4 and 5.5 .

Case 1 was the base case. The calculated gas temperature contour is given in Fig. 5.7. In this figure and the following temperature contour plots, the reactor is plotted by rotating $90^{\circ}$ from its vertical setting for the convenience of showing the contour levels. So, the overall gas flow direction is from left to right and the center axial line of the reactor is the bottom line. After examining the results, it appears that the primary air velocity is too high. The coal combustion took place mostly in the region down in the bottom of the reactor. The coal/air mixing needed to be improved to correct this problem. The tube inlet diameters were then adjusted in order to enhance the mixture. 


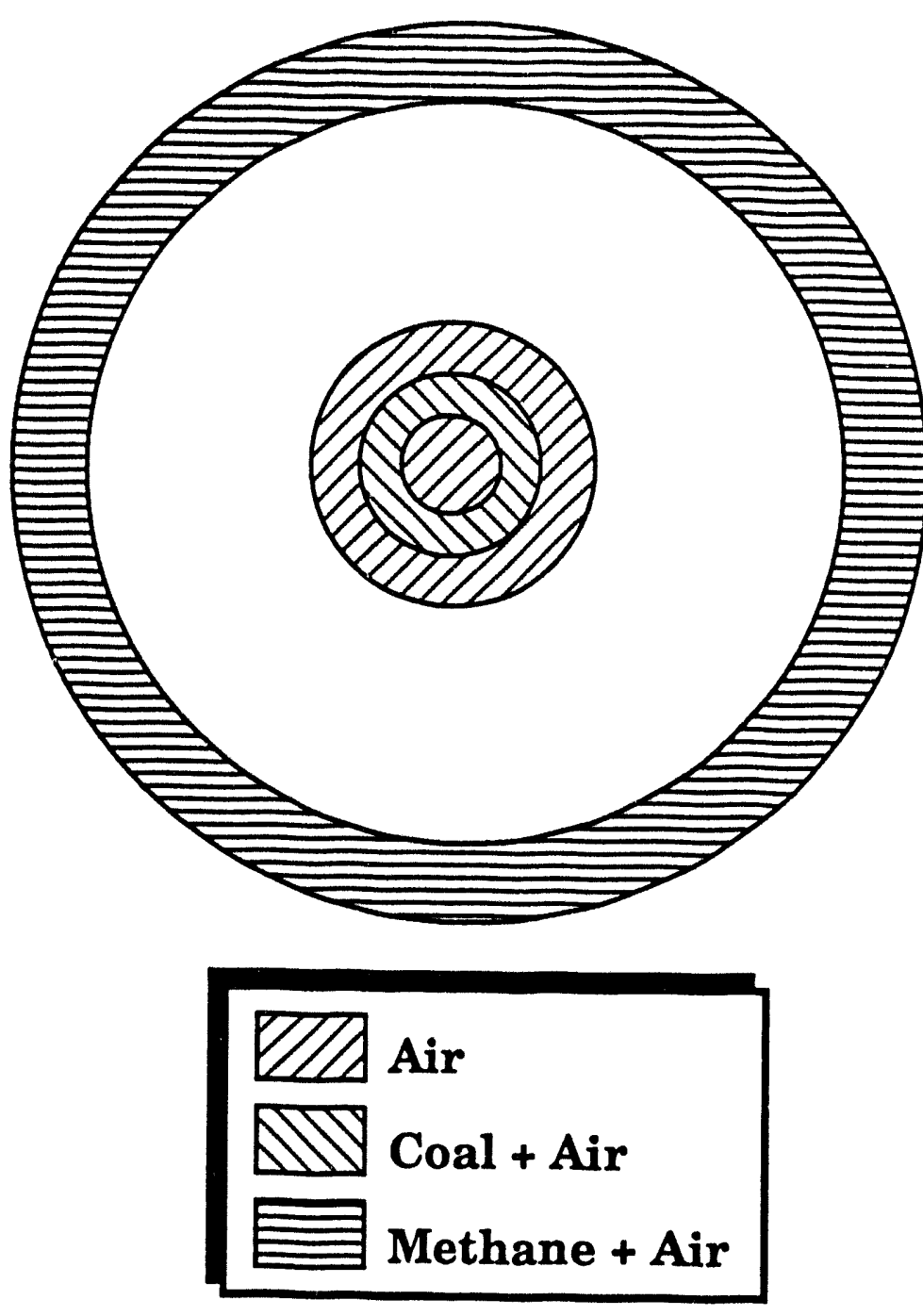

Figure 5.5. HITAF/REACH-Exchange Reactor, Top View. Case 7. 


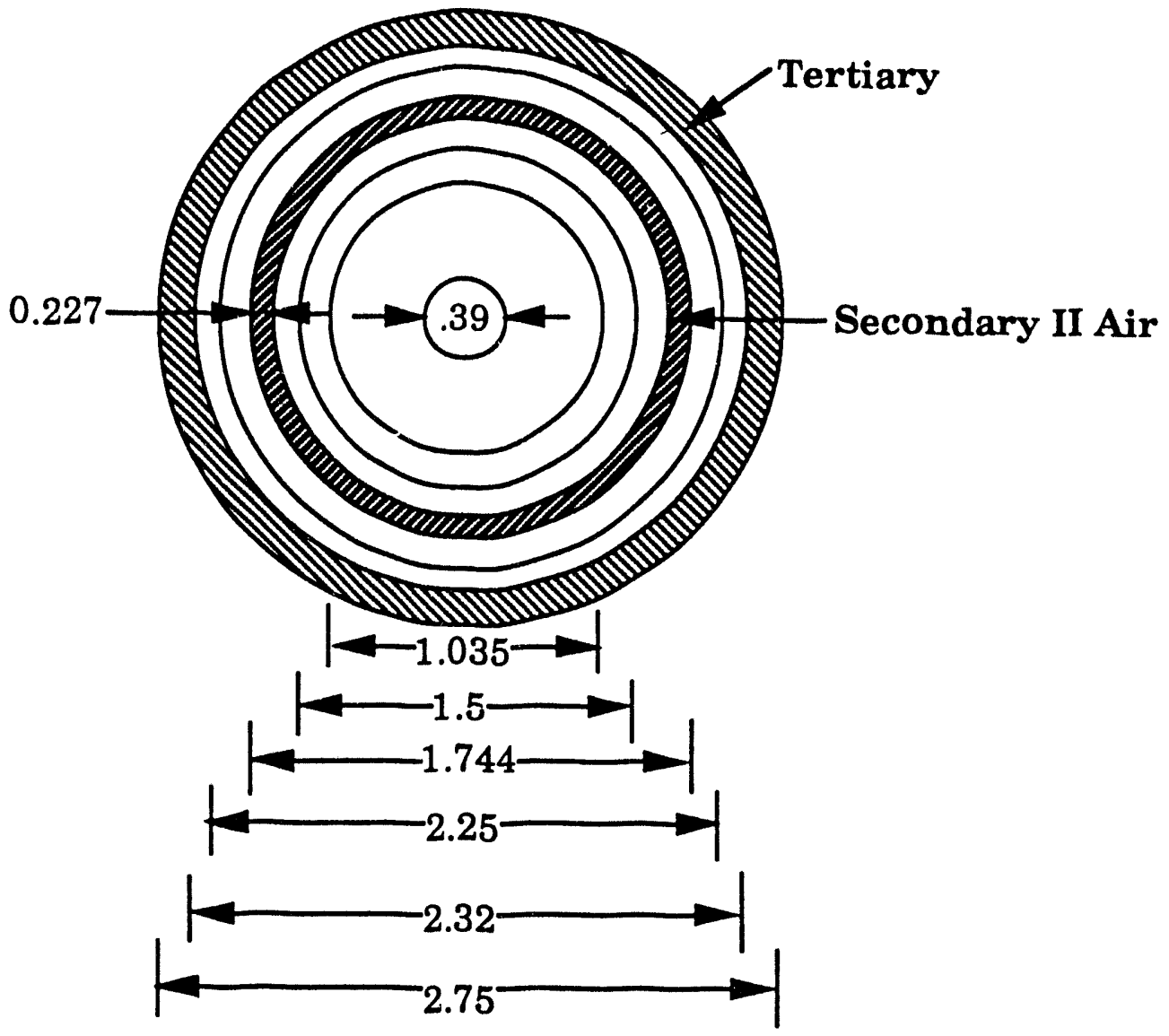

\section{Summary}

Primary Air and Coal $\quad=0.39 \mathrm{~m}$ Secondary I Air $\quad=1.035 \mathrm{~m}$ Secondary II Air $\quad=1.744 \mathrm{~m}$ Flame U-Tubes

$=1.5 \mathrm{~m}$

Reactor

$=2.25 \mathrm{~m}$

$=2.75 \mathrm{~m}$

Figure 5.6. HITAF/REACH-Exchange Reactor, Top View. Cases 8 and 9. 
Table 5.1 Operation conditions modeled with PCGC-2 in task 2. All flow rates are in lbs/hr.

\begin{tabular}{|c|c|c|c|c|c|c|c|c|c|}
\hline & Case 1 & Case 2 & Case 3 & Case 4 & Case 5 & Case 6 & Case 7 & Case 8 & Case 9 \\
\hline Primary diameter, $M$ & 0.35 & 0.39 & 0.39 & 0.39 & 0.39 & 0.39 & 0.39 & 0.39 & 0.39 \\
\hline \multirow[t]{2}{*}{ Secondary diameters, $M$} & 0.85 & 1.2 & 1.2 & 1.2 & 1.2 & 1.2 & 1.2 & 1.04 & 1.04 \\
\hline & - & - & - & - & - & - & - & $\begin{array}{l}1.74 \\
+0.22 \\
7\end{array}$ & $\begin{array}{l}1.74 \\
+0.22 \\
7\end{array}$ \\
\hline Tertiary air & No & Yes & Yes & Yes & Yes & Yes & Yes & Yes & Yes \\
\hline Swirl number & - & - & 0.5 & 0.5 & 1.0 & 0.5 & 0.5 & - & - \\
\hline Converging/Diverging Sec. & No & No & $D$ & No & No & $\mathrm{C}$ & No & No & No \\
\hline Coal in primary & $3.95 E 3$ & $3.95 E 3$ & $3.95 \mathrm{E} 3$ & $3.95 E 3$ & $3.95 E 3$ & $3.95 \mathrm{E} 3$ & * & $3.95 E 3$ & $3.95 \mathrm{E} 3$ \\
\hline Primary flow (AIR) & $6.95 E 3$ & $6.95 \mathrm{E} 3$ & $6.95 \mathrm{E} 3$ & $6.95 \mathrm{E} 3$ & $6.95 \mathrm{E} 3$ & $6.95 \mathrm{E} 3$ & & $6.95 E 3$ & $6.95 \mathrm{E} 3$ \\
\hline Secondary flow I (AIR) & $3.94 E 4$ & $3.94 \mathrm{E} 4$ & $3.94 \mathrm{E} 4$ & $3.94 \mathrm{E} 4$ & $3.94 E 4$ & $3.94 \mathrm{E} 4$ & & 1.97E4 & $1.31 \mathrm{E4}$ \\
\hline Secondary flow \| (AIR) & - & - & - & - & - & - & & $1.97 \mathrm{E} 4$ & 2.64E4 \\
\hline \multicolumn{10}{|l|}{ Tertiary flow } \\
\hline $\mathrm{CH}_{4}$ & - & \multicolumn{8}{|c|}{$5.03 \mathrm{E} 2$} \\
\hline AIR & - & \multicolumn{8}{|c|}{$1.06 \mathrm{E} 4$} \\
\hline
\end{tabular}

Special flow condition was tested for Case 7, but computational convergence was not achieved (see text). 


\section{TEMPERATURE CONTOURS - CASE 1}

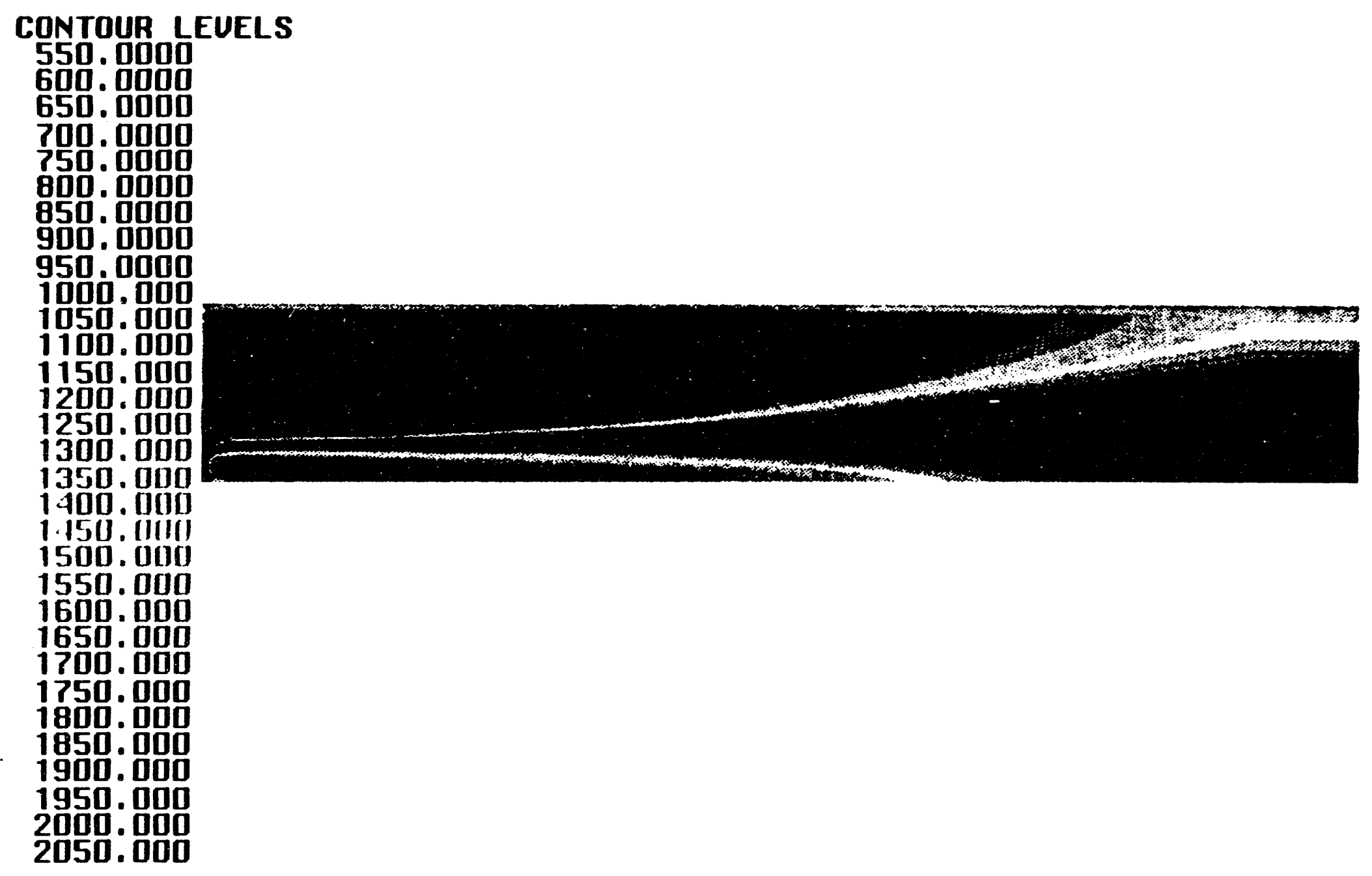

Figure 5.7 Temperalure Contours , Case I 
The diameters of both the primary and the secondary inlets were enlarged. It was hoped that the resulting reductions in the inlet velocities could provide a longer coal particle resicience time and so improve the mixture. The adjustments are given in Table 5.2 (Case 2). Starting from Case 2, the tertiary $\mathrm{CH}_{4}$ /air combustion stream was included $i$ the computation. This stream is fed from a large annulus on the top of the furnace near the outer edge (tertiary inlet).

Figure 5.8 displays the temperature contours of Case 2 . It seems that the reduction in the primary and the secondary air velocities did not help much in lifting the combustion zone to the top of the reactor. Most of the coal particles still burned in the bottom area. The overall burriout of the coal was just $82 \%$, compared to $88 \%$ in Case 1 . The reduction of the burnout is believed due to the decrease in the coal/oxidant mixing because of the larger primary tube diameter in Case 2. Also the decrease in velocity may affect the turbulent mixing. Modifications were needed to be done to increase the mixing.

The effect of tertiary air, was very evident in th at it swept the hot combustion zone away from the wall in the bottom of the reactor. This effect can be noticed by comparing the temperature contours of Fig. 5.8 with that of Fig. 5.7.

Cases 3, 4 and 5 were to improve the mixing by adding swirl in the secondary. Case 3 was featured with a quarl region around the secondary inlet (divergent), but convergence was not achieved for this case. The difficulty in converging the gas field might come fro. I the special geometry and the swirl.

Cases 4 and 5 had swirl numbers of 0.5 and 1.0, respectively. With swirl 0.5 , Case 4 did not accomplish any pronounced improvement over Case 2 in terms of the burnout $(83 \%)$. But comparing its temperature contours (Fig. 5.9) with those of Case 2 shows more combustion in the top section of the reactor. With swirl number of 1.0, Case 5 increased the overall burnout to $90 \%$. Its temperature contours are plotted in Fig. 5.10 , which shows the most stabilized flame and thorough combustion among the five cases presented so far. However, the increasing swirl created a large tangential stirring force, which caused an unfavorable particle dispersion pattern.

Orie attempt to reduce the adverse effect of the swirl on the particle dispersion was Case 6 , in which the secondary inlet had a convergent configuration so that there was a radial gas velocity component at the secondary inlet. This test was shown to be unsuccessful by the calculation. The radial gas momentum dispersed very quickly upon the secondary air entered the reactor, and the tangential stirring force created by the swirl dominated the gas flow field. Unless an unpractical large radial gas velocity is used in the secondary inlet, the convergent can not counterbalance the swirl in affecting the gas flow.

The above computation results clearly indicate that swirl needs to be avoided in the HITAF/REACH reactor. The improvement of the mixing needs to be achieved via multiple coal particle injector burners. This was modeled in Case 7, but a numerical converge was not obtained.

The most evident validation of the REACH concept was obtained in modeling Cases 8 and 9. As presented in Section 5.2, the most important feature of these two cases is that two secondary injections were used. With the secondary 11 inlet, one part of the secondary air is now utilized to enhance the gas flow from the tertiary inlet, so that there 


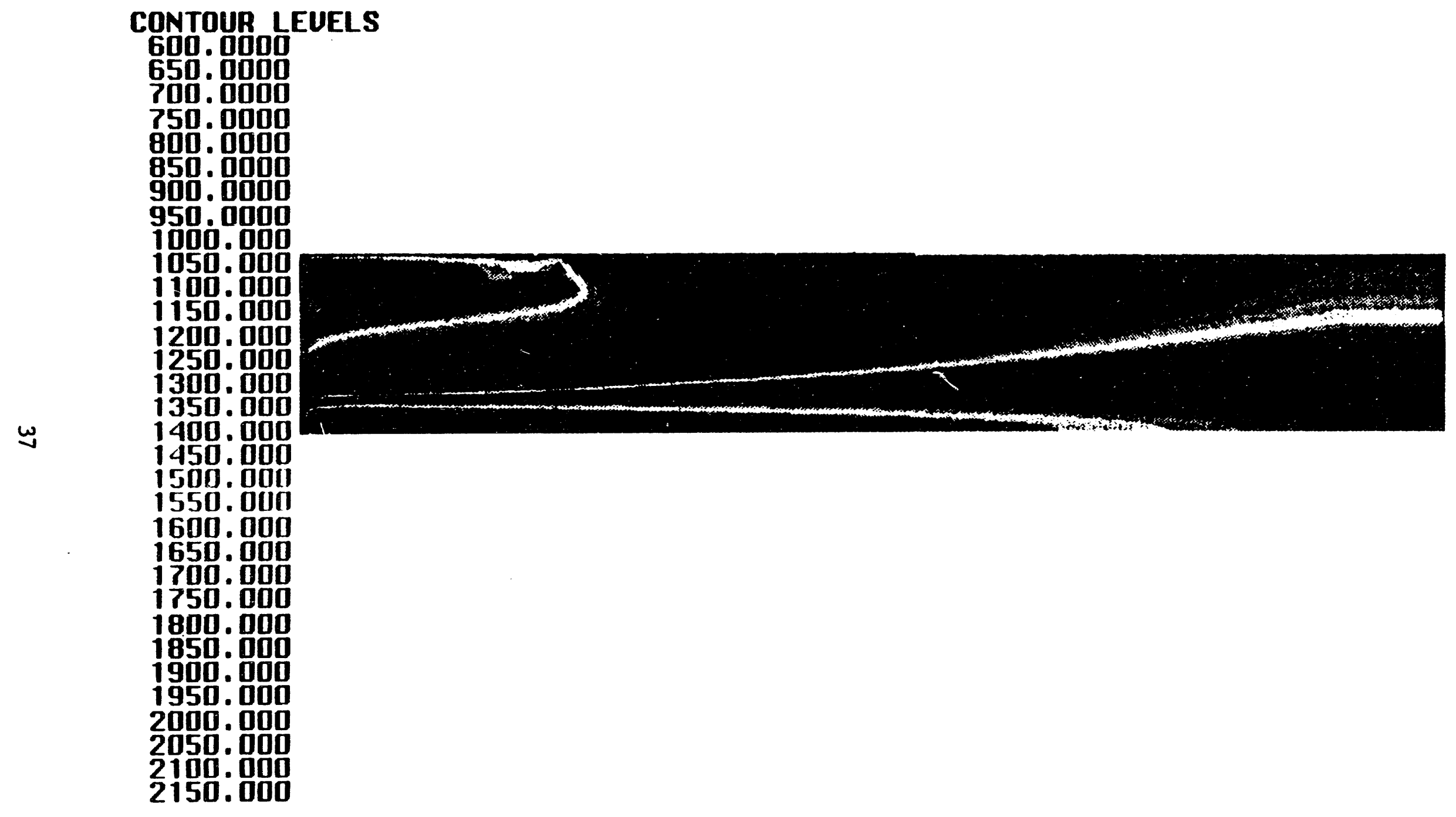

Figure 5.8 Temperature Contours, Case 2. 


\section{CONTOUR LEUELS}

650.0000

700.0000

750.0000

800.0000

850.0000

900.0000

950. 0000

1000.000

1050.000

1100.000

1150.000

1200. 000

1250. 000

1300.000

1350.000

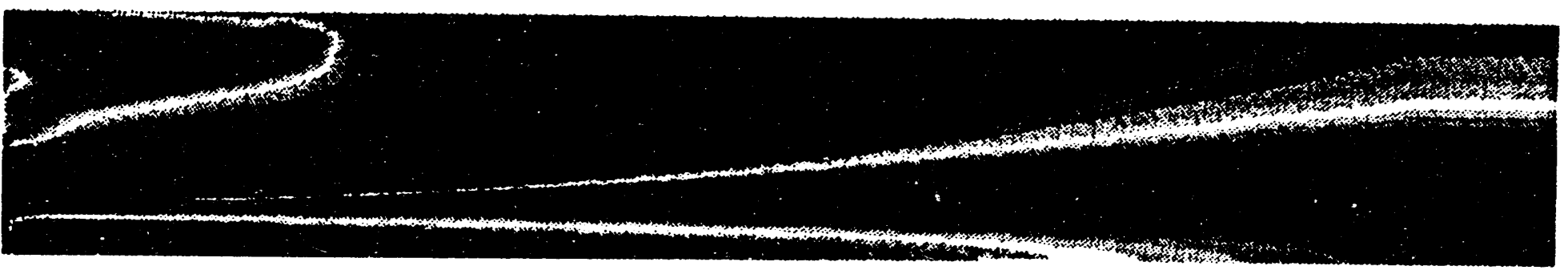

1450.000

1500 . 000

1550. 000

1600.000

1650.000

1700.000

1750.000

1800.000

1850.000

1900.000

1950 .000

2000.000

2050.000

2100 .000

2150.000

Figure 5.9 Temperature contours of case 4. 


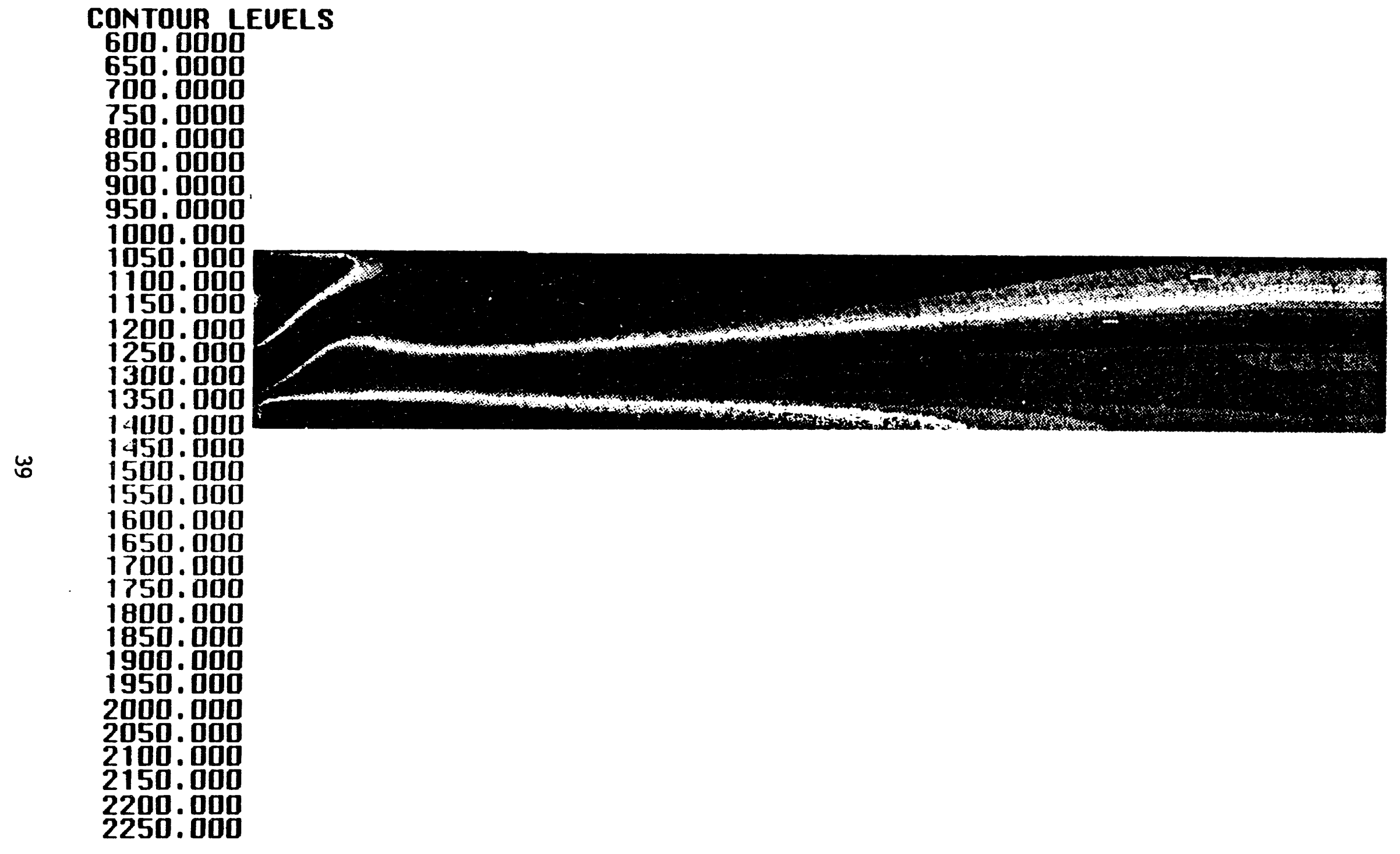

Figure 5.10 Temperature Contours of Case 5. 
forms a larger air buffer in front of the heat exchange tubes. Figure 5.11 displays the temperature contours of Case 8.

For all cases modeled under task 2, the average burnout remained constantly about $85 \%$, except for Case 5 in which the swirl significantly improved the mixing and so the combustion (swirl number 1.0). This result indicates the flexibility for the manipulation of inlet configurations to achieve the best aerodynamic cleaning effect without adversely affecting the combustion. The basic concept is to fully utilize the length of the reactor by employing staggered combustion and hence maintain a low turbulence flame. The first stage combustion is fuel rich with coal fed through the primary and air from the secondary I. The secondary stage combustion proceeds down stream when the rest of the coal particles are mixed with air from the secondary 11 inlet. This design concept delivers three benefits, i.e. 1) low $\mathrm{NO}_{x}$ emission, 2) good aerodynamic cleaning effect and 3) low turbulence flame for easy particle dispersion control.

\subsection{Particle Turbulent Dispersion Model (Task 2)}

One of the critical issues is whether the HITAF/REACH design would enable us to control the coal particle dispersion in the reactor so that the particle fouling on the heat exchange tubes can be prevented. To answer this, the particle dispersion inside the REACH reactor needs to be modeled. Since currently there is no single code which models both coal combustion and particle dispersion appropriately, two computer codes were used to provide the complete solution. PCGC-2 was employed to model the coal combustion and CELMINT was used to model the particle dispersion. In the meantime, a standalone particle turbulence dispersion model was developed in Task 2 as a post-processor of PCGC-2 to model the particle dispersion.

During the past decade, two major types of particle turbulent dispersion models have been developed: empirical and stochastic. In the empirical models by Lockwood et al. (11) and Smith et al. (12), the dispersion is assumed to be a diffusion process and is modeled by adding a diffusion velocity component to the mean particle velocity determined from the mean gas velocity. Empirical relations are used to calculate the diffusion velocity from the gas turbulence $(11,12)$. On the other hand, the stochastic models $(13-15)$ treat particle motions in turbulence statistically. They trace the instantaneous interactions between particles and the turbulent eddies. Since the gas turbulence is stochastic in nature, these models are favored.

Under this contract, we further developed the stochastic particle turbulent dispersion model and used it to model the particle dispersion inside the HITAF/REACH reactor.

\section{Stochastic Model}

The particle motion is described in a Lagrangian framework

$$
\begin{gathered}
\frac{d U_{i}}{d t}=\Gamma\left(\bar{V}_{i}-U_{i}\right)+\Gamma V_{i}^{\prime}+g \\
\frac{d X_{i}}{d t}=U_{i}
\end{gathered}
$$




\section{TEMPERATURE CONTOURS - CASE 8}

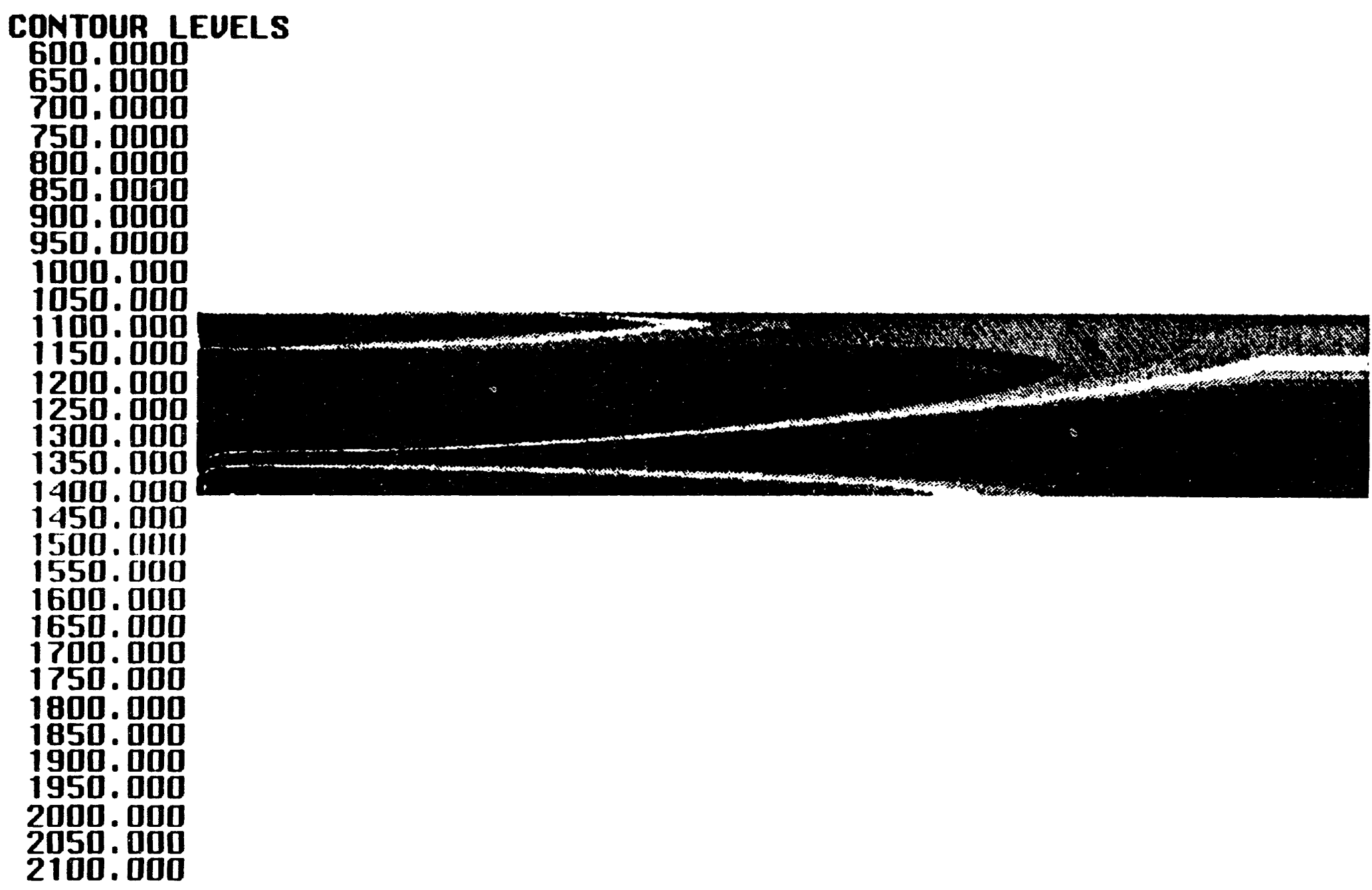


where $U_{i}$ and $V_{1}$ are the $i^{\text {th }}(i=1,2,3)$ components of velocity vectors of a particle and the gas, respectively; accounts for the Stokes drag; $X$ is the spatial coordinate of the particle; $g_{1}$ is the gravity. Stochastic processes are specified with upper case characters and their realizations are given with corresponding lower case characters. A prime indicates the fluctuation component of a stochastic process, and a bar indicates the mean value. In the stochastic model, $V_{1}^{\prime}$ is simulated with a random number generator. The particle is assumed to interact with eddies when it travels along with the gas stream. The gas velocity is assumed to be constant in each eddy. The length of the eddy is given by the length scale of the turbulence and the eddy decays with time according to the time scale. In other words, a particle sees a new eddy when it enters another eddy or the old one fades away. In the previous work (13-15), $V_{i}^{\prime}$ was generated directly by Monte Carlo methods and the interaction is handled in the numerical integration. A disadvantage of this method is that the results can be largely influenced by the numerical time step and it is not very efficient since the stochastic spectrum of the turbulence is not used. In this study, improvements of these early models were made based on the recent developments in the numerical integration of stochastic differential equations $(16,17)$.

The stochastic characteristics of $V_{i}$ are given by those of $V_{i}^{\prime}$ (turbulence model, $k-\varepsilon$ ) in terms of $k, l_{0}$, and $t_{0}$, where $k$ is the turbulence kinetic energy, and $I_{0}$ and $t_{0}$ are the length and time scales of the turbulence. $V_{i}^{\prime}$ is a stochastic process of both time, $t$, and distance, $x$. The autocorrelation functions of $t$ and $x$ are by definition

$$
R_{v_{1}^{\prime}}^{t}(\Delta t)=\exp \left(-|\Delta t| / t_{e}\right)
$$

and

$$
R^{1} v_{i}^{\prime}(\Delta x)=\exp \left(-|\Delta x| / I_{e}\right)
$$

The double correlation is not readily available and is assumed to be

$$
R_{V_{i}^{\prime}}(\Delta x, \Delta t)=\exp \left(-\sqrt{\left(\Delta t / t_{e}\right)^{2}+\left(\Delta x / I_{e}\right)^{2}}\right)
$$

Since a particle sees the gas when it travels, the decay of the gas velocity seen by a particle traveling with velocity $U$ is a function of $t$ only. If $R_{v i}$. decays quickly enough against $x$, we have 


$$
R_{V_{1}^{\prime}, p}(\Delta t)=\exp (-\beta|\Delta t|)
$$

where

$$
\left.\beta=\sqrt{\left(1 / t_{e}\right)^{2}+\left((\bar{U}(\boldsymbol{x}, t)-\bar{V}(\boldsymbol{x}, t)) / I_{e}\right)^{2}}\right)
$$

The second subscript $P$ of $R$ means that the correlation in Eq. $(5)$ is for the gas seen by particles. From Eq. (5), we know that when seen by particles, the gas velocity fluctuation, $V_{i}^{\prime}$, can be approximated with an Ornstein-Uhlenieck process and can be generated with a filtered white noise (14)

$$
\frac{d V_{i}^{\prime}}{d t}=-\beta V_{i}^{\prime}+\sigma_{v^{\prime}} \sqrt{2 \beta} \xi_{i}(t)
$$

where $\sigma_{v^{\prime}}=(2 / 3 k)^{0.5} . \xi_{1}(t)$ is a Guassian white noise function. Or more formally

$$
d V_{i}^{\prime}=-\beta V_{i}^{\prime} d t+\sigma_{v^{\prime}} \sqrt{2 \beta} \Delta W_{i}(t)
$$

where $\Delta W_{\mathrm{i}}(t)$ is an incremental Wiener process of Guassian, $N(0, t)$. Since Eq. (8) contains explicitly $\sigma_{\mathrm{v}}$, and $\beta$, it can generate $V_{\mathrm{i}}{ }^{\prime}$ with correct gas turbulence statistics. We used differential equations (1) and (8) to model the particle dispersion by turbulence.

This set of equations is, however, intrinsically stiff for coal combustion problems, since very often the time scale, $1 / \beta$, is much smaller than the particle relaxation time scale $1 / \Gamma$. An implicit Euler scheme was employed in the integration to maintain the numerical stability.

\section{Particle Dispersion Modeling}

The basic modeling procedure consisted of two steps, i.e., 1) modeling the coal combustion with PCGC-2 and 2) calculating the particle dispersion with the model presented above. This procedure was exercised for all the cases modeled with PCGC-2 given in Section 5.3. The results were found to be in very good agreement with those given by the more complete turbulent dispersion modeling with CELMINT which will be discussed in Section 5.5. 
Figure 5.12 and 5.13 compare the calculated results using the particle turbulent dispersion model for Case 1 and Case 9. The combustion was modeled with PCGC-2 which provided the gas velocity and turbulence field information. The particle stochastic differential equations (1) and (8) were then solved. In each calculation, 100 particles were injected from 5 positions inside the primary tube and 100 particle trajectories were generated with our stochastic model. We used a PC based post-processor to visualize the results by injecting 5 particles every 0.08 second, so that a continuous particle stream was simulated. The particle diameter used in the calculation was $70 \mu \mathrm{m}$.

\section{Case 1}

Pulverized coal particles were down fired from a 0.39 meter diameter tube along with $15 \%$ of the combustion air. The secondary air which comprises the remainder of the total air entered through a 1.27 meter annulus. The vector plot of the mean gas velocity is shown in Fig. 5.12a and the particle dispersion in Fig. 5.12b. As expected, there was a large recirculation zone in the top part of the reactor. The positive radial velocity along with the turbulence caused a large scale particle dispersion in this case. Significant numbers of particles reached the refractory wall.

\section{Case 9}

This case is displayed as a comparison to Case 1. Two additional inlets, secondary 11 and tertiary, were added in order to shield the ceramic heat exchanger tubes from the coal and ash particles. The tertiary gas stream was pre-mixed $\mathrm{CH}_{4}$ and air which entered through the outer annulus behind the heat exchanger tubes. To provide a buffer between the tubes and the flame, 2/3 of the secondary air was injected from secondary $\|$ and $1 / 3$ of it entered from the secondary 1 . The secondary 11 inlet was approximately 0.25 meters in front of the heat exchanger tubes.

Figure 5.13 a displays the gas flow pattern for this case and Fig. $5.13 \mathrm{~b}$ is the particle dispersion. The flow pattern obtained was considerably different from that obtained in Case 1 (Fig. 5.12a). This is due to the added gas flux from the tertiary and the secondary II inlets. It demonstrates that firing schemes can effectively control the gas flow pattern. The particle dispersion near the wall region was much reduced in this case compared to Case 1. However, there were still a number of particles reaching the refractory wall at the bottom of the reactor.

Comparison of Figs. 5.12 and 5.13 clearly indicates that the gas flow pattern and the particle dispersion are controllable by the firing scheme as proposed. More discussions and results of particle dispersion modeling will be given in Se-tion 5.6.

\subsection{D CFD Modeling (Task 3)}

To investigate the detail interactions among the gas flow, coal particles and the heat exchange tubes, 3D fluid dynamics modeling needs to be carried out. In viewing the fact that the reactor modeled is an axisymmetrical cylinder, both $2 D$ and $3 D$ modeling were performed with 2D modeling being concentrated on the turbulance/particle interaction and the 3D modeling on the effect of tubes on the gas flow.

\subsubsection{Two Dimensional Calculations}

Two-phase computational fluid dynamics (CFD) was employed to investigate 
a.

Radlal Distance, $M$

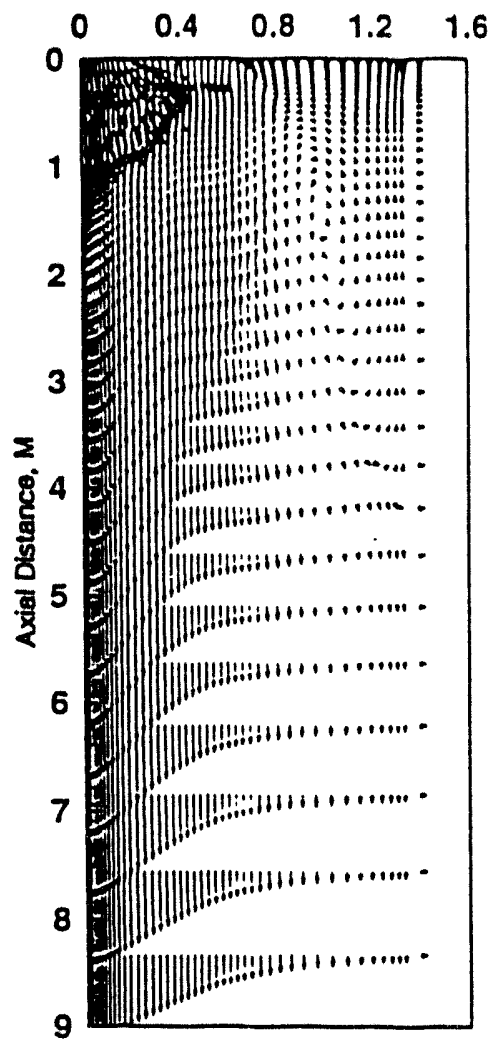

b.

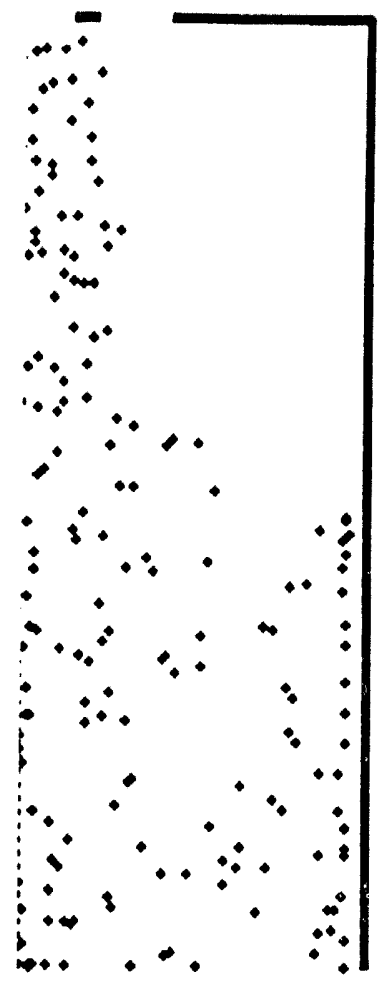

Figure 5.12. a. Velocity vector plot and b. particle dispersion of Case 1.

Radlal Distance, M

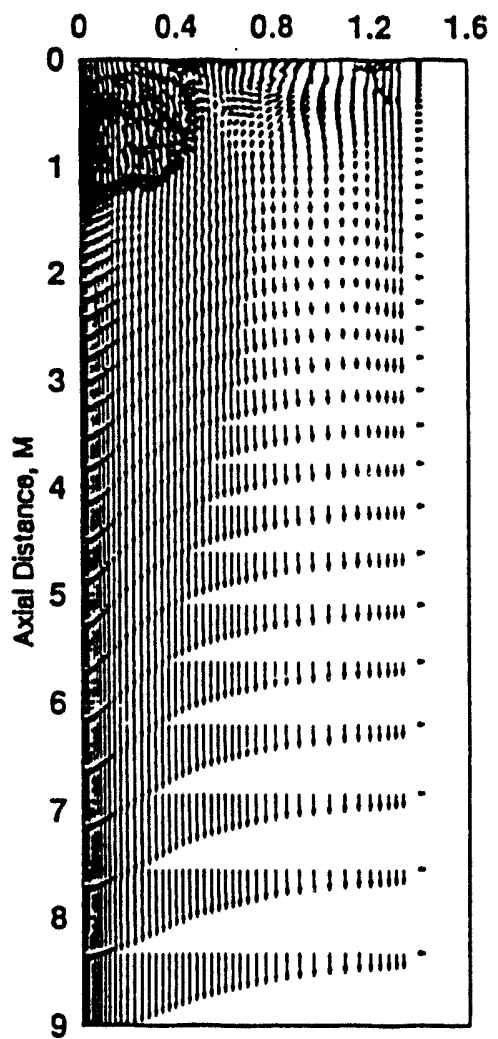

b.

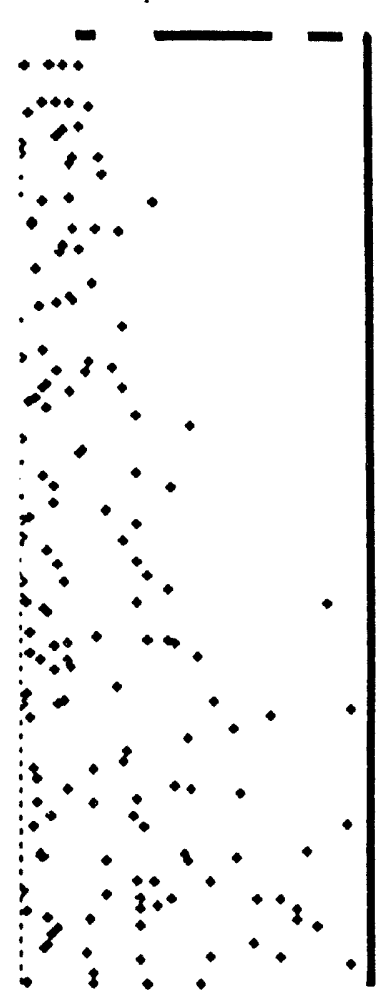

Figure 5.13. a. Velocity vector plot and b. particle dispersion of Case 9. 
potential strategies for injecting a cleansing stream into the HITAF/REACH exchanger to protect the heat-exchanger elements from coal particles and corrosive coal combustion products. At present there is no single code which contains the appropriate coal chemistry package and particle dispersion model to provide a complete solution. Therefore, a combination of two codes was used. The first code was PCGC-2 $(1,2)$ which has been developed for pulverized coal combustion. This code contains the required coal combustion models as well as radiative heat transfer. The major problem of PCGC- 2 in regard to the present effort is dispersion of particles by the background turbulent flow. The second code used was CELMINT $(3,4)$ which has been developed for two-phase rocket flows. Although CELMINT has a variety of chemical reaction modules, it does not have coal chemistry and does not include radiative energy transfer. However it does have a verified model for particle dispersion by turbulence (e.g., Refs. 4 and 18).

In the present study, a combusting gaseous flow calculation was first run with PCGC-2 to obtain the energy field including heat transfer effects. The resulting temperature was then used as input for CELMINT, which solved the momentum and continuity equations for the gaseous flow under the PCGC temperature solution. For the present study, the flow was assumed to be lightly loaded. Under lightly loaded conditions, the gaseous continuous phase is not affected by the discrete particulate phase.

Therefore, the Lagrangian portion of CELMINT was then used to track particles under the influence of the background gaseous flow and gravity. Table 5.2 lists the correspondence of runs in task 2 and task 3. Three major mechanisms are present which would cause particle and trace species dispersion. The first is convective transport by the background flow, the second is the ballistic trajectory dictated by the particle flow angle on inflow, and the third is dispersion of particles by the turbulent component of the background flow. The CELMINT analysis used here to tract the particles includes all three. Thermophoresis is an additional mechanism for the deposition of fine particles, but was not included in the current analysis.

For the present study particles are tracked from the inflow port, which is the central coal/air stream along the axis (Fig. 5.2). For the purpose of the present study, it is assumed that upon inflow the axial velocity is equal to the axial velocity of the background flow. In addition, a particle radial velocity is assumed such that the flow angle relative to the axis of symmetry is $6^{\circ}$. The turbulence of the continuum background flow was obtained from a solution of the two equation $k-\epsilon$ turbulence model. This provided a local turbulence intensity which is input into a statistical algorithm to provide the instantaneous flow leading to particle dispersion by background turbulence. This algorithm adds a fluctuating component to the local background mean flow, allowing the particle to be influenced by the background flow turbulence. The procedure is based upon a random number generator; however, for each run the generator is always started at the same place, thus making the results deterministic in the sense that for (i) a given background flow and (ii) a given number of inflow particles with prescribed velocity and position, the generated particle paths are repeatable. However, if a new particle is added between two existing particles, the new particle path, in general, will not be confined to the region between the two original particle paths. This is important in interpreting the plots. In addition, due to the random nature of the process, there is always a chance that any single particle may follow an unexpected path. 
Table 5.2 Correspondence of runs in task 2 and task 3.

\begin{tabular}{||l|c|c|c|c|c|c|}
\hline & \multicolumn{6}{|c|}{ Case Number } \\
\hline Task 2 & 1 & \multicolumn{5}{|c|}{2} \\
\hline Task 3 & 1 & 2 & 3 & 4 & 5 & 6 \\
\hline
\end{tabular}

The initial radial velocity is most important for the large particles as it provides the initial particle momentum which is modified with time by the background flow drag force and turbulence. It is less important for small particles since their low mass (i.e., low momentum) makes them come to equilibrium with the background flow more quickly. In contrast, the background turbulence has more influence on the smaller particles. This provides a random, instantaneous flow field which influences the particles via a random drag force and those particles having lower momentum, i.e., the smaller particles, are more subject to these turbulent fluctuations.

The calculations were carried out for a single burner with the geometry shown in Fig. 5.2. The calculation assumes a primary stream mass flux of $10.9 \times 10^{\mathrm{m}} \mathrm{lbs} / \mathrm{hr}(1.37$ $\mathrm{kg} / \mathrm{sec})$, a secondary mass flux of $39.3 \times 10^{3} \mathrm{lbs} / \mathrm{hr}(4.96 \mathrm{~kg} / \mathrm{sec})$, and a tertiary stream mass flux of $11.1 \times 10^{3} \mathrm{lbs} / \mathrm{hr}(1.40 \mathrm{~kg} / \mathrm{sec})$ for the second and third cases considered. Six sets of calculations were performed. The first had no tertiary injection; the second had tertiary injection from an annulus located at the top of the furnace near the outer edge; the third had flow injected from a slit at the outer diameter wall located approximately one-half way along the length of the furnace. The fourth had tertiary flow injected from both top and outer walls. The fifth had injection from the top and two places on the outer walls. Both the forth and fifth cases had twice the total tertiary injection of Cases 2 and 3 . The sixth case had two secondary inlets and one tertiary injection as defined as Case 8 in Section 5.3 (task 2). Gravity was included in the calculation. The furnace radius was approximately $4.5^{\prime}(1.4 \mathrm{~m})$ and the length $30^{\prime}(9.2 \mathrm{~m})$.

Velocity vector plots for two of the six cases are shown in Figs. 5.14 and 5.15. both for the overall flow field and a "close-up" of the recirculation zone. The direction of flow is shown by the direction of arrows plotted on the figure and the amplitude is represented by the length of the arrows. Particle paths were run for particles originating in the primary stream. Particle path results are shown in Figs. 5.16 and 5.17. In both cases, the inflow at the top of the furnace is at the left, the axis of symmetry at the bottom, the outer wall at the top and outflow at the right. The plots have been rotated by $90^{\circ}$ from their physical orientation for ease of viewing. Gravity is in the left-to-right direction. Particle paths were calculated for particle radii of $10 \mu \mathrm{m}, 30 \mu \mathrm{m}$ and $100 \mu \mathrm{m}$ and each result is shown separately. In assessing these results it should be noted that twenty-four particles were injected at the inflow port. Their path is changed due to the mean background flow and the turbulence. Twenty-four particles are a relatively small number to demonstrate the effect of turbulence; however, they are sufficient to provide an estimate of the envelope of particle paths and the results should be viewed in this sense.

Figures 5.14 and 5.16 show the base case; no tertiary injection. The development of the flow field shows the primary and secondary jets mixing with the quiescent flow and the resulting recirculation region are evident in Fig. 5.14. In these plots, velocity vectors 


\section{VELOCITY VECTOR PLOTS}

\section{No Tertiary Flow}
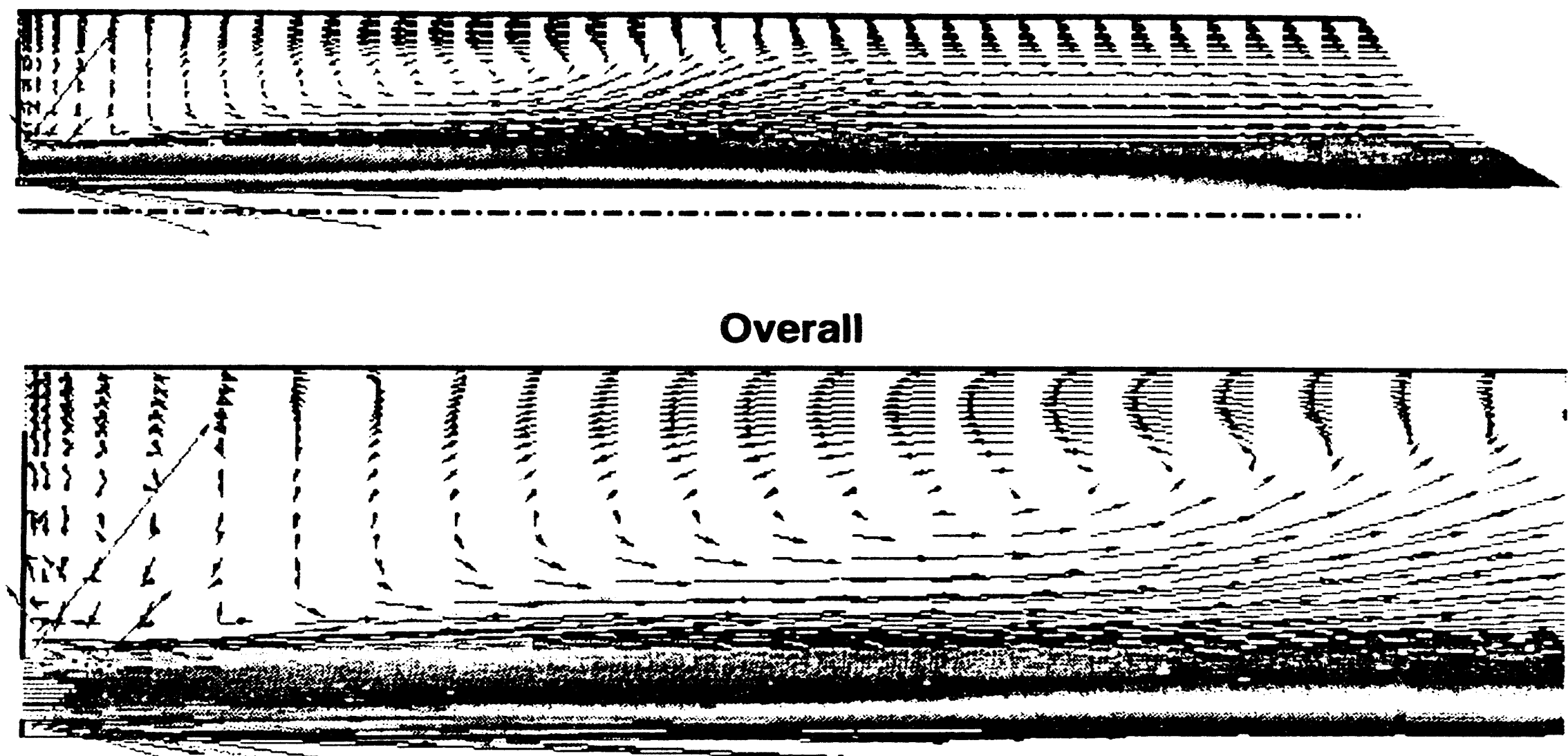

\section{Closeup}

Figure 5.14. Veloxity Vector Plots - No Tertiary Flow. 


\section{VELOCITY VECTOR PLOTS \\ Tertiary Flow (Combined Injection)}

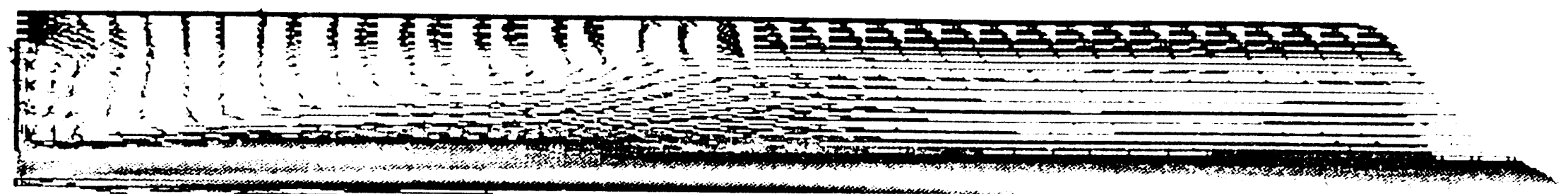

篮 $=0$ -

\section{Overall}

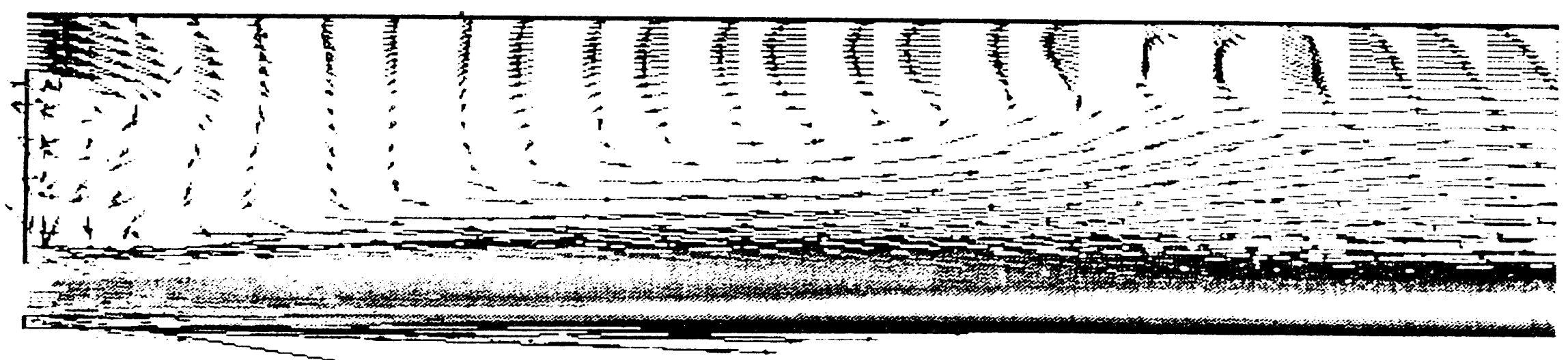

\section{Closeup}

Figure 5.15. Velocity Vector Plots - Tertiary Flow (combined injection). 


\section{PARTICLE PATHS - NO TERTIARY FLOW}

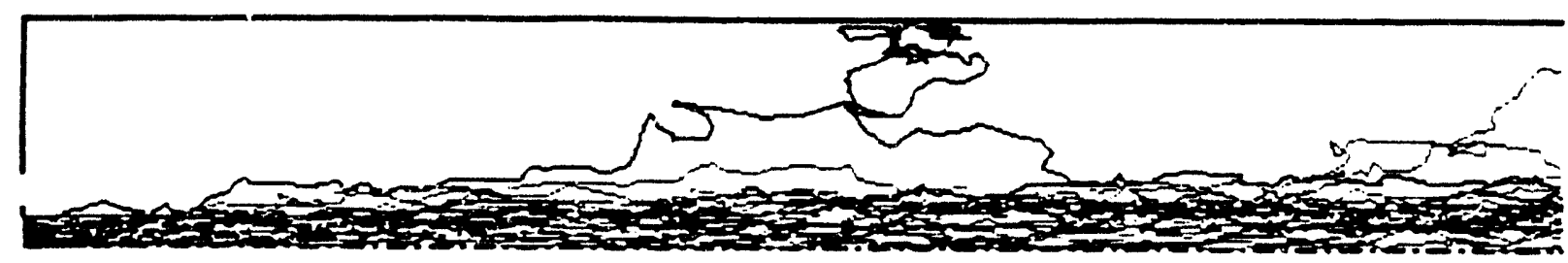

10 microns

\section{0 microns}

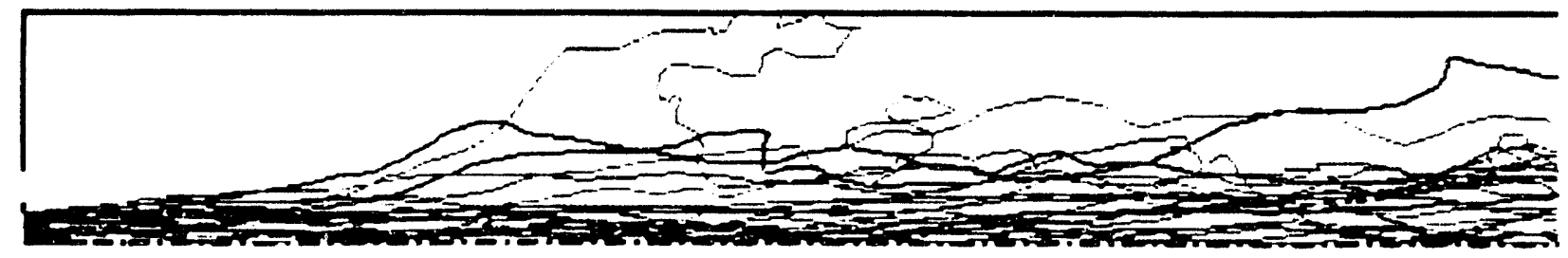

\section{0 microns}

Figure 5.16. Particle Paths - No Tertiary Flow. 


\section{PARTICLE PATHS - TERTIARY FLOW (SIDE INJECTION)}

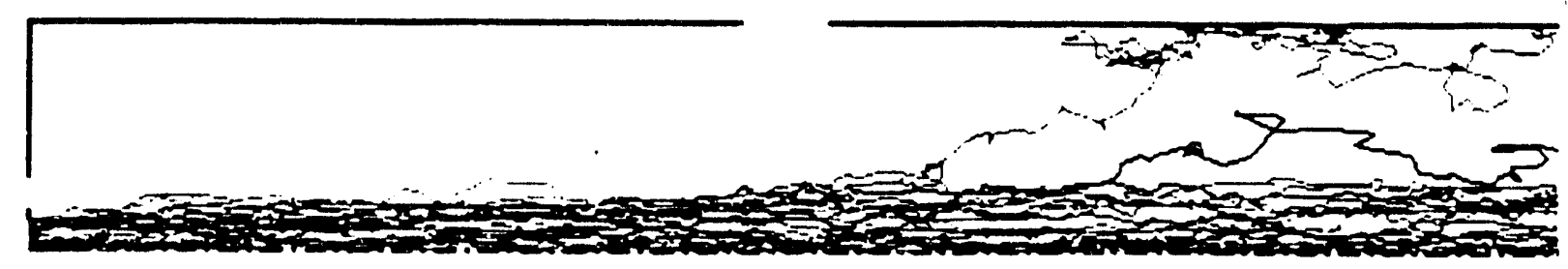

\section{0 microns}

\section{0 microns}

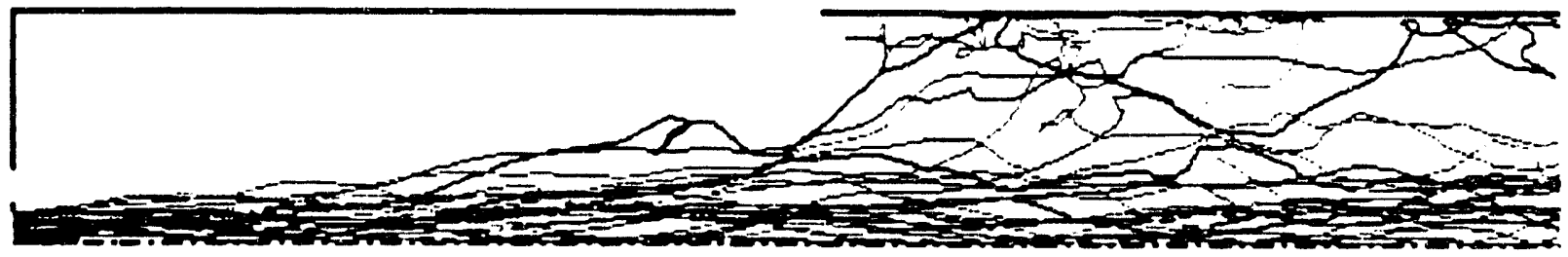

\section{0 microns}

Figure 5.17. Particle Paths - Tertiary Flow (side injection). 
near the centerline are omitted, as they were large and obscured the rest of the plot. Figure 5.16 shows particle trajectories for the base case. In assessing the results note that the heat-exchanger is to be placed at $80 \%$ of the furnace radius. For no tertiary flow, it is clear that the entire range of particles considered presents a problem. The particles would be dangerously close to the heat-exchanger at approximately $40 \%$ of the length (for $10 \mu \mathrm{m}$ ), $60 \%$ (for $30 \mu \mathrm{m}$ ) and $40 \%$ (for $100 \mu \mathrm{m}$ ), respectively.

For tertiary air injected at the top of the reactor, Case 2, the tertiary air is very quickly turned toward the centerline after injection and adds an additional buffer to the original secondary stream buffer around the primary coal/air stream. This should add protection to the flow. The particle trajectories now become dangerously close at $60 \%$ of the length (for $10 \mu \mathrm{m}$ ), $70 \%$ of the length (for $30 \mu \mathrm{m}$ ) and $50 \%$ of the length (for $100 \mu \mathrm{m})$, respectively. Clearly, even this modest amount of tertiary injection is very beneficial. Figures 5.15 and 5.17 show the flow for side injection, which energizes the flow downstream of the injection hole. This provides protection in the downstream region for $75 \%, 83 \%$, and $60 \%$ of the length, for the 10,30, and $100 \mu \mathrm{m}$ particles, respectively. For the two combined injection cases, where gas was injected at the top of the furnace and along the side wall, further improvement is noted. These results are summarized in Table 5.3.

These preliminary calculations indicate that even with a modest amount of cleansing air, heat exchange elements can be protected for $60 \%$ of the furnace length. Other strategies combining top and side injection, changing the side injection angle and/or changing the side injection number of ports are likely to further improve these results.

TABLE 5.3

LENGTHS PROTECTED

\begin{tabular}{|c|c|c|c|c|c|c||}
\hline $\begin{array}{c}\text { Particle } \\
\text { Size }\end{array}$ & $\begin{array}{c}\text { Case 1 } \\
\text { No Inj }\end{array}$ & $\begin{array}{c}\text { Case 2 } \\
\text { Top Inj }\end{array}$ & $\begin{array}{c}\text { Case 3 } \\
\text { Side Inj }\end{array}$ & $\begin{array}{c}\text { Case 4 } \\
\text { Comb. Inj }\end{array}$ & $\begin{array}{c}\text { Case 5 } \\
\text { Comb. Inj. }\end{array}$ & Case 6 \\
\hline $10 \mu \mathrm{m}$ & $40 \%$ & $60 \%$ & $75 \%$ & $90 \%$ & $90 \%$ & $30 \%$ \\
\hline $30 \mu \mathrm{m}$ & $60 \%$ & $70 \%$ & $83 \%$ & $100 \%$ & $95 \%$ & $95 \%$ \\
\hline $100 \mu \mathrm{m}$ & $40 \%$ & $50 \%$ & $60 \%$ & $70 \%$ & $80 \%$ & $95 \%$ \\
\hline
\end{tabular}

From above results, it appears that additional optimization of the cleaning effect could be achieved by adjusting the relative amounts of secondary and tertiary air buffers. Based on this understanding, one more calculation (Case 6) was carried out. In Case 6 , the original secondary air flow was split into two equal parts. One half of it was fed from the secondary inlet I with a reduced diameter of 1.04 meters. The other half was injected from the secondary $I I$ inlet which is an annulus located at 0.872 meters from the center line of the reactor cylinder. There is no side injection.

The velocity vector plots are given in Fig. 5.18. The flow patterns obtained were considerable different from those obtained in the previously run cases. The large recirculation normally obtained on the outer wall was not observed. As expected two small recirculation zones were formed in the base regions, but these zones are small and 


\section{VELOCITY VECTOR PLOTS}

\section{Two Injector Tertiary Flow}

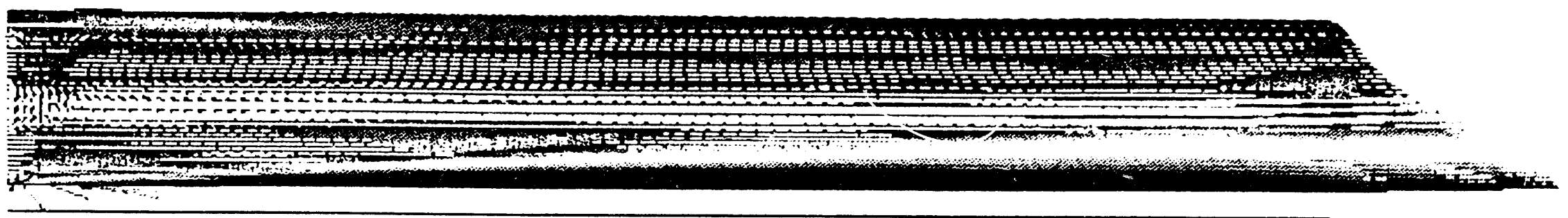

\section{Overall}

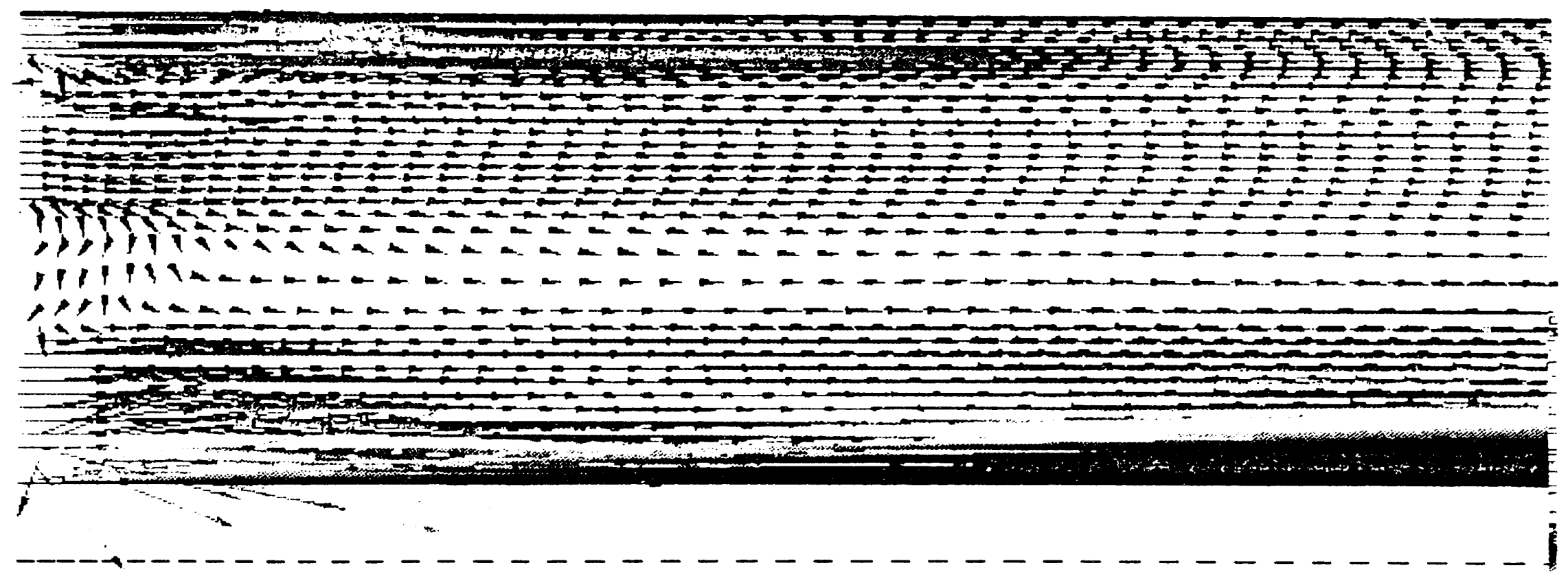

$=0$

\section{Closeup}

Figure 5.18. Velocity Vector Plots - Two Injector Tertiary Flow. 
have little effect on the flow pattern. The particle paths are shown in Fig. 5.19. For all the cases run to date these results are the most promising for larger particles. For the 10 micron case one particle does penetrate the region of the heat exchanger. This design controls particle transport mechanism No. 1 very well, but the small particles which are mostly affected by the turbulence can still cause fouling problem. Better turbulence control could be achieved by design modifications in both geometry and firing schemes.

In addition, although not shown here, results have been obtained to show the sensitivity of the calculations to inlet primary stream flow angle and turbulence level. As expected, in general, although anomalies do appear due to the statistical nature, reducing the inlet primary stream flow angle reduces particle spread and increasing turbulence increases primary stream spread.

\subsubsection{Three Dimensional Calculations}

The 3D version of CELMINT computer code was used to model the three-dimensional tertiary flow case previously run for the axisymmetric tertiary flow case (Case 2 in task 2). The flow conditions were the same as for the previously reporied axisymmetric case. The inflow consists of a primary coal/air flow, a secondary air flow and a tertiary methane/air flow. The initial condition was taken from the converged axisymmetric case. For the three-dimensional case, a heat transfer tube was inserted in the flow device. The streamwise and cross plane grid are shown in Fig. 5.20. Because the heat transfer tubes are symmetrically placed, the flow pattern repeats every 6 degrees as is shown by the cross plane grid. The streamwise grid consists of 100 streamwise stations and 50 radial stations. In the circumferential direction 25 grid points were used. Convergence was obtained in 300 time steps.

Results of the calculation are shown in Figs. 5.21 to 5.23. In Fig. 5.21 the velocity vectors are shown in the injection region. The flow pattern shows the effect of the heat transfer tube. The down flow from the tertiary injection cannot be seen. In contrast, in Fig. 5.22 the downflow is evident. This effect was seen in the axisymmetric case as would be expected. Because the size of the heat transfer tube is a small percentage of the cross section of the combustor, the overall effect on the flow pattern is minimal. This can be seen in Fig. 5.23, the pressure contours. Very little difference is seen between the streamwise pressure contours located over the center of the blade and in the region between the blades. 'To some extent, the basic flow patterns differ little from the axisymmetric case. This is probably due to the large number of heat transfer blades and the fact that they prevent the circumferential velocity component from becoming large.

\subsection{Emissivity Measurement of Ceramic Heat Exchange Materials (Task 2)}

\subsubsection{Materials and Background of Materials Emissivity}

One of the critical issues identified in the proposal is whether the current ceramic technology would provide us with a superior ceramics or ceramics composite with good high temperature strength, toughness, thermal shock resistance, corrosion and erosion resistances and high emissivity for sufficient heat transfer rate from coal flame to the working fluid. 


\section{PARTICLE PATHS CASE - MODIFIED}

\section{(two secondary injections)}

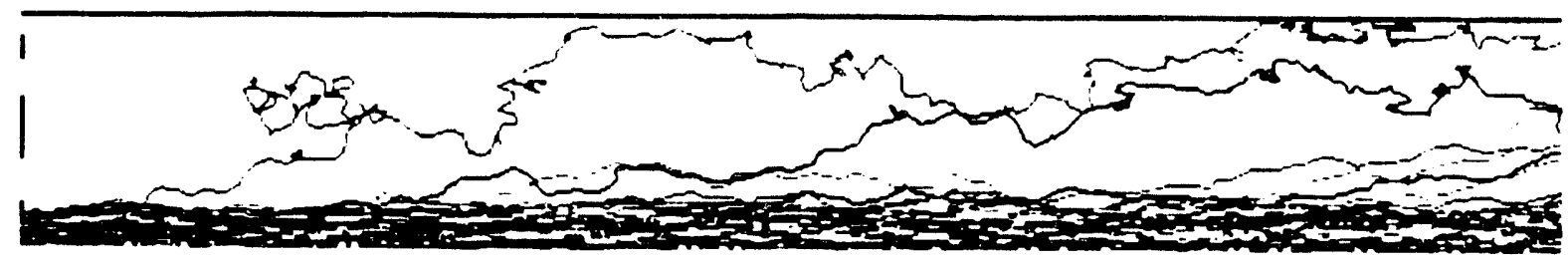

\section{0 microns}

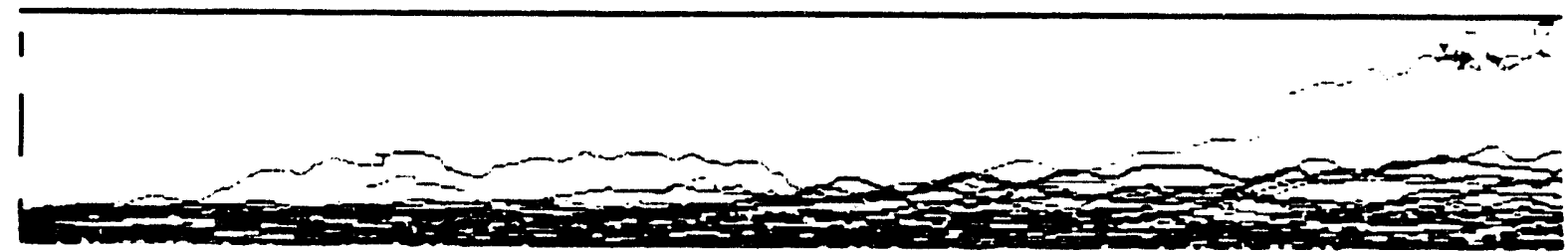

30 microns

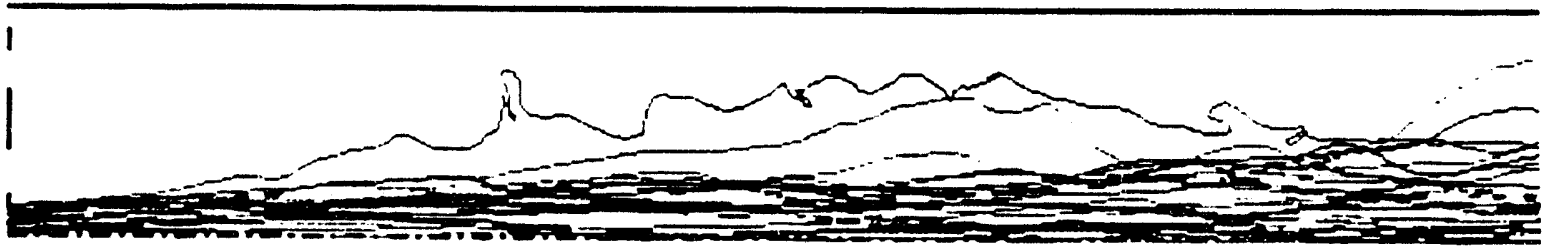

100 microns

Figure 5. 19. Particle Paths - Modified Secondary Air Flow (two secondary injections). 


\section{STREAMWISE \& CROSS-PLANE GRID}

\section{Tertiary Flow}

Tube

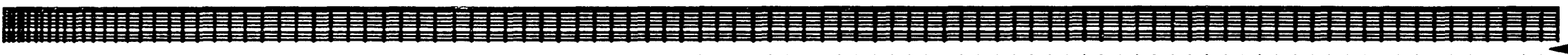



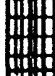
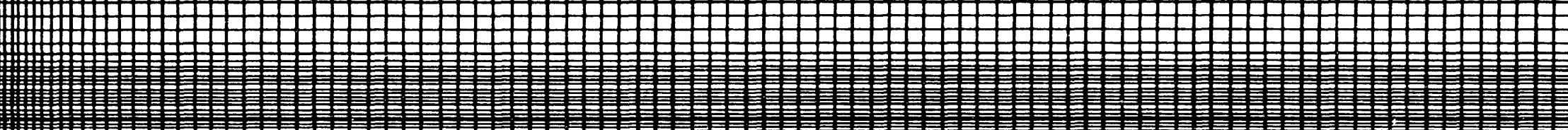

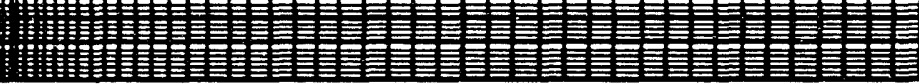

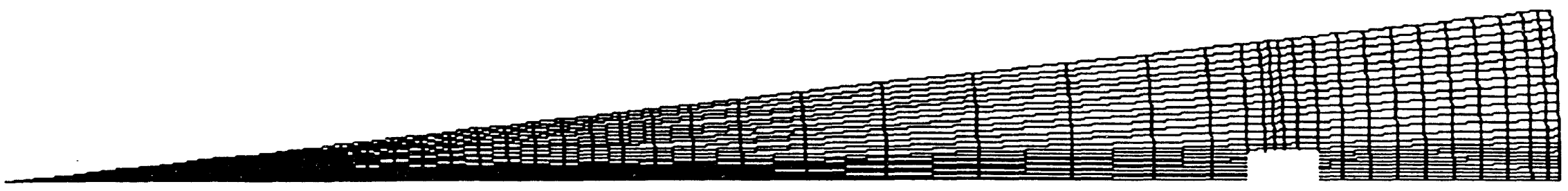

Figure 5.20. Streamwise \& Cross-Plane Grid (tertiary flow). 


\section{VELOCITY VECTOR PLOTS}

\section{Tertiary Flow}

\section{Center of Blade}
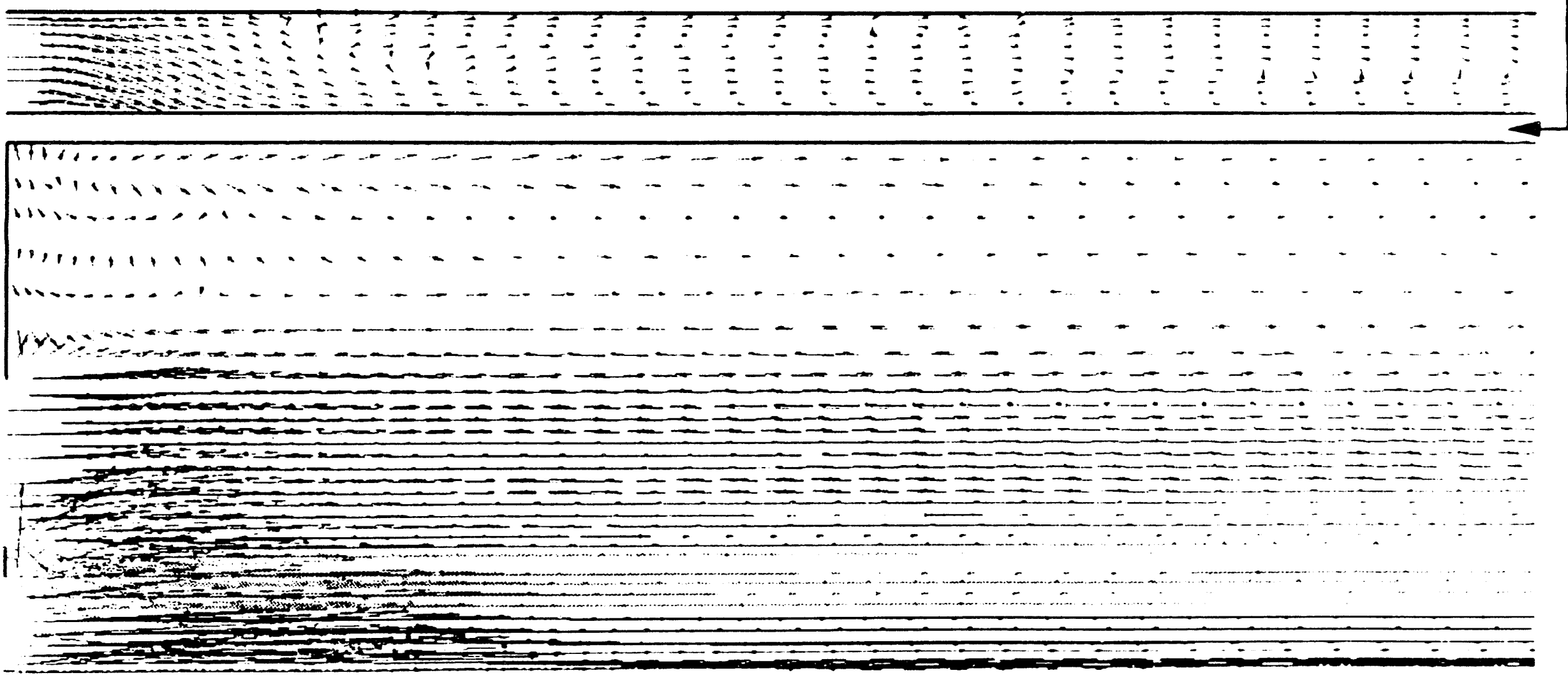

\section{Closeup}

Figure 5.21. Velocity Vector Plots - Center of Blade (tertiary flow). 


\section{VELOCITY VECTOR PLOTS}

\section{Tertiary Flow}

\section{Between Blades}

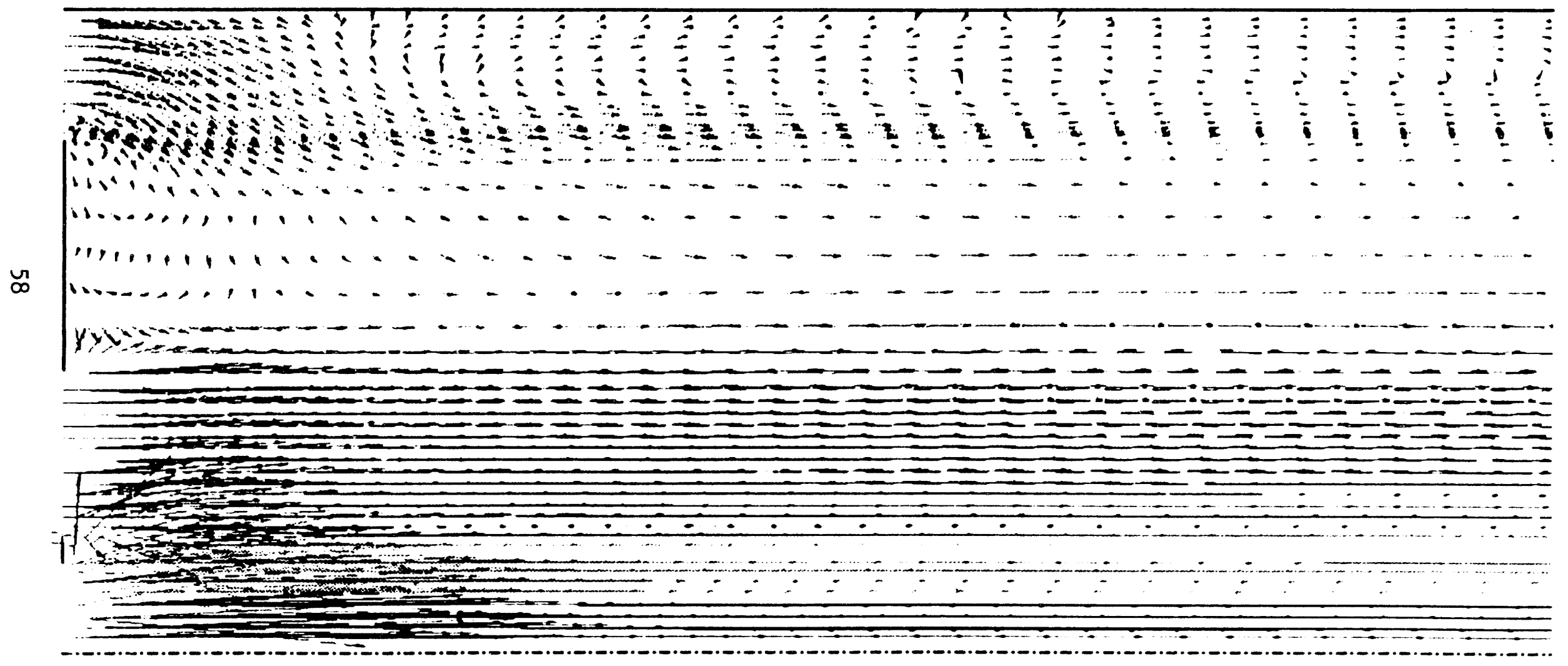

\section{Closeup}

Figure 5.22. Velocity Vector Plots - Between Blades (tertiary now). 


\title{
PRESSURE CONTOURS
}

\author{
Tertiary Flow \\ Center of Blade
}

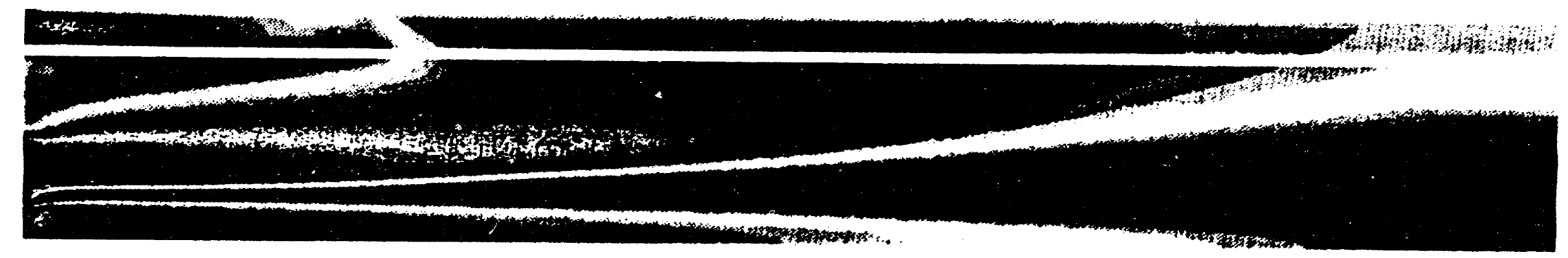

\section{Between Blades}

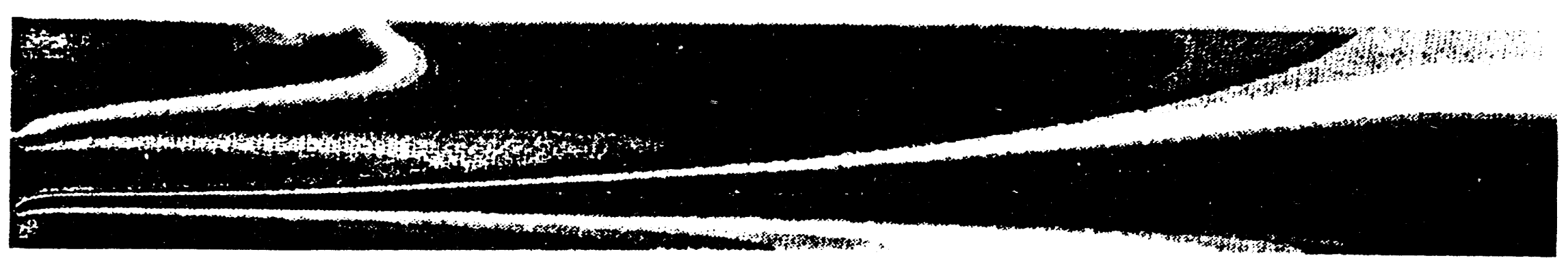

Figure 5. 23. Pressure Contours (tertiary now). 
Lanxide $\mathrm{SiC} / \mathrm{Al}_{2} \mathrm{O}_{3}$ composites, manufactured by Du Pont Lanxide Composites, Inc. are finding useful applications in high temperature environments due to their high temperature properties and fracture toughness. They were selected in this project as candidate materials for heat exchange tubes. Their spectral emittance data were measured in task 2 of this project.

The surface radiative property emittance is defined as the ratio of the radiation emitted by the surface to the radiation emitted by a blackbody at the same temperature and for the same spectral and directional conditions. For a material at elevated temperature, it is a property which must be known if an accurate temperature determination is to be made by measurement of emitted electromagnetic radiation with a radiation thermometer. Emittance is also important as a fundamental parameter to predict thermal radiation interactions of a surface with its surrounding environment.

AFR has developed and constructed a bench top instrument which measures spectral emittance while simultaneously determining the sample temperature. The instrument and measurement methodology are described in detail in Ref. 19. Sections 5.6.2 and 5.6.3 will briefly summarize the measurement technique and present measurements of spectral emittance for three Lanxide $\mathrm{SiC} / \mathrm{Al}_{2} \mathrm{O}_{3}$ composites as a function of temperature, up to $1500^{\circ} \mathrm{C}$. Measurements of SiC and $\mathrm{Al}_{2} \mathrm{O}_{3}$ will also be presented for comparison. Table 5.4 presents the sample designations and measurement temperatures for the spectral emittance determinations.

TABLE 5.4

SAMPLE DESIGNATIONS AND MEASUREMENT TECHNIQUES

\begin{tabular}{||l|c|c|c|c||}
\hline SOURCE & DESIGNATION & MATERIAL & SIZE (inches) & $\begin{array}{c}\text { MEASUREIMENT } \\
\text { TEMPERATURES } \\
\left({ }^{\circ} \mathrm{C}\right)\end{array}$ \\
\hline Lanxide & $92 \cdot \mathrm{X}-2056$ & $\mathrm{SiC} / \mathrm{Al}_{2} \mathrm{O}_{3}$ & $5 / 8 \times 3 / 4 \times 3 / 16$ & $540,1038,1500$ \\
\hline Lanxide & $91-\mathrm{X}-1096$ & $\mathrm{SiC} / \mathrm{Al}_{2} \mathrm{O}_{3}$ & $1 \times 1 \times 1 / 4$ & $556,1027,1456$ \\
\hline Lanxide & $\begin{array}{c}90-\mathrm{X}-048 \\
\mathrm{SiC} / \mathrm{Al}_{2} \mathrm{O}_{3}\end{array}$ & $1 \times 1 \times 1 / 4$ & $591,1009,1511$, \\
\hline Cercom & $\begin{array}{c}\text { PAD SiC } \\
\text { Type B }\end{array}$ & $\mathrm{SiC}$ & $3 / 4 \times 1 / 2 \times 1 / 16$ & $533,1230,1487$ \\
\hline Coors & Sintered & $\mathrm{Al}_{2} \mathrm{O}_{3}$ & $1 \times 1 / 2 \times 3 / 16$ & 929 \\
\hline
\end{tabular}

\subsubsection{Instrumentation and Measurement Technique}

The bench top emissometer is shown schematically in Fig. 5.24. The FT-IR spectrometer (a Bomem/Hartmann \& Braun, model 151) is utilized in emission mode, and can accept radiation from either side of the sample by positioning the selector mirror. The design of the Bomem's interferometer allows for the incoming beam to be modulated and then split into two beams of identical information. In our instrument, two separate detectors are utilized to measure near- and mid-IR energy. A room temperature indium- 


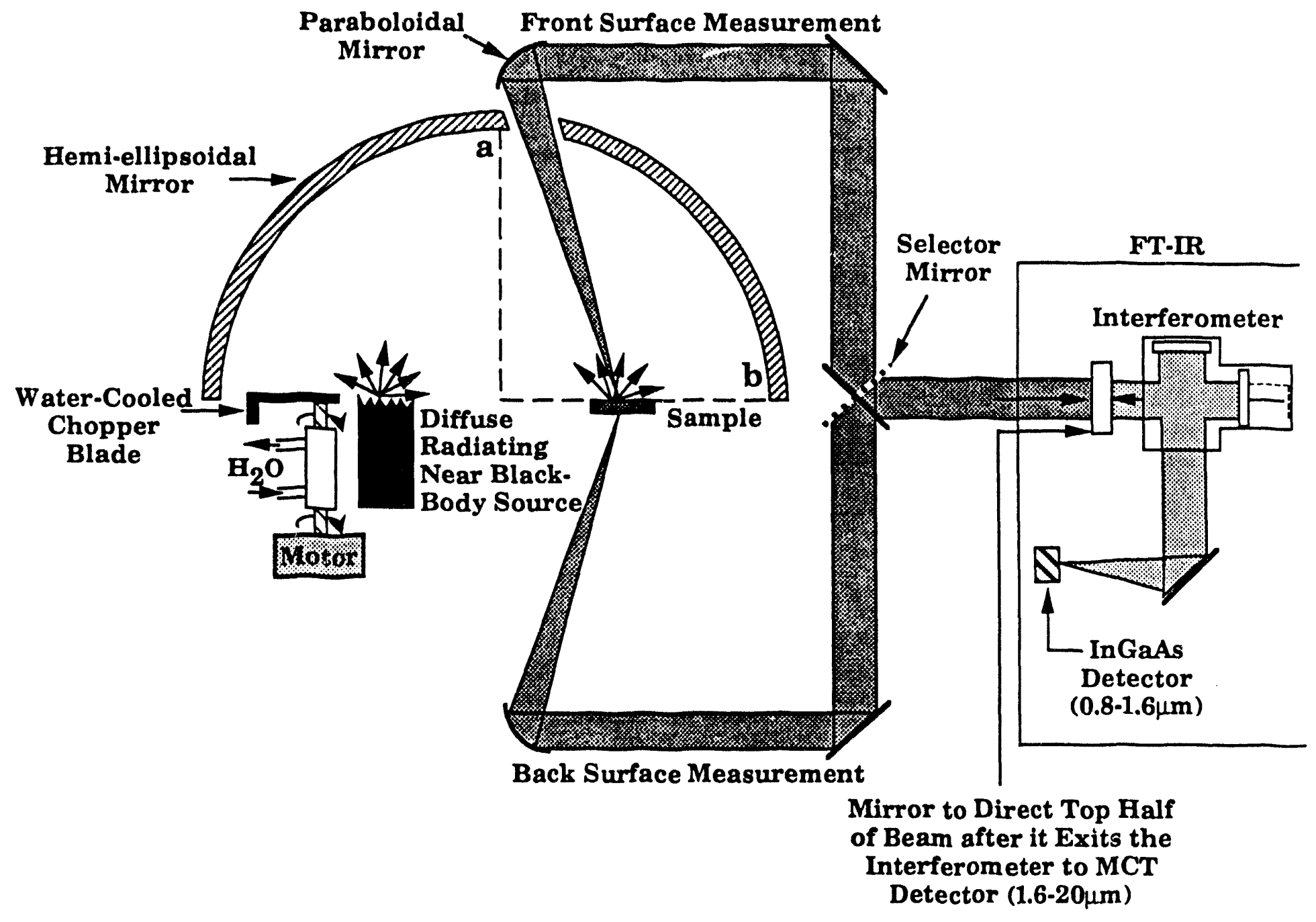

Figure 5.24. Schematic of Benchtop Emissometer Showing Components and Optical Paths for Radiance, Reflectance, and Transmittance Measurements. The Lanxide $\mathrm{SiC} / \mathrm{Al}_{2} \mathrm{O}_{3}$ Composites are Non-Transmissive to IR Energy; Therefore Only Front Surface Measurements are Required. 
gallium-arsenide detector is sensitive to near-IR energy $10.8-1.6 \mu \mathrm{m}$, or

$\left.12,500-6250 \mathrm{~cm}^{-1}\right)$, and a liquid nitrogen cooled mercury-cadmium-telluride detector for longer wavelengths $\left(1.6-20 \mu \mathrm{m}\right.$, or $\left.6250-500 \mathrm{~cm}^{-1}\right)$. Both spectral regimes can be measured simultaneously. The measurements presented here are limited to the mid-IR regime.

The hemi-ellipsoidal mirror which has a semi-minor axis (a) of 11.13" and a semimajor axis (b) of 11.81" has both foci inside the mirror with a source located at one of the foci and the sample located at the other focus. The foci are separated by 7.88 ". This mirror geometry, combined with the radiating characteristics of the near-blackbody source, provides a means of irradiating the sample both hemispherically and diffusely. Therefore, the measurement of reflected radiation from the front surface in a given direction is that of directional-hemispherical reflectance since the sample is irradiated uniformly from all directions. Likewise, for transmissive samples, the back surface measurement is of directional-hemispherical transmittance. All of the Lanxide samples were several millimeters thick, and opaque. Therefore, transmission measurements were not necessary.

An integral part of the optical system is the rotating chopper system which moves either an aperture or a cold near-blackbody element in front of the source. The FT-IR data collection system is synchronized with these two states, and allows for the distinction of sample radiation from reflected radiation as follows. For the reflectance measurement, the IR beam originates at the near-blackbody source at one focus of the hemi-ellipsoidal mirror. The radiation reflects from the hemi-ellipsoidal mirror and is focused onto the sample at the other focus where it is reflected (scattered) by the sample into the interferometer. The reflectance and the sample radiance are measured together when the aperture on the chopper rotor is in place over the source (chopper open condition). When a cold nearblackbody is substituted for the aperture over the source (chopper closed condition) it is the sample radiance alone which is measured. Both the radiance and directionalhemispherical reflectance can be obtained from these two spectra and their difference.

Figure 5.25a compares measured radiance from hot Lanxide $90-\mathrm{X}-048$ for the chopper closed condition to that of the chopper open condition. The increased radiant intensity due to the reflection from the wafer surface is observed over all wavenumbers.

The measurement of directional-hemispherical reflectance $\left(\rho_{v}\right)$ from a nontransmissive material allows for the determination of spectral emittance $\left(\epsilon_{v}\right)$ by closure:

$$
\epsilon_{v}=1-\rho_{v}
$$

Figure $5.25 \mathrm{~b}$ presents the determined spectral emittance by closure with $\rho_{v}$ derived from the data in Fig. 5.25a. The spectral emittance is now utilized with the sample radiance to determine the precise surface temperature by direct comparison in both shape and amplitude to theoretical Planck function calculations of temperature, $R_{v}^{b}\left(T_{s}\right)$, where $T_{s}$ is the temperature of the sample. 

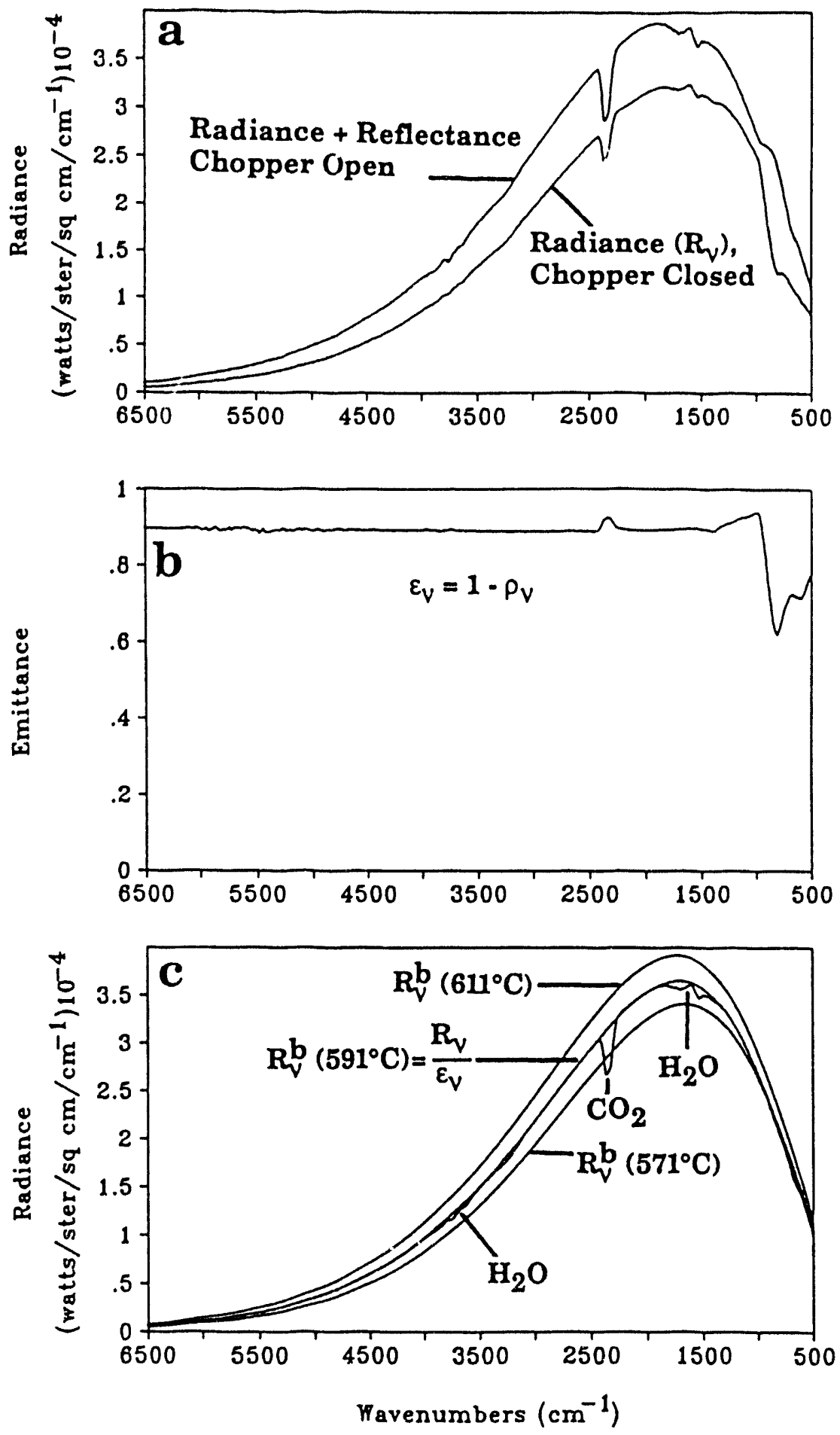

Figure 5.25. Spectral Emittance and Temperature Determination for Lanxide 90-x-048. a) Sample Radiance (chopper closed) Compared to Radiance + Reflectance (chopper open), b) Spectral Emittance by Closure, $\varepsilon_{v}=1-\rho_{v}$, and c-d) Surface Temperature Determination by Overlaying Radiance/ $\varepsilon_{v}$ with Theoretical Blackbody Temperature Curves. The Surface Temperature is $591^{\circ} \mathrm{C} \pm 10^{\circ} \mathrm{C}$. 


$$
R_{v}^{b}\left(T_{s}\right)=\frac{R_{v}}{\epsilon_{v}}
$$

Such a determination is shown in Fig. 5.25c, where the measured temperature spectrum for the Lanxide $90-X-048$ slab shows best agreement with a theoretical spectrum calculated at $591^{\circ} \mathrm{C}$. The deviation at $2400 \mathrm{~cm}^{-1}$ in the measured spectrum is due to a change in the $\mathrm{CO}_{2}$ concentration in the beam path. Slight changes in the ambient $\mathrm{H}_{2} \mathrm{O}$ concentration are also indicated in the figure. As indicated in the figure, the temperature was determined to within $\pm 10^{\circ} \mathrm{C}$.

Samples are mounted into position for spectral emittance measurements with a clamping device which is arranged so it does not contribute extraneous radiation to the measurement. Three intersecting visible laser beams are utilized to ensure correct positioning of the sample. The Lanxide samples were back-heated with a propane flame for the low temperature measurements. This was replaced with an oxy-acetylene flame for the high temperature measurements. The influence on the measurements due to the radiation contributions from the combustion products of a torch flame $\left(\mathrm{CO}_{2}\right.$ and $\left.\mathrm{H}_{2} \mathrm{O}\right)$ is limited to narrow spectral regions, as shown in Fig. 5.25c.

\subsubsection{Spectral Emittance of Lanxide $\mathrm{SiC} / \mathrm{Al}_{2} \mathrm{O}_{3}$ Composites}

Spectral emittance was measured for the Lanxide composites $92-X-2056$, $91-\mathrm{X}-1096$, and $90-\mathrm{X}-048$ at temperatures near $500^{\circ} \mathrm{C}, 1000^{\circ} \mathrm{C}$, and $1500^{\circ} \mathrm{C}$. Figure 5.26 presents the data to allow comparison of spectral emittance as a function of temperature and composite formulation. All measurements near $1500^{\circ} \mathrm{C}$ exhibit an increase in spectral noise. This is inherent as the sample temperature becomes much larger than the temperature of the near black body source in the instrument. For these measurements, the temperature of the source was held constant at $800^{\circ} \mathrm{C}$. For samples of high emissivity (low reflectivity), such as the Lanxide composites, the $800^{\circ} \mathrm{C}$ radiant intensity which is reflected by the sample is a small component compared to the $1500^{\circ} \mathrm{C}$ sample radiance. This small change in sample radiance vs sample radiance plus reflectance propagates through the difference calculations which results in the spectral emittance, and is observed as an increase in spectral noise. Increasing the source temperature and/or increasing the data collection time would serve to increase the signalto-noise ratio (reduced noise) for the $1500^{\circ} \mathrm{C}$ sample cases.

All three Lanxide composites exhibit fairly high spectral emittance in the mid-IR spectral regime. Some decrease is observed at high wavenumbers for all three samples as temperature is increased. Below $1500 \mathrm{~cm}^{-1}$, which is the characteristic region of infrared absorption for discrete chemical species of ceramics, compositional differences are indicated for the three Lanxide samples.

For comparison, the spectral emittance of a pure slab of $\mathrm{SiC}$ at three temperatures, and a pure slab of $\mathrm{Al}_{2} \mathrm{O}_{3}$ at one temperature are shown in Fig. 5.27. Clearly.. the $\mathrm{SiC}$ in the Lanxide samples is the dominating species in the emittance measurement. Of interest. is that the Lanxide $92-X-2056$ at and above $1000^{\circ} \mathrm{C}$, and the Lanxide $91-X-1096$ at all temperatures exhibit the highest emittance at a wavenumber $\left(\sim 1350 \mathrm{~cm}^{-1}\right)$ which is significantly higher than that for $\mathrm{SiC}$ or $\mathrm{Al}_{2} \mathrm{O}_{3}$. This feature compares well with the characteristic absorption band for $\mathrm{SiO}_{2}$. 

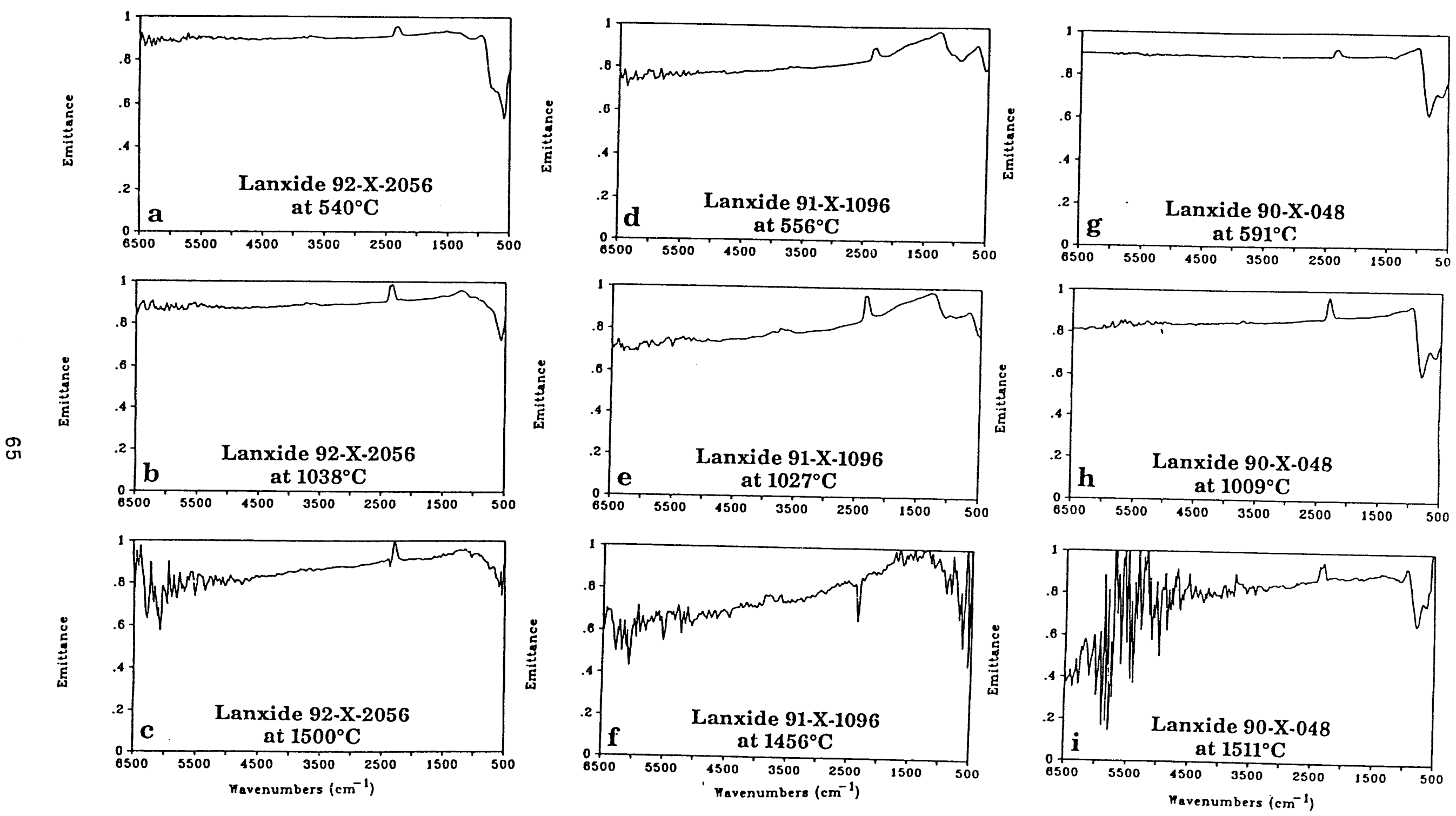

Figure 5.26. Spectral Emittance by Closure $\left(\varepsilon_{v}=1-\varepsilon_{v}\right)$ for Three Lanxide SiC/Al ${ }_{2} \mathrm{O}_{3}$ Composites at Temperatures Near $500^{\circ} \mathrm{C}, 1000^{\circ} \mathrm{C}$ and $1500^{\circ} \mathrm{C}$. a,b,c) Lanxide 92-X2056; d,e,f) Lanxide 91-X-1096; g,h,i) Lanxide 90-X-048. 

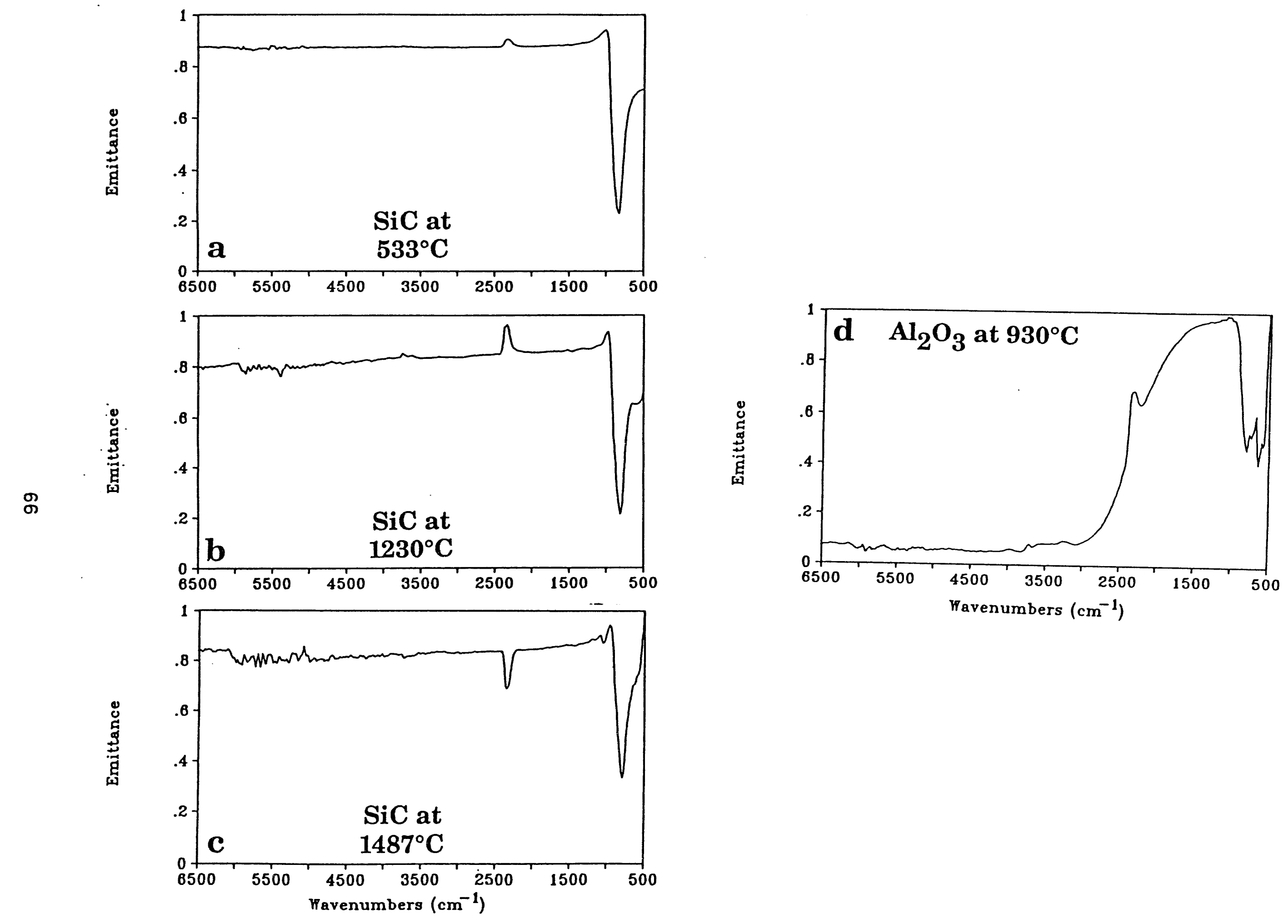

Figure 5.27. Spectral Emittance for $\mathrm{SiC}$ and $\mathrm{Al}_{2} \mathrm{O}_{3}$ (sintered) at Elevated 
Concern was expressed that the Lanxide $90-X-048$ would begin to degrade at temperatures above $1250^{\circ} \mathrm{C}$. As shown in Fig. $5.26 \mathrm{~g}-5.26 \mathrm{i}$, measurements were

performed up to $1500^{\circ} \mathrm{C}$. Fig. 5.28 compares the spectral emittance measured at $591^{\circ} \mathrm{C}$ from the original sample, to that at $509^{\circ} \mathrm{C}$ measured after the sample had been heated to $1500^{\circ} \mathrm{C}$ for 10 minutes, and to that at $523^{\circ} \mathrm{C}$ after heating the sample to $1500^{\circ} \mathrm{C}$ for one hour. The spectral emittance compares well at all wavenumbers except for below $1500 \mathrm{~cm}^{-1}$, again indicative of formation of $\mathrm{SiO}_{2}$. After exposure to temperatures above $1250^{\circ} \mathrm{C}$, it was visually observed that physical separation of the sample's fibers was occurring. 

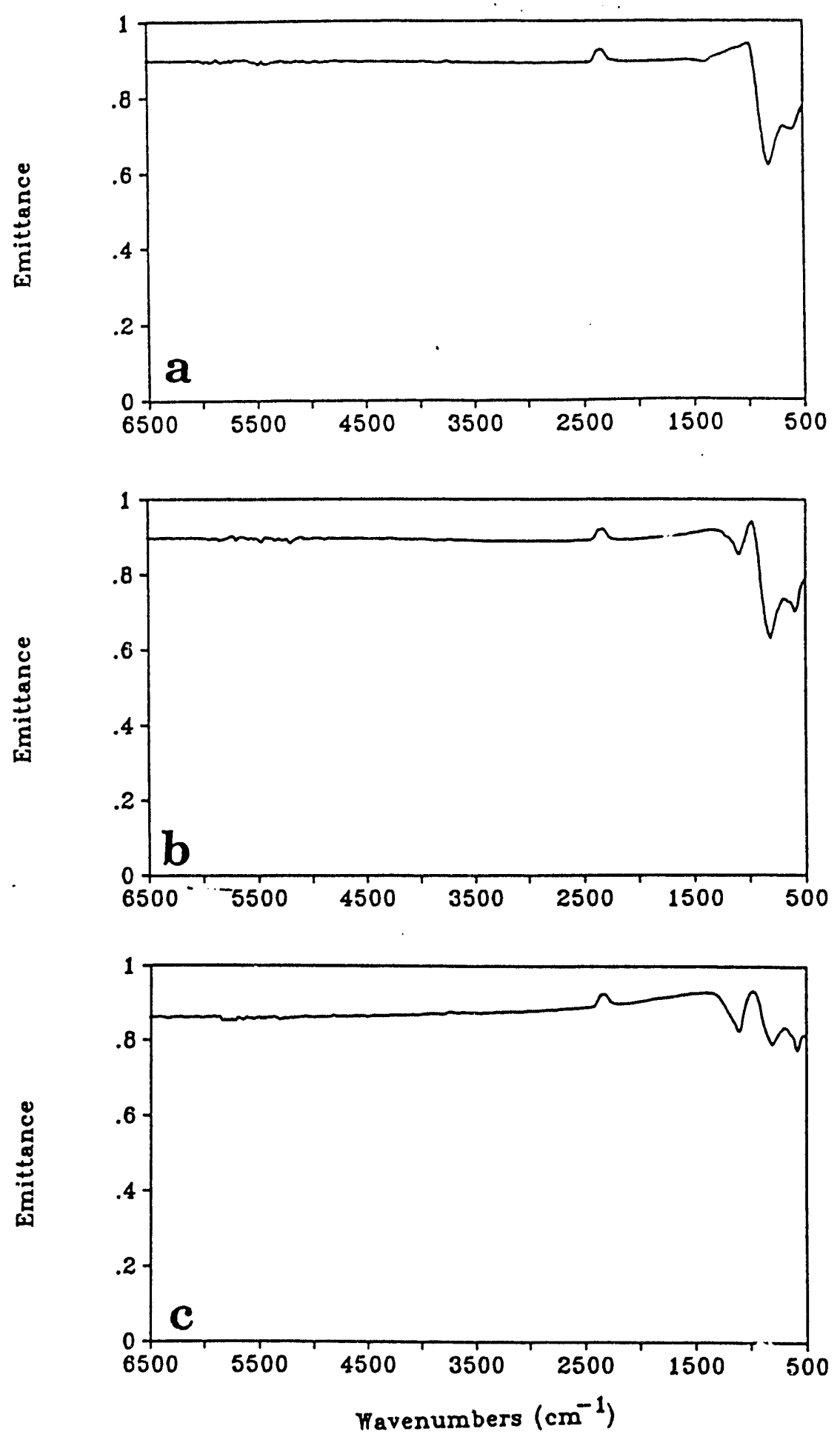

Figure 5.28. Comparison of Spectral Emittance of Lanxide $90-\mathrm{X}-048$ at $-550^{\circ} \mathrm{C}$.

a) First Heating of Original Sample and b) After Heating to $1500^{\circ} \mathrm{C}$ for 10 Minutes, and c) After Heating to $1500^{\circ} \mathrm{C}$ for 1 Hour. 


\section{Conclusions and Recommendations}

The main objective of this project is to develop and validate a new and proprietary concept for an externally fired gas turbine system. The chief advantage of this route is that the potential problems caused by the coal's inorganic constituents are diverted from the high temperature rotating parts of the gas turbine to the high temperature stationary parts of a heat exchanger. By using two comprehensive computational fluid dynamics codes, PCGC-2 and CELMINT, the coal combustion and the particle turbulent dispersion inside the HITAF/REACH reactor were modeled. We have presented the main results that satisfy the objective of this project. These results clearly validate the basic concept of the HITAF/REACH-Exchanger design. The coal particle dispersion is controllable by using special firing schemes and appropriate geometry and hence the particie fouling on the heat exchange tubes can be prevented. The main conclusions are as follows:

- With the cylindrical HITAF/REACH reactor, the 2D fluid mechanics calculations with PCGC-2 show that the combustion efficiency is not significantly affected by the alternations in the oxidant air injection schemes. It is quite feasible to change the air injection. Hence, it is permissible to redesign the firing scheme to optimize the aerodynamics cleaning effect in HITAF/REACH reactor without adversely affecting the combustion.

- The application of the swirl air in the system was shown to increase the difficulty of controlling the coal particle dispersion and should be avoided in the HITAF/REACH-Exchanger reactor design.

- Due to the flexibility of placing the air injection, an air buffer can be created between the coal flame and the heat exchange tubes to provide the protection, by using a specially designed firing scheme. Calculations showed that this air buffer is very effective in controlling the flame and redirecting the large particles and that the particle fouling on the heat excha, e tubes was significantly reduced. Noticeably, this is achieved with only $15 \%$ excess air.

- Both 2D and 3D two phase fluid mechanics calculation with CELMINT demonstrated that the firing scheme can be favorably iedesigned to control the gas flow pattern and the particle stream in the reactor.

- Three particle transport mechanisms were identified, i.e., i). the convective transport by the background flow, ii). the initial particle injection angle on inflow, and iii). the gas turbulence dispersion. Calculation showed that mechanism i. and ii. can be effectively controlled by the firing scheme, so the key process is the particle dispersion by the turbulence. Our results suggested that the control of turbulence dispersion can be achieved by optimizing the reactor geometry.

- High temperature emissivity measurements show that the advanced ceramics and ceramic composites are currently available as the candidates for heat exchange materials in HITAF/REACH system. 
Our results suggest that better particle dispersion control could be achieved by design modifications in both geometry and firing schemes, so that not only the heat exchange tubes are protected by the air buffer but also the particle flow is redirected by the gas flow. We recommend further investigation along this direction.

We suggest an inlet configuration for the HITAF/REACH reactor that uses two secondary inlets as specified in the Cases 8 and 9 of Section 5.2. The secondary 1 inlet supplies the air for the first stage, fuel rich combustion and the secondary 11 inlet provides the cleaning air for the particle dispersion control and the second stage combustion. To ensure a good initial mixing, the multiple injector burners need to be used. 


\section{References}

1. User's Manual, 93-PCGC-2: Pulverized Coal Gasification and Combustion Model 12 Dimensionall with a Generalized Coal Reactions Submodel (FG-DVC), Brigham Young University and Advanced Fuel Research, Inc., 1993.

2. Solomon, P.R.,Markham, J.R., Zhang, Y.P., Carangelo, R.M., Brewster, B.S., and L.D. Smoot, "The Study of a Coal Flame by FT-IR emission/Transmission Tomography and Comprehensive Modeling", Sci-Mix Poster Session, ACS Meeting, Washington, DC, (1990).

3. Sabnis, J.S., de Jong, F.J., and Gibeling, H.J., "Calculation of Particle Trajectories in Solid-Rocket Motors with Arbitrary Acceleration", J. of Prop. and Power, 8, \#5, (Sept. - Oct. 1992).

4. Sabnis, J.S., Choi, S.K., Buggeln, R.C., and Gibeling, H.J., "Computation of TwoPhase Shear Layer Flow using an Eulerian-Lagrangian Analysis", AIAA paper 883202.

5. Zabolotny, E.R., Vivenzio, T.A., and LaHaye, P., Proceedings of the American Power Conference, 52nd Annual Meeting, Chicago, IL, April 23-25, 1990.

6. LeHaye, P.G. and Zabolotny, E., IGTI, 4, 263, (1989).

7. Foster Wheeler Development Corporation, "Development of a High-Performance Coal-Fired Power Generating System with Pyrolysis Gas and Char-Fired High Temperature Furnace (HITAF)", Quarterly Progress Report (3), for U.S. DoE/PETC Contract No. DE-AC22-91PC1154, (1992).

8. United Technologies Research Center, "Coal-Fired High Performance Power Generating System", Quarterly Progress Report, for U.S. DoE/PETC Contract No. DE-AC22-92PC91155, (July 1, 1992 - Sept. 30, 1992).

9. Keeth, R.J., Miranda, J.E., Reisdorf, J.B., and Scheck, R.W., "Economic Evaluation of FGD Systems", EPRI Report No. CS-3342, (Dec. 1983).

10. Arnold, C.W., Dickerman, J.C., Hargrove, O.W., and Noblett, J.G., "Investigation of High $\mathrm{SO}_{2}$ Removal", Volume I: Design, EPRI Report No. CS-1439, (June, 1980).

11. Lockwood, F. C., Salooja, A. P., and Syed, S. A., "A Prediction Method for CoalFired Furnaces," Combust. Flame, 38, 1 (1980).

12. Smith, P. J., Fletcher, T. J., and Smoot, L. D., "Model for Pulverized Coal-Fired Reactors," 18th Symp. (Int.) on Combustion, Combustion Int. Pittsburgh, $1185(1981)$.

13. Yuu, S., Yasukouchi, N., Hirosawa, Y, and Jotaki, T., "Particle Turbulence Diffusion in a Dust Laden Round Jet," AlChE J., 24, 509(1978).

14. Shuen, J-S., Chen, L-D., and Faeth, G. M., "Evaluation of a Stochastic Model of Particle Dispersion in a Turbulent Round Jet," AIChE J., 29, 167(1983).

15. Jang, D. S. and Acharya, S., "Calculation of Particle Dispersion Due to Turbulence in Elliptic Flows," AIChE J., 34, 514(1988).

16. Sobczyk, K., Stochastic Differential Equations, Kluwer Academic Publishers, Boston, 1990.

17. Kloeden, P. E. and Platen, E., Numerical Solution of Stochastic Differential Equations, Springer-Verlag, New York, 1992.

18. Sabnis, J.S. and de Jong, F.J., "Calculation of the Two-Phase Flow in an Evaporating Spray using an Eulerian-Lagrangian Analysis" AlAA paper 90-0447.

19. Markham, J. R., Kinsella, K, Carangelo, R. M., Brouillette, C. R., Carangelo, M. D., Best, P. E., and Solomon, P. R., "A Bench Top FT-IR Instrument for Simultaneously Measuring Surface Spectral Emittance and Temperature", accepted for publication in Rev. Sci. Intr., September, 1993. 

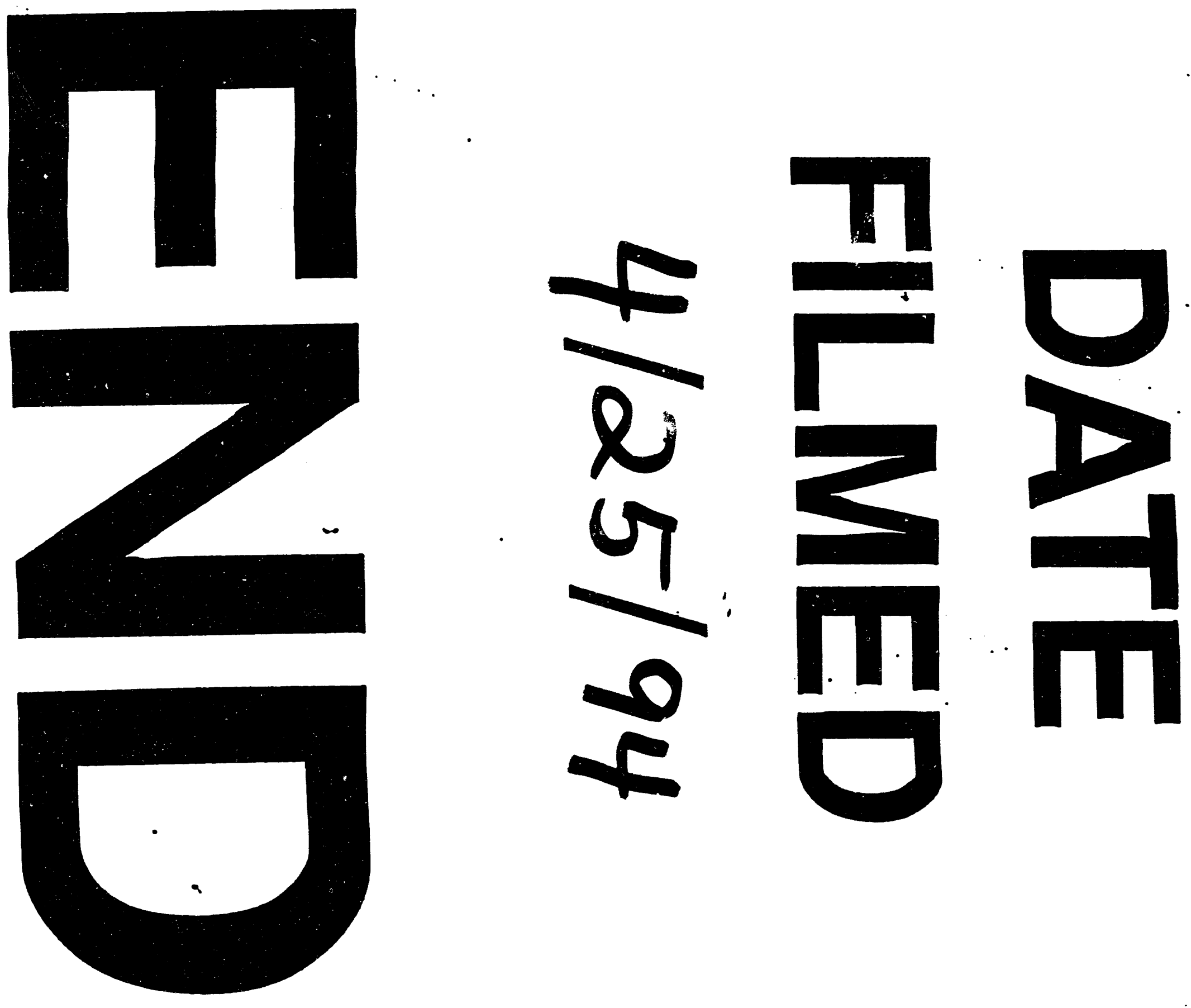
